\title{
Swift heavy ion irradiation of semiconducting materials - defect production, phase transformation and annealing
}

\section{Dissertation}

zur Erlangung des Doktorgrades

der Mathematisch-Naturwissenschaftlichen Fakultäten der Georg-August-Universität zu Göttingen

vorgelegt von

Anne-Katrin Nix

aus

Dortmund

Juni 2010 
D7

Referent: Prof. Dr. H. C. Hofsäss

Koreferent: Prof. Dr. M. Seibt

Tag der mündlichen Prüfung: 02.07.2010 


\section{Contents}

$\begin{array}{lll}1 & \text { Objectives and outline } & 1\end{array}$

2 Introduction $\mathbf{5}$

2.1 Swift heavy ion irradiation . . . . . . . . . . . . 5

2.2 Low energy implantation . . . . . . . . . . . . . . . . 7

2.3 Ion-solid interaction $\ldots \ldots \ldots \ldots . \ldots . \ldots . \ldots$

$2.3 .1 \quad$ Nuclear energy loss $\ldots \ldots \ldots$. . . . . . . . . . . 8

$2.3 .2 \quad$ Electronic energy loss . . . . . . . . . . . . . . . . . . . . . . 9

$2.3 .3 \quad$ Comparing nuclear and electronic energy loss . . . . . . . . 10

2.4 Semiconducting materials $\ldots \ldots \ldots \ldots$. . . . . . . . . . 10

2.4 .1 Tetrahedral amorphous carbon $t a-C$. . . . . . . . 10

2.4.1.1 Growth model for ta-Cl. . . . . . . . . . . . . 13

2.4 .2 Gallium nitride $G a N \ldots \ldots \ldots . . \ldots . . \ldots 13$

2.4 .3 Diamond . . . . . . . . . . . . . . . 15

2.4 .4 Silicon carbide $\mathrm{SiC}$. . . . . . . . . . . . . . 16

$\begin{array}{lll}3 & \text { Luminescence of semiconductors } & 19\end{array}$

3.1 Excitation of luminescence . . . . . . . . . . . . . . . . . . . . . . . . 19

3.2 Luminescence of gallium nitride . . . . . . . . . . . . . . 21

3.3 Luminescence of diamond . . . . . . . . . . . . . . . . . . 22

3.4 Luminescence of silicon carbide . . . . . . . . . . . . . . 24

\begin{tabular}{lll}
\hline 4 & Experimental methods & 27
\end{tabular}

$4.1 \quad$ Mass selected ion beam deposition $M S I B D \ldots \ldots$. . . . . . . 27

4.2 Implantation for doping and defect production . . . . . . . . . . . . . 30

$4.3 \quad$ Swift heavy ion irradiation at the GSI . . . . . . . . . . . . . 30

4.4 Electrical transport measurements . . . . . . . . . . . . . . . . 32

4.4 .1 AFM with conductive cantilever . . . . . . . . . . . . . . 32

4.4 .2 Measurements with macroscopic contact pad . . . . . . . . . 32

4.5 Luminescence measurements . . . . . . . . . . . . . . 34 
$\begin{array}{lll}5 & \text { Results } & \mathbf{3 7}\end{array}$

5.1 Doping and irradiation of ta-C . . . . . . . . . . . . . . 37

5.2 Irradiation of gallium nitride . . . . . . . . . . . . . . . 53

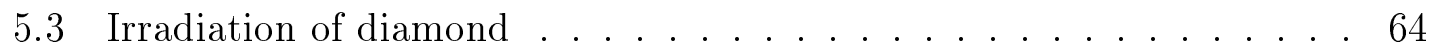

5.4 Irradiation of silicon carbide . . . . . . . . . . . . . . . . . 72

$\begin{array}{llr}6 & \text { Discussion and Conclusion } & 83\end{array}$

6.1 Doping and irradiation of ta-C . . . . . . . . . . . 83

6.2 Irradiation of gallium nitride . . . . . . . . . . . . . . 86

6.3 Irradiation of diamond $\ldots \ldots \ldots . \ldots . \ldots . \ldots 8$

6.4 Irradiation of silicon carbide . . . . . . . . . . . . . . . . 89

6.5 Closing remarks . . . . . . . . . . . . . . . . . 90

\begin{tabular}{lc}
\hline List of Figures & 93
\end{tabular}

\begin{tabular}{ll}
\hline List of Tables & 95
\end{tabular}

\begin{tabular}{lr}
\hline Bibliography & 99
\end{tabular}

\begin{tabular}{lr}
\hline Publications & 111
\end{tabular} 


\section{Chapter 1}

\section{Objectives and outline}

Within this doctoral thesis the effect of swift heavy ion irradiation ${ }^{1}$ on semiconducting materials is analyzed with two different aims.

One topic within this thesis is the analysis of conductive ion tracks observed in insulating tetrahedral amorphous carbon (ta-C). Tetrahedral amorphous carbon shows a phase transformation from an insulating to a conductive phase after ion irradiation at room temperature and forms nanowires in an insulating matrix [1]. Intensive research regarding the conductivity of these ion tracks was performed by our group [2, 3, 4. For application of these ion tracks as a vertical conductor or field emitter, the conductivity has to be improved. Two approaches were made. First, ta-C was doped during deposition with nitrogen, boron, iron or copper. These impurities are supposed to increase the number of localized states at the Fermi level [5, 6] and thus increase the conductivity. Second, ta-C samples were irradiated with $\mathrm{C}_{60}$ molecules which deposit more energy along their trajectory than single ions, which should result in tracks with a higher conductivity [3].

The other aim of this work is to find an ion energy regime in which a certain effect of irradiation, namely annealing of defects, occurs. A possible ion beam induced annealing effect was analyzed on three different semiconductors, namely gallium nitride, diamond and silicon carbide. Ion beam induced annealing has in principal many advantages compared to other annealing techniques. During swift ion irradiation, the material is locally heated along the ion trajectory for a time span of about $10^{-12}$ seconds [7]. Surrounding material stays unaffected, contrary to furnace annealing. Sample decomposition and dopant diffusion could be reduced. During laser annealing [8], most of the energy is deposited directly at the surface region, also, most of the material stays unaffected. However, the surface temperature is higher than the temperature at the damaged region. This undesired side effect can be avoided by ion beam annealing. The energy deposited per unit length of a swift

\footnotetext{
${ }^{1}$ for example $1 \mathrm{GeV}$ uranium ions
} 
ion is uniform over typical implantation depths (several hundred nanometers).

Recovery from implantation defects in silicon after ion irradiation was found by HodGSON et al. [9], published in 1980, using a $200 \mathrm{keV} \mathrm{H}^{+}$beam for annealing. WESCH et al. report on ion beam induced annealing of GaAs after $390 \mathrm{MeV}$ Xeirradiation [10]. Also, annealing of InP after $140 \mathrm{MeV}$ Kr-irradiation was found [11. In their studies, the samples were analyzed using the Rutherford Backscattering Spectroscopy in channeling direction RBS/channeling technique. When a crystalline sample is irradiated and a crystal axis is aligned to the beam, the ions are not backscattered and therefore not detected. They penetrate the sample along "channels", which are formed by the crystal structure. A relatively large amount of impurities, over $0.1 \mathrm{at} \%$, is necessary to achieve reasonable spectra [12. A method more sensitive to impurities and defects also based on the channeling effect is the emission channeling method [13]. Here, radioactive probe atoms are implanted into the sample. The radiation from decay is measured with respect to the crystallographic axis. With this technique, materials implanted with fluences in the range of $10^{12}-10^{13} \frac{\text { ions }}{\mathrm{cm}^{2}}$, which is too low for RBS analysis, can be analyzed.

In this work, the crystal quality of all samples is analyzed by luminescence measurements. Incident light, or an incident electron beam, can generate electron-hole pairs. When recombining, a photon is emitted, which may be detected outside the sample. The intensity of the detected light depends on the crystal structure and dopant concentration. This method is sensitive to defects and impurities; Impurities of a concentration as low as $10^{10}$ to $10^{12} / \mathrm{cm}^{3}$ can be detected [14]. The atomic density of the analyzed materials is in the order of $10^{22} / \mathrm{cm}^{3}$.

GaN is a widely used semiconductor. Although there are several established methods for defect annealing with thermal treatment, there is a need for a method with does not use protective caps [15], which require chemical treatment before device implementation, such as light emitting diodes. In this work, the effect of swift ions with a variety of electronic energy loss will be analyzed to obtain parameters in which ion beam annealing may occur.

Diamond is a wide band-gap semiconductor. Device implementation requires doping of diamond, but it is damaged during ion implantation [16], furnace annealing may result in graphite formation of the damaged region. Therefore, alternative annealing methods should be applied. Ion beam annealing of diamond was observed by ADEL et al. and NAKATA after irradiation with light ions [17, 18]. Both groups use the RBS/channeling technique for characterization. As diamond withstands swift heavy ion irradiation [2], an annealing effect after swift heavy ion irradiation is expected. Ion beam annealing of silicon carbide due to swift heavy ion irradiation was found by Benyagoup and Audren [19]. After iodine implantation below the amorphization threshold of SiC, a decrease in the RBS/channeling signal was found after $827 \mathrm{MeV}$ $\mathrm{Pb}$-irradiation at room temperature. The decrease of the signal implies re-ordering of the crystal. Within this present work, the effect of swift heavy ion irradiation at 
temperatures above room temperature was analyzed in order to improve an annealing effect.

This doctoral thesis is structured as follows; Chapter 2 is the introduction section, which gives motivation and a specimen overview including results of previous research.

Chapter 3 will give a view on luminescence theory. The general luminescence properties of the samples analyzed within this thesis are presented as well.

It is followed by chapter 4, in which the experimental methods used in this work are specified. The apparatuses used for sample preparation and characterization are introduced.

Chapter 5 is entitled results. Here, the obtained results are presented.

The statements, which ca be derived from these results, are discussed in the sixth chapter 6. This chapter also includes the conclusion. 


\section{Chapter 2}

\section{Introduction}

The main focus of this thesis is the effect of swift heavy ion irradiation on materials. Therefore, this process will be described at first. This section is followed by a sample overview.

\subsection{Swift heavy ion irradiation}

(a)

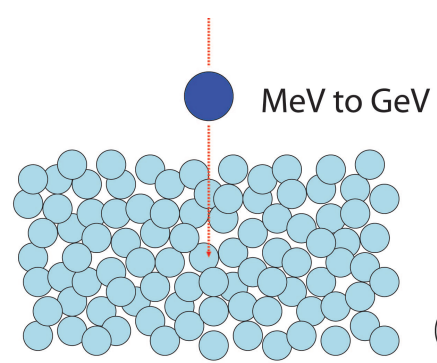

(b)

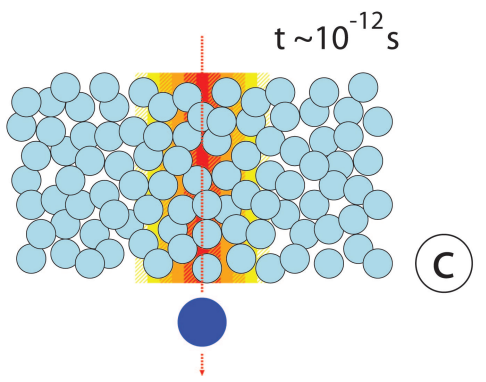

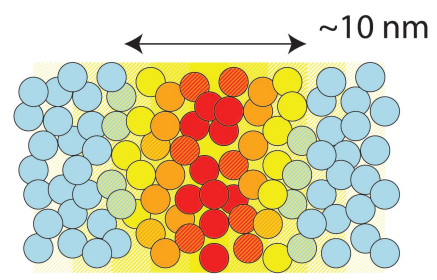

Figure 2.1: Sketch of swift heavy ion irradiation. Redrawn from [20]. An ion with an energy in the range of several $\mathrm{MeV}$ to $\mathrm{GeV}$ is impinging on the sample @. The energy is transferred mainly by electronic energy loss (b). Due to electron-phonon-coupling, the lattice is locally heated along the ion trajectory (c).

As mentioned before, swift heavy ion $S H I$ irradiation was applied for material transformation. The process of swift heavy ion irradiation is sketched in Fig. 2.1, using an amorphous target. The ion is impinging on the target (a). Due to the massive electronic energy loss (the energy transferred during quasi-elastic scattering with the target electron), which may amount to several tens of $\mathrm{keV} / \mathrm{nm}$, the electronic 
system of the target is activated (b). This energy will be transferred to the lattice via electron-phonon coupling. Thus, if the electronic energy loss is high enough, the material is locally heated for a time span of about $10^{-12}$ seconds (c). This process is described with the thermal spike model. The parameters of the molten zone, the thermal spike, such as temperature and radius can either be calculated by numerical solution of the thermodynamical equations [21] or by molecular dynamics simulations [22, 23]. Analysis of the Auger electrons ejected from these tracks showed an electron temperature in the order of $10^{4} \mathrm{~K}[24]$.

Track formation due to swift heavy ion irradiation: Depending on target, ion species and energy, this process has different effects on the target. A topic of this work is the swift heavy ion irradiation of ta-C. Insulating ta- $\mathrm{C}$ shows conductive filaments along the ion trajectory after irradiation. Due to the high energy loss of the impinging ions, which should be at least $20 \mathrm{kev} / \mathrm{nm}$ [1], the $\mathrm{sp}^{3}$-rich sample is locally transformed into the thermodynamically stable $\mathrm{sp}^{2}$ structure. Some material is transported to the sample surface and forms a small hillock with about $2 \mathrm{~nm}$ in height.

Ion beam induced annealing after swift heavy ion irradiation: The other main topic of this work is ion beam induced annealing. The heating during irradiation does not result into track formation below a certain threshold value. Nonetheless, energy is deposited into the material. This energy must be used for crystal recovery. Ion beam induced annealing has some advantages over other annealing methods. Contrary to furnace annealing, the material is only locally affected. Dopant diffusion should be reduced. Also, sample decomposition, which occurs during furnace annealing of GaN, can be avoided. During laser annealing, the material close to the surface is affected [8], which also reduces sample decomposition. However, most of the energy is deposited directly at the surface. During irradiation with swift ions, the energy deposited per unit length is uniform over the regime of typical implantation depth. In [9], published in 1980, annealing of implantation defects was found after ion irradiation. A silicon crystal was damaged by $100 \mathrm{keV}$ Ar-irradiation using a fluence of $10^{14}$ ions $/ \mathrm{cm}^{2}$. After $200 \mathrm{keV} \mathrm{H} \mathrm{H}^{+}$-irradiation, the sample surface showed a different reflectivity. RBS measurement in channeling geometry revealed that the silicon crystal structure is recovered. Also, annealing after swift heavy ion irradiation was found by WESCH et al. [10]. According to their results, pre-damaged GaAs is recovering from implantation defects after $390 \mathrm{MeV}$ Xe-irradiation. KAMAROU et al. found an annealing effect of InP after irradiation with $140 \mathrm{MeV}$ Kr-ions [11]. In both studies, the samples were analyzed by the RBS/channeling technique. One model to explain ion beam annealing is proposed by CHADDERTON and FINK, the particle activated prompt anneal PAPA [25]. The authors found that after irradiation of natural graphite with lead ions of about $1 \mathrm{GeV}$, no tracks were observed in the bulk material. According to their model, the irradiated target is locally heated due to the electronic energy loss and causes a thermal spike. A heat 
wave is propagating inside the target from the thermal spike, which is followed by a cooling wave in direction to this spike. The authors suggest that the heat wave causes an amorphous/crystalline boundary and the rapid cooling wave causes epitaxial re-crystallization. The possibility of crystallization due to the thermal spike was mentioned before in [26], published in 1956. The authors suggest that the undisturbed material outside the thermal spike is a perfect nucleus for reestablishment of the crystal structure after cooling. However, the authors do not expect complete reordering due to the short duration of the cooling process.

A different model for ion beam induced annealing is described phenomenologically in [27, the ion-beam-induced epitaxial crystallization IBIEC. The annealing behavior of implanted, and thus damaged, silicon (implanted ions were boron, phosphor and arsenic) was analyzed. For analysis of ion beam induced annealing, the samples were irradiated with $600 \mathrm{keV} \mathrm{Kr-ions}$ at $350{ }^{\circ} \mathrm{C}$. In this energy regime, the nuclear energy loss exceeds the electronic energy loss. During irradiation, the sample transient reflectivity using a He-Ne laser $(\lambda=633 \mathrm{~nm})$ was measured to monitor the motion of the amorphous/crystalline $(\mathrm{a} / \mathrm{c})$ interface caused by ion implantation. It was found that the implanted silicon sample recovers from defects after lower fluence than impurity-free amorphous silicon samples. The recovering rate increases with increasing dopant concentration. The authors suggest that the presence of kink-like steps at the amorphous/crystalline interface is responsible for defect recovery and not defects caused by elastic collisions during ion irradiation. During irradiation, a small volume at the a/c interface re-arranges at kink-like defects at the interface. Ion beam induced annealing was also analyzed after heavy ion implantation [28]. It was found that either annealing or damage occurs, depending on the temperature during irradiation. This is also noted in [27].

\subsection{Low energy implantation}

Fig 2.2 shows a sketch of low energy implantation. In this work, crystalline samples were irradiated with ions with an energy of typically $100 \mathrm{keV}$ (a). These ions have an implantation depth in the range of hundred nanometers, which can be calculated with the SRIM[1] code [29]. Elastic scattering at the target nuclei b), referred to as nuclear stopping, causes point defects and cluster defects (c). Also sputtering may occur, see [30], chapter 2 and 3. Ion implantation is widely used and widely investigated for doping of materials, see references given in section 2.4. With setting of the implantation energy and fluence, depth and dopant concentration can be controlled. This is a major advantage compared to other doping techniques, such as doping during growth, which usually forms homogeneously doped samples. If crystals are doped with diffusion techniques, the process is hampered due to solubility of the

\footnotetext{
${ }^{1}$ Program available under: www.srim.org
} 
dopant atoms. However, the lattice defects caused by ion implantation have to be removed before device implementation.

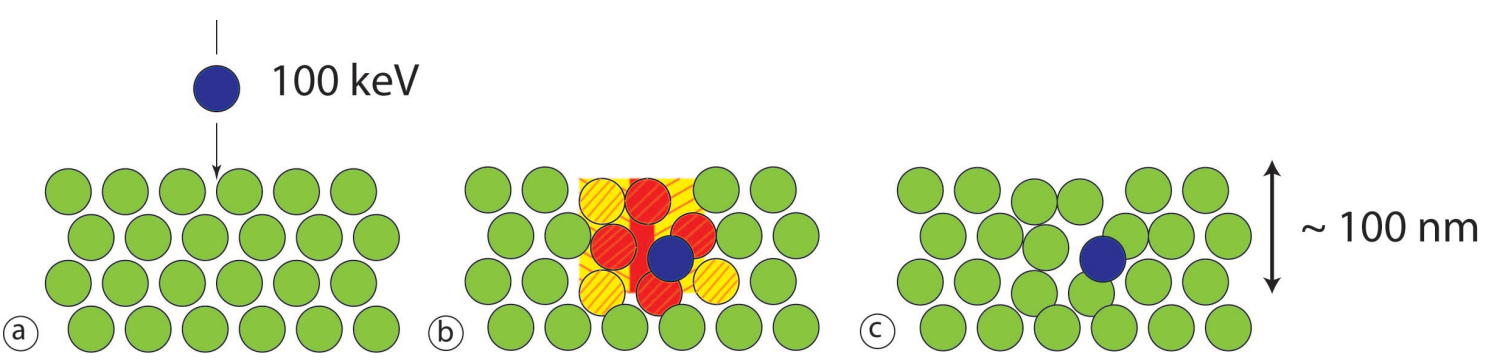

Figure 2.2: Sketch of low energy implantation. An ion with energy of typically $100 \mathrm{keV}$ is impinging on the sample (a). The energy transferred is indicated by red colored spheres (b). The implantation depth is in the range of about $100 \mathrm{~nm}$ (c).

\subsection{Ion-solid interaction}

The interaction between an ion beam and the target is of great interest in this work. Main emphasis is given on the elastic scattering on target nuclei and quasi-elastic scattering on target electrons. The energy transferred is referred to as nuclear energy loss and electronic energy loss, respectively, usually given in units of energy per path length. The stopping power is the sum of electronic and nuclear energy loss. The electronic energy loss causes excitation of the electronic system of the target, the energy is transferred to the lattice by electron-phonon coupling. The nuclear energy loss causes displacements and point or cluster defects.

\subsubsection{Nuclear energy loss}

The nuclear energy loss $\frac{d E}{d x_{n}}$ results from the elastic scattering of impinging ions on target nuclei. The energy $\mathrm{T}$ transferred by an elastic collision of two particles with mass $\mathrm{M}_{1}$ and $\mathrm{M}_{2}$ can be described with [29]:

$$
T=\frac{4 E_{0} M_{1} M_{2}}{\left(m_{1}+M_{2}\right)^{2}} \sin ^{2} \frac{\Theta}{2}
$$

$E_{0}$ is the initial kinetic energy of the impinging ion beam and $\Theta$ the scattering angle in center-of-mass coordinates. This angle is correlated to the scattering angle $\vartheta$ in the lab system with

$$
\vartheta=\tan ^{-1}\left[\sin \Theta /\left(\cos \Theta+M_{1} / M_{2}\right)\right]
$$


The scattering angle depends on the interatomic potential $\mathrm{V}(\mathrm{r})$ with $\mathrm{r}$ as the distance of the atoms in the center-of-mass system and the collision parameter $\mathrm{p}$ (the distance from a head-to-head collision):

$$
\Theta=\pi-2 \int_{r_{\min }}^{\infty} \frac{p d r}{r^{2}\left[1-\frac{V(r)}{E_{c}}-\frac{p^{2}}{r^{2}}\right]^{1 / 2}} \text { with } E_{c}=E_{0} M_{2} /\left(M_{1}+M_{2}\right)
$$

$\mathrm{V}(\mathrm{r})$ can be the Coulomb potential. However, the charge of the nucleus is screened by the electron shell, and one uses a screened Coulomb potential by multiplying a screening function. The maximum energy transferred by a collision of two particles is:

$$
T_{\max }=\frac{4 M_{1} M_{2}}{\left(M_{1}+M_{2}\right)^{2}} E_{0}
$$

The nuclear energy loss can be calculated with $\mathrm{n}$ as atomic density and $d \sigma$ as the differential cross section to:

$$
\frac{d E}{d x_{n}}=n \int^{\infty_{0}} T d \sigma=n \int^{\infty_{0}} T(E, p) 2 \pi p d p=\frac{n 8 \pi M_{1} M_{2} E}{\left(M_{1}+M_{2}\right)^{2}} \int_{0}^{p_{\max }} \sin ^{2} \frac{\Theta}{2} p d p
$$

This is the sum over all energies transferred at all possible impact parameters multiplied by the atomic density. The ion ranges and values of the nuclear energy loss were calculated using the Monte Carlo based SRIM code. In [29], the formula for practical calculation of the nuclear energy loss are described using numerical solutions for the integrals above using the universal screening function for $\mathrm{V}(\mathrm{r})$.

\subsubsection{Electronic energy loss}

The electronic energy loss $\frac{d E}{d x_{e l}}$ results from quasi-elastic scattering of the on to the target electrons. The value of the electronic energy loss for high energies can be estimated with the Bethe-formula [12]:

$$
-\frac{d E}{d x_{e l}}=n \frac{Z_{P}^{2} Z_{T} e^{4}}{4 \pi \epsilon_{0}^{2} v^{2} m_{e}}\left[\ln \frac{2 m_{e} v^{2}}{\langle I\rangle}-\ln \left(1-\frac{v^{2}}{c^{2}}\right)-\frac{v^{2}}{c^{2}}\right]
$$

Here, $\mathrm{n}$ is the atomic density and $Z_{T}$ the atomic number of the target, $Z_{P}$ the atomic number and $\mathrm{v}$ the velocity of the incident ion beam. $\langle I\rangle$ is the mean excitation potential of the target electrons. When the velocity is much lower than the velocity of light, $\mathrm{v} \ll \mathrm{c}$, the relativistic terms can be neglected and therefore, $-\mathrm{dE} / \mathrm{dx} e l . \propto$ $\mathrm{v}^{2}$. The regime of high energy can be defined by the effective charge of moving ions. Bohr proposed that electrons are stripped off a swift ion when its velocity 
Introduction

is larger than the velocity of the electrons orbital velocity [31, 32]. It was found experimentally by NORTHCLIFFE [33] for ions with $\mathrm{Z}>\mathrm{Z}_{\mathrm{He}}$ :

$$
\frac{Z^{*}}{Z}=1-\exp \left[\frac{-v}{v_{0} Z^{2 / 3}}\right]
$$

with $\mathrm{Z}^{*}$ as the charge state of the ion, $\mathrm{v}$ its velocity and $\mathrm{v}_{0}$ as the Bohr velocity, the velocity of an electron in the inner orbit of a hydrogen atom. Regarding the impinging ion as a bare nucleus, the interatomic potential can be described with the Coulomb potential [7].

Similar to the values for the nuclear energy loss, the values for the electronic energy loss were calculated using the SRIM code. Some assumptions had to me made to calculate the electronic energy loss for low energies, which are described in [29].

\subsubsection{Comparing nuclear and electronic energy loss}

In fig. 2.3, the energy loss of uranium in tetrahedral amorphous carbon is shown. Whereas nuclear energy loss dominates during irradiation with low energy (keV to $\mathrm{MeV}$ ), electronic energy loss is the main interaction during high energy irradiation (several $\mathrm{MeV}$ to $\mathrm{GeV}$ ). The curves were calculated with the SRIM code.

In the following, the low energy implantation process will be referred to as implantation and swift heavy ion irradiation process will be named irradiation.

\subsection{Semiconducting materials}

The main properties of the semiconducting materials analyzed within this work and results of previous research will be described here. Also, the motivation of analysis will be given in each section.

\subsubsection{Tetrahedral amorphous carbon $t a-C$}

Tetrahedral amorphous carbon is a material which consist mainly of $\mathrm{sp}^{3}$ bonded carbon atoms with a fraction of about $80 \%$ [34]. The bond orientations of $\mathrm{sp}^{2}$ and $\mathrm{sp}^{3}$ hybridisation are different, ta-C shows neither short range nor long range order. Another widely used name for ta-C is diamond like carbon $D L C$. This name implies some physical properties, ta-C is optical transparent, hard, insulating and dense. A detailed overview of ta- $\mathrm{C}$, including deposition methods, photoluminescence spectra and mechanical properties, is given by ROBERTSON in [35. Its density, however, is with $3 \mathrm{~g} / \mathrm{cm}^{3}$ lower than the density of diamond $\left(3.52 \mathrm{~g} / \mathrm{cm}^{3}\right)$, thus, the material can be compressed. After swift heavy ion irradiation, $140 \mathrm{MeV}$ Xe-ions, ta-C forms conductive ion tracks [1]. These conductive ion tracks with a diameter of about 


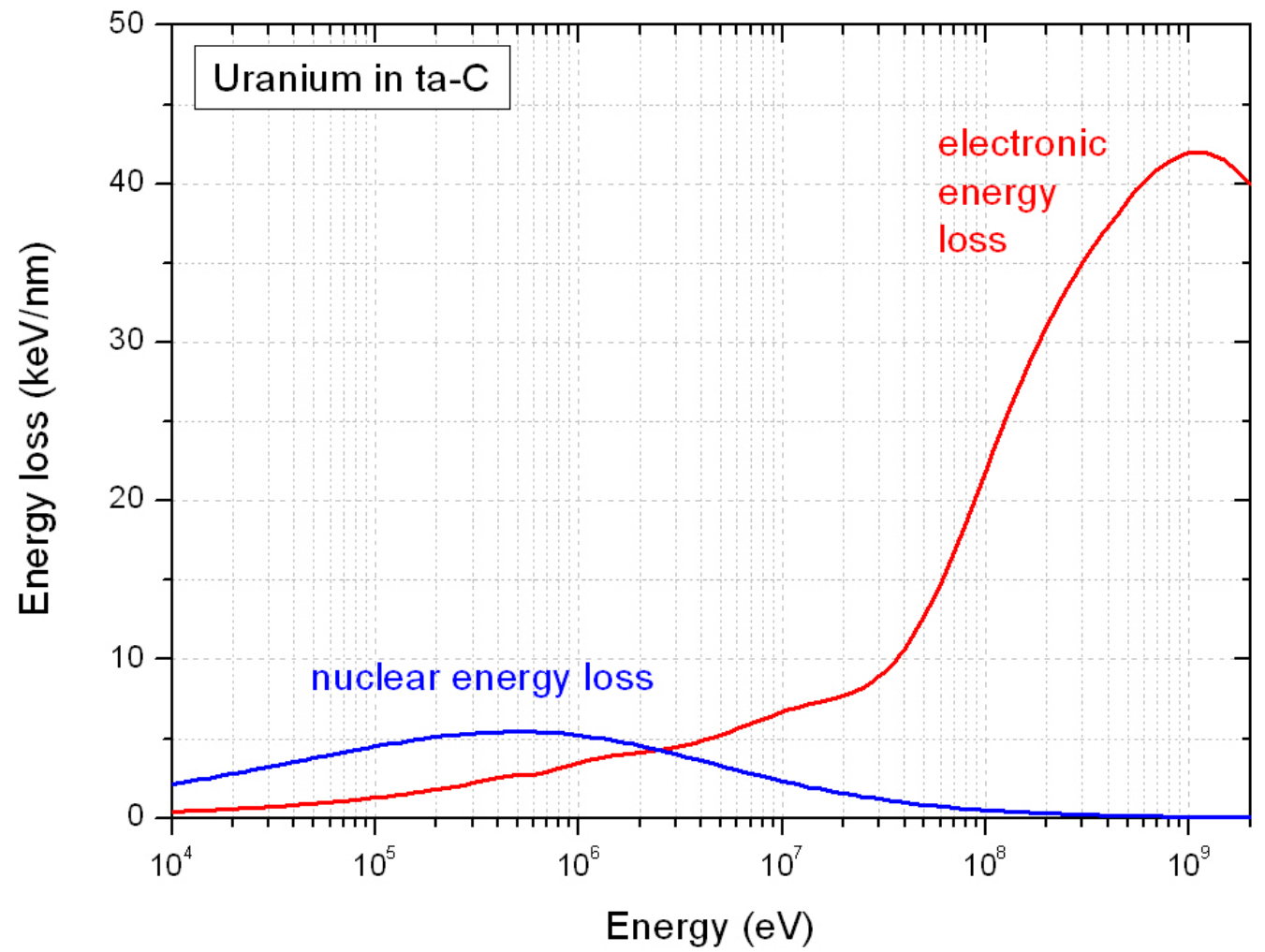

Figure 2.3: Stopping power of uranium in tetrahedral amorphous carbon, see section 2.4.1. with varying energies. Nuclear energy loss is dominant in the low energy regime, electronic energy loss is huge in the high energy regime. The curve was calculated with the SRIM code.

$8 \mathrm{~nm} \mathrm{[2]} \mathrm{in} \mathrm{insulating} \mathrm{ta-C} \mathrm{are} \mathrm{an} \mathrm{experimental} \mathrm{realization} \mathrm{of} \mathrm{quasi} \mathrm{one-dimensional}$ conductors. The conduction mechanism of these ion tracks is expected to differ from amorphous graphite films due to their small diameter. This was analyzed in [4]. Their conduction mechanism at low temperatures can be described with the phonon assisted tunneling model of variable-range hopping with moderate field correction. The conductivity $\sigma$ described after variable range hopping is given as 36

$$
\sigma=q \nu_{P h} N\left(E_{F}\right) R^{2} \exp \left(B / T^{1 / 4}\right), \text { with } B=B_{0}\left(\alpha^{3} / k_{B} N\left(E_{F}\right)\right)^{1 / 4} .
$$

Here, $B_{0}$ is a constant with the value 1.66, $q$ is the carrier charge, $\nu_{P h}$ the phonon frequency, $N\left(E_{F}\right)$ is the density of defects at the Fermi level (usually given in units of $\left./ \mathrm{eV} / \mathrm{cm}^{3}\right), R$ is the hopping distance with $R=3^{5 / 4} / 4\left(2 \pi \alpha N\left(E_{F}\right) k_{B} T\right)^{1 / 4}$ and $\alpha$ is the inverse defect radius. $k_{B}$ and $T$ have their typical meanings as Boltzmann constant and temperature, respectively. The voltage-current curves described by this equation are linear. For moderate field correction, one has to multiply the 


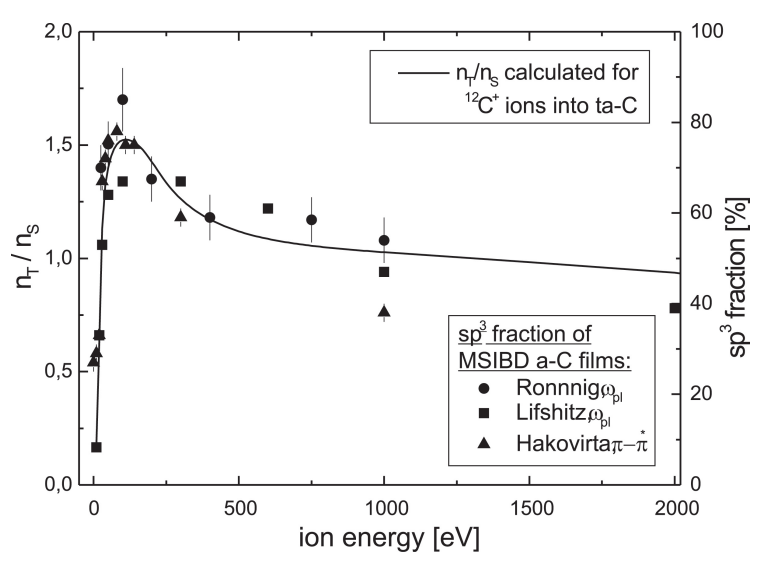

Figure 2.4: Measured $s p^{3}$ content, right axis, over deposition energy compared to $n_{T} / n_{S}$, left axis, [40]. See [40] for references given in the figure. $n_{T} / n_{S}$ is the ratio of possible dislocations $n_{T}$ in a thermal spike over the amount of atoms in this spike $n_{S}$.

conductivity by $\exp \left(q E \gamma R / k_{B} T\right)[37]$. $E$ is the electrical field and $\gamma$ is a constant with value 0.17 . The range of validity is described by $q E / 2 K_{B} \alpha T<1$. Therefore, analyzing the conductivity gives a hint of microscopical properties such as density of states at the Fermi level.

The field emitting properties of these ion tracks have been analyzed as well [38], also possible application for self aligned field emitting devices is a current area of research [39].

This work will focus on increasing the conductivity of the tracks and retaining the insulating properties of the surrounding matrix rather than analyzing the conduction mechanism. One approach was performed by ZOLLONDZ et al. [3] by reducing the $\mathrm{sp}^{3}$-content of the film, see following section for growth model. Electrical transport measurements show that the track conductivity increases with decreasing $\mathrm{sp}^{3}$-content, but the conductivity contrast, the conductivity ratio of irradiated and unirradiated ta-C, decreases also. In this work, the results of two options for increasing the track conductivity are shown. First, as the conduction mechanism of the ion tracks can be described by variable-range hopping, increasing the amount of hopping sites could increase the conductivity. To test this assumption, doped ta-C samples were prepared by co-depositing of carbon and the desired dopant. Second, as mentioned in [3], a higher energy loss during irradiation can result in tracks with a higher conductivity. Hence, beside $1 \mathrm{GeV}$ uranium and gold ions, irradiation was also performed using $30 \mathrm{MeV} \mathrm{C}_{60}$ projectiles. 


\subsubsection{Growth model for ta-C}

Tetrahedral amorphous carbon films can be produced by low energy deposition of carbon atoms, see chapter 4.1. The deposition energy of the atoms influences the $\mathrm{sp}^{3}$ content [34]. An impinging carbon ion transfers its energy by electron and phonon excitation in a certain volume, the thermal spike. In [34], the cylindrical spike model is introduced by HOFSÄss et al.. Using this model, the number of rearrangements in a thermal spike $n_{T}$ and the number of atoms in a spike $n_{S}$ can be calculated. In [40], several amorphous carbon films with different $\mathrm{sp}^{3}$ contents are compared. The highest $\mathrm{sp}^{3}$ content is found in films in which the carbon atoms had an deposition energy of about $100 \mathrm{eV}$ at room temperature. The solid line in fig. 2.4 refers to a numerical solution for $\frac{n_{T}}{n_{S}}$. The energy dependence of this solution is compared to measured $\mathrm{sp}^{3}$ contents of carbon films deposited with different energies. The model describes the data well and one can conclude that $\frac{n_{T}}{n_{s}}>1$ is a condition for the formation of ta-C during deposition.

\subsubsection{Gallium nitride $G a N$}

Gallium nitride is a very attractive material for optoelectronic devices. This material is used for commercially available blue light emitting diodes, see 42 for a theoretical background. Usually, $\mathrm{GaN}$ is grown on sapphire substrates, although there is a lattice mismatch [43. This results in many structural and point defects. Ref. [44] gives an over-view of the deposition process and how to overcome the lattice mismatch. For this doctoral thesis, GaN was implanted with magnesium for p-doping, see chapter 4.2 . The luminescence of GaN:Mg is well examined. Typical luminescence spectra are shown in fig. 2.5 [4]. In their work, the GaN:Mg samples were grown by metal-organic chemical vapor deposition and doped

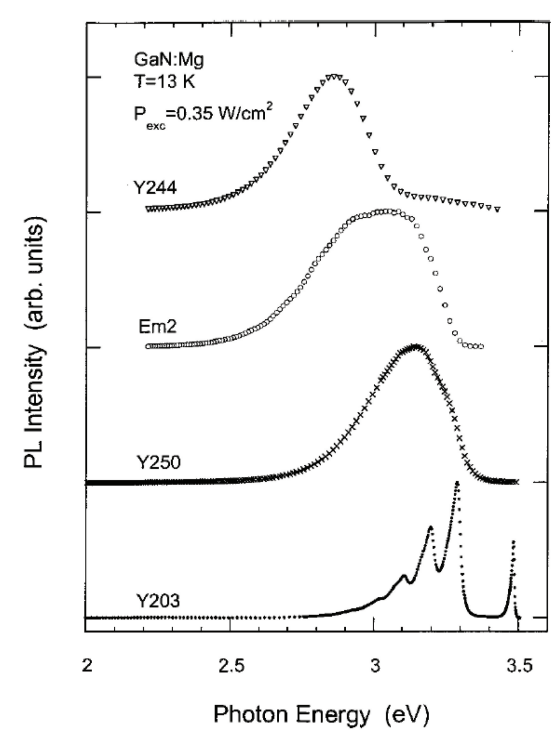

Figure 2.5: Photoluminescence of GaN:Mg taken from [41. The upper curves have a higher $M g$ concentration. during the growth process. The lowest curve was measured on the sample with the lowest $\mathrm{Mg}$ concentration. Its luminescence is dominated by a donor-acceptor pair transition with a zero phonon line at $379 \mathrm{~nm}(3.27 \mathrm{eV})$. A broad band located close to $400 \mathrm{~nm}(3.1 \mathrm{eV})$ may also be observed. Highly doped GaN:Mg shows a 
broad blue band located in the range of $420 \mathrm{~nm}$ to $496 \mathrm{~nm}(2.5 \mathrm{eV}$ to $2.95 \mathrm{eV})$. One speaks of highly doped GaN if the $\mathrm{Mg}$ concentration exceeds $10^{19} \mathrm{~cm}^{-3}$ [45]. Doping by ion implantation has some advantages compared to doping during growth. The dopant concentration and the dopant depth can be controlled. Doping during growth usually results in homogeneously doped samples, which might not be suitable for some applications. The major disadvantage of implantation is the defect production. Some difficulties may occur during thermal annealing of $\mathrm{GaN}$ to retain the crystal quality. Also GaN samples which were doped during growth have to be annealed to activate the dopant [46]. In [15], the GaN was covered with $\mathrm{Si}_{3} \mathrm{~N}_{4}$ before furnace annealing. It is known that $\mathrm{GaN}$ becomes unstable at about $800{ }^{\circ} \mathrm{C}$ and $1 \mathrm{~atm}$, but furnace annealing has to be performed as higher temperatures. In [47, a lightly Mg-doped sample, which was doped during growth, was n-type as grown, although Mg-doping should lead to p-type GaN. The sample was thermally annealed to activate the dopant. The annealing was performed under nitrogen ambiance. However, this sample was still n-type.

Annealing using swift heavy ion is possibility to avoid those problems. The sample is heated along the ion path for about $10^{-12} \mathrm{~s}$, thus, sample decomposition should not occur. Some experiments were already performed concerning swift heavy ion irradiation of GaN. In [48], GaN was irradiated with $100 \mathrm{MeV}$ gold ions using fluences of $1 \times 10^{12}, 1 \times 10^{13}$ and $5 \times 10^{13} \frac{\text { ions }}{\mathrm{cm}^{2}}$. The sample is heavily disordered after irradiation with $5 \times 10^{13} \frac{\mathrm{ions}}{\mathrm{cm}^{2}}$, which is derived from XRD measurements. None of the irradiated samples showed luminescence at room temperature. One can conclude that irradiation with an electronic energy loss of $24 \mathrm{keV} / \mathrm{nm}$, which is achieved with $100 \mathrm{keV} \mathrm{Au}$ ions, is not suitable for ion beam annealing. Also, ion tracks have been observed in GaN after ion irradiation [49. After irradiation with $200 \mathrm{MeV}$ gold ions, noticeable, but not amorphous, ion tracks were found during TEM analysis. Their diameters amount to a value of about $10 \mathrm{~nm}$. Assuming a similar diameter for the thermal spike which occurs during swift heavy ion irradiation, an irradiation fluence of $1 \times 10^{12} \frac{\text { ions }}{\mathrm{cm}^{2}}$ would suffice for total sample covering. In Ref. [50], annealing using either rapid thermal or swift heavy ion induced annealing was analyzed. The GaN samples implanted with cobalt were either treated at $1150{ }^{\circ} \mathrm{C}$ for $20 \mathrm{~s}$ and $700{ }^{\circ}$ for 5 min under argon atmosphere or irradiated with $200 \mathrm{MeV}$ silver ions. To avoid surface decomposition during rapid thermal annealing, the samples were put face to face. For ion beam annealing fluences of $5 \times 10^{11}$ and $1 \times 10^{12} \frac{\text { ions }}{\mathrm{cm}^{2}}$ were chosen. The authors conclude that rapid thermal annealing at $1150{ }^{\circ} \mathrm{C}$ is more effective than rapid thermal annealing at $700{ }^{\circ} \mathrm{C}$, but swift heavy ion irradiation did not result crystal quality improvement. In this work, implanted GaN samples were irradiated with a variety of ions in order to find a regime, in which ion beam annealing occurs. 


\subsubsection{Diamond}

Diamond is an unique material. It is valuable and popular as a gemstone. Due to its outstanding properties like hardness and thermal conductivity, much investigation was performed [51]. The application of diamond was hampered by the costs and rarity of natural diamonds in required size [51, 52]. The possibility of synthesizing diamond enabled the application of diamond for industrial use. The luminescence of diamond, and thus the color, is affected by nitrogen. Diamond is classified in two groups: the nitrogen containing I-group and the almost nitrogen free II-group. These groups have subcategories, in which the nature of the nitrogen defects or other impurities, regarding the II-group, is specified. If diamond contains nitrogen in a so-called A- or B-aggregate, this diamond is called Ia diamond. A nearest neighbor substitutional nitrogen pair is called A-aggregate, the B-aggregate is a quad of substitutional nitrogen surrounding a vacancy. A triplet of substitutional nitrogen surrounding a vacancy is called N3 center, which is also found in Ia diamond. Nitrogen containing diamond, in which the nitrogen substitutes a carbon atom is called Ib diamond. This substituting nitrogen is called $\mathrm{C}$ form nitrogen. Type IIb diamond contains boron and forms a p-type semiconductor. Type IIa diamond has almost no nitrogen nor boron impurities. A broad overview of luminescence in diamond and the above mentioned classification is given in Ref. [53. A very important note in this reference is the possibility of inhomogeneous diamonds. This means that, e.g., some parts of a diamond crystal can be type I and other parts can be type II. Diamond is quite inert to swift heavy ion irradiation, unlike ta-C, it shows no track formation after swift heavy ion irradiation [2]. For irradiation under high pressures, diamond anvil cells are used [54]. Even after irradiation with $70 \mathrm{GeV}$ uranium ions, the pressure inside the cell does not change, implying the absence of heavy irradiation damage. However, application of diamond as a semiconducting devise requires doping. Diamond can be doped with boron during growth [55, 56], but homogeneous doped sample may be unsuitable for several applications. As diamond is doped by diffusion with unsatisfying results [57] (here, diamond was doped with lithium), ion implantation is applied. BRAUNSTEIN et al. found a critical implantation fluence of $1.5 \times 10^{14} \frac{\text { ions }}{\mathrm{cm}^{2}}$ for $350 \mathrm{KeV}$ Sb ions, this means a graphite layer is formed [16]. Annealing of such implanted samples at $1150^{\circ} \mathrm{C}$ for one hour in an evacuated quartz ampule did not lead to complete defect annealing. Thermal annealing of diamonds implanted with higher fluences causes the transformation of the damaged layer into graphite. It is possible to avoid implantation damage by high temperature implantation [58], however, annealing methods after implantation are still desired. Good results were obtained after high temperature, high pressure annealing of diamond [59]. UEDA et al. found an annealing effect and optical activation of the dopant 
after treatment at $7 \mathrm{GPa}$ at about $1400{ }^{\circ} \mathrm{C}$. However, the samples had to be covered with metal encapsulated layers to avoid reactions with the pressure medium.

Diamond was irradiated with swift ions in order to anneal implantation defects before [17]. The slightly pre-damaged crystals were irradiated with $2.3 \mathrm{MeV}$ He-ions, $320 \mathrm{keV}$ and $160 \mathrm{keV} \mathrm{H}$-ions at room temperature. ADEL et al. also regard whether the irradiation is performed under channeling conditions. The defect concentration was measured by means of RBS in channeling geometry. A clear decrease of the channeling yield after irradiation is seen for all experiments performed. Plotting the annealing rate over the electronic energy loss shows no correlation. When plotting the annealing rate over the nuclear energy loss, the data are nearly overlapping. Thus, the authors conclude, that nuclear collisions and not electronic collisions cause ion beam annealing.

Experiments concerning ion beam annealing were also carried out at temperatures above room temperature [18]. NAKATA found that implanted diamond was annealed after irradiation with neon and argon ions in the $\mathrm{MeV}$ regime at temperatures of $750{ }^{\circ} \mathrm{C}$. Defect recovery was also found after temperature treatment, but the crystallization rate is higher for the simultaneously irradiated and annealed samples. The author suggests that both nuclear and electronic scattering contributes to the annealing process. These experiments show that ion beam induced annealing of diamond does occur. This work will focus on the possibility of ion beam induced annealing with heavier ions as in [17, 18], which means that the main interaction between ion beam and target is the electronic energy loss.

\subsubsection{Silicon carbide $\mathrm{SiC}$}

Silicon carbide forms many polytypes, several crystal phases are formed. These phases differ in their crystal layer stacking sequence. The pure cubic phase, zincblende structure, is called $3 \mathrm{C}$, the hexagonal (wurtzite) structure $2 \mathrm{H}$ [60]. In this work, $\mathrm{SiC}$ in the so-called $6 \mathrm{H}$-phase was analyzed, which means, that two zincblende layers $(3 \mathrm{C})$ are enclosed between two wurtzite layers $(2 \mathrm{H})$, see fig. 2.6. This polytype has a band edge of $3 \mathrm{eV}[61]$.

Silicon carbide is a widely investigated material and a promising candidate for fabrication of high temperature and high power devices, see [62] and references therein. Most of these applications require doping of silicon carbide. As mentioned above, ion implantation is a widely used technique for doping. Unfortunately, this technique results in lattice defects which require annealing temperatures up to $1400^{\circ} \mathrm{C}$ regarding $\mathrm{SiC}$ [63, 64]. Defects were found even after annealing at $1700{ }^{\circ} \mathrm{C}$ [65, 66]. Intensive research was performed in order to reduce implantation defects, for example, implantation at different temperatures [67]. According to HEFT et al. implantation defects can be avoided by performing implantation $700 \mathrm{~K}$. This finding is also described by MCHARGUE and Williams in [64]. 


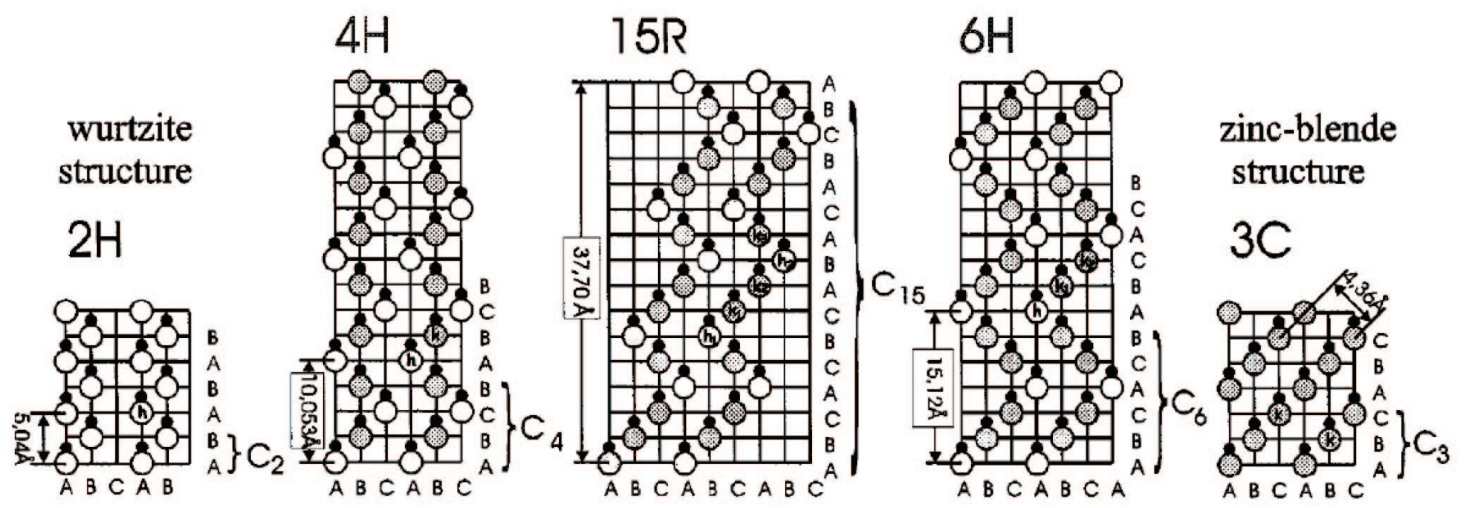

Figure 2.6: Stacking sequences of different $\mathrm{SiC}$ polytypes from [60].

Ion beam annealing of $\mathrm{SiC}$ was analyzed before [68]. BENYAGOUB et al. performed experiments, where $\mathrm{SiC}$ was implanted with $700 \mathrm{keV}$ I ions and subsequently irradiated with $827 \mathrm{MeV} \mathrm{Pb}$ ions at room temperature. An annealing effect was observed for all implanted samples after irradiation with lead ions with a fluence of $4 \times 10^{13} \frac{\mathrm{ions}}{\mathrm{cm}^{2}}$. Also, ion beam annealing was observed after irradiation with lighter ions, $910 \mathrm{MeV}$ Xe-ions [69]. The annealing effect was analyzed by BenYAGOUB and AUDREN in detail in [19]. As a conclusion, silicon carbide can be annealed with swift heavy ions and also ion beam induced epitaxial crystallization IBIEC was found [70]. This work will analyze the possibility of ion beam induced annealing at elevated temperatures. 


\section{Chapter 3}

\section{Luminescence of semiconductors}

This chapter will give an overview of the theory of luminescence of semiconductors. Also, the luminescence properties of the materials analyzed in this work will be presented.

\subsection{Excitation of luminescence}

Incident light with an energy above the band gap of the lighted semiconductor causes the exciting of an electron from the valence band to the conduction band, resulting in a hole in the valence band. After a certain time, recombination of this electron and hole occurs, called band-to-band transition. As the electron-hole pairs are generated by the absorption of photons, this mechanism is called photoluminescence. One differentiates between two type of transitions, called indirect and direct transitions. If the maximum energy of the valence band and the minimum energy of the conduction band are located at the same point in the wavenumber vector $\mathrm{k}$-space of the electron wave, one speaks of a direct band gap and a direct transition, see fig. 3.1(a). If this is not the case, one speaks of an indirect band gap and an indirect transition, fig. 3.1(b). Indirect transitions would imply a change in the k-value, which is a forbidden transition. However, with simultaneous absorption or emission of phonons, this transition may occur [14].

Also, transitions between the conduction band and an acceptor state or a donor state to the valence band may happen. Recombination of an electron at a donor with a hole at an acceptor is called donor-acceptor pair transition (DAP).

A quasi-particle consisting of an electron and a hole may form, the exciton [71. These excitons move through the crystal and after recombination, a photon may be emitted. One speaks of the recombination of a free exciton. The emitted photon has an energy which is lower than the band gap due to the binding energy of the 


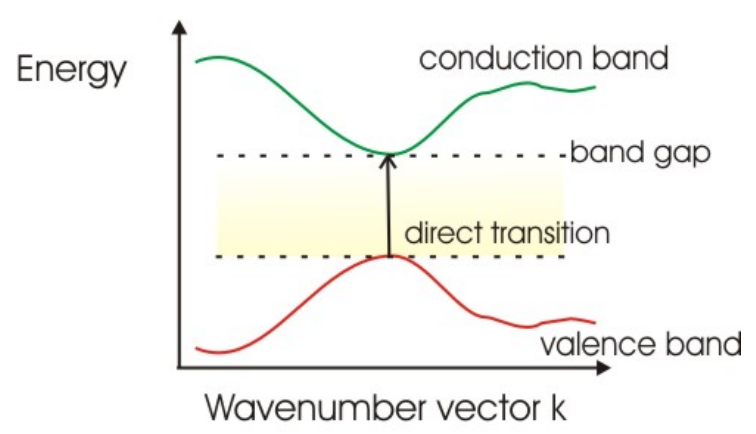

(a) direct transition

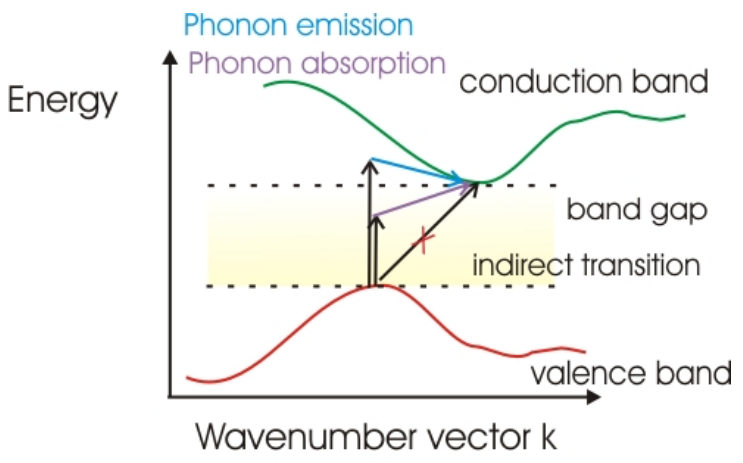

(b) indirect transition

Figure 3.1: Sketch of a direct and indirect band-to-band transition, redrawn from [14].

exciton. An exciton may also be bound to neutral acceptors $\left(\mathrm{A}^{0} \mathrm{X}\right)$ or neutral $\left(\mathrm{D}^{0} \mathrm{X}\right)$ or charged donors $\left(\mathrm{D}^{+} \mathrm{X}\right)$. The bohr radius of an exciton $a_{B}^{e x}$ is given as [72]:

$$
a_{B}^{e x}=a_{B}^{H} \epsilon \frac{m_{0}}{\mu}
$$

with the bohr radius of a hydrogen atom $a_{B}^{H}$ and the reduced exciton mass $\mu$

$$
a_{B}^{H}=\frac{4 \pi \epsilon_{0} \hbar^{2}}{m_{0} e^{2}} \text { and } \mu=\frac{m_{e} m_{h}}{m_{e}+m_{h}}
$$

Here, $\epsilon$ is the dielectric constant, $m_{0}$ the rest mass of an electron and $m_{e}$ and $m_{h}$ the effective masses of electrons and holes. The values for the exciton bohr radius are between $50 \mathrm{~nm}$ and $1 \mathrm{~nm}$ and thus lager than typical lattice constants.

An exciton can interact with the phonons in the crystal. If an exciton annihilates with the emission of a longitudinal optical phonon, a line appears in the luminescence spectrum which is shifted relative to the exciton line, the zero-phonon line, by the energy value of the emitted phonon. This line is called phonon replica.

During cathodoluminescence measurements, luminescence is stimulated by an electron beam, usually with an electron beam in the $\mathrm{keV}$ regime. If a semiconductor is irradiated with electrons, secondary electrons, Auger-electrons or electron-hole pairs may be produced [14]. When an electron-hole pair is generated, the same recombination mechanisms occur as described above, such as band-to-band transition or donor-acceptor transition. Excitons may be generated as well. Some electrons may be backscattered. However, the penetration depth of electrons in matter is low. It can be calculated with the simulation software CASINO [73, 74, 75]. Cathodoluminescence was measured within this work for samples with a wide band gap, as the laser available emits light with energy lower than the band gap.

If the crystal is disturbed, many non-radiative recombinations occur which quench 

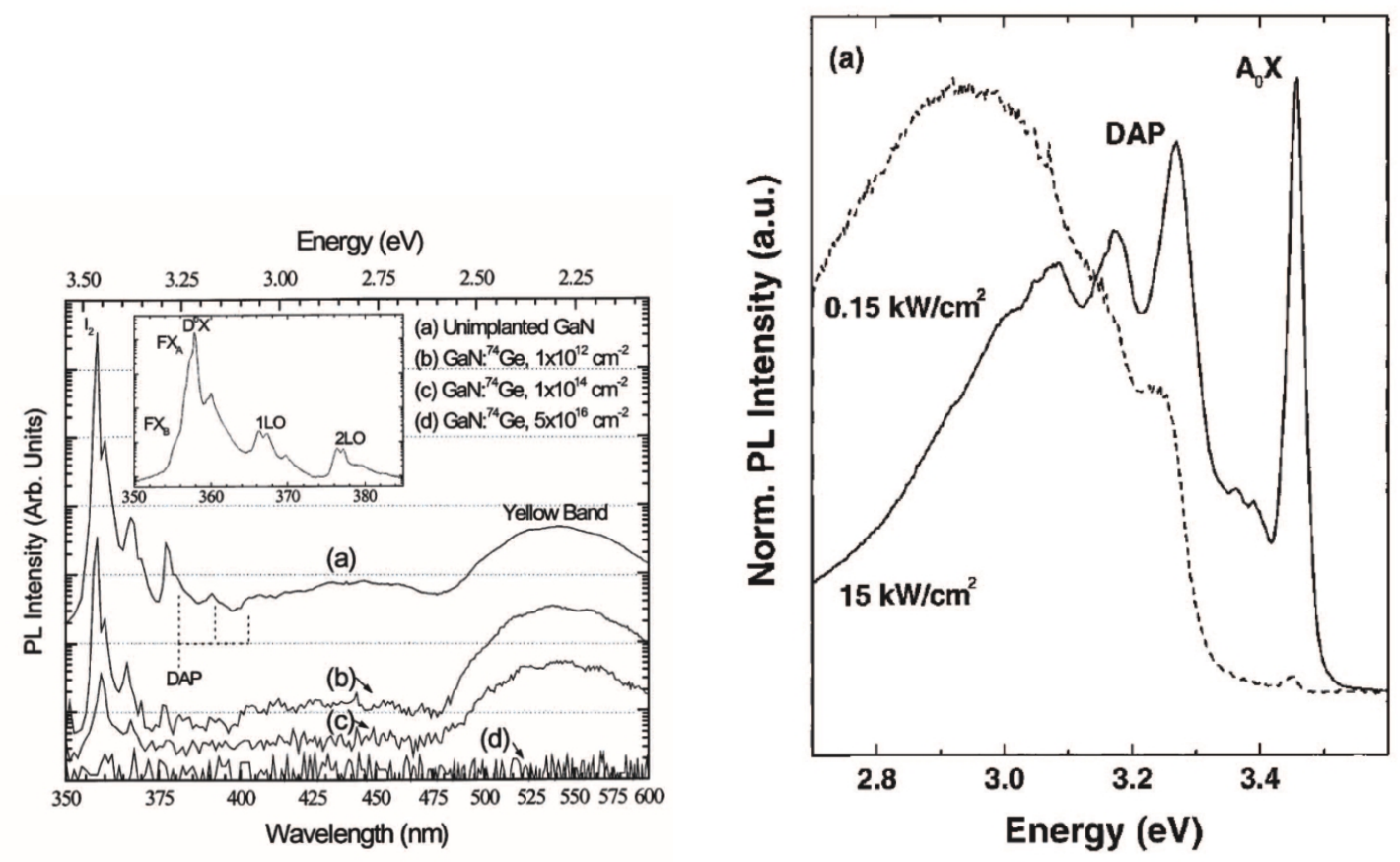

Figure 3.2: Photoluminescence of GaN, Figure 3.3: Photoluminescence spectra of taken from [76], before and after implan- GaN:Mg [77]. Beside the near band-edge tation with germanium. The luminescence transistion, the Mg-related donor acceptor intensity decreases with increasing implan- pair transition is visible.

tation fluence.

the luminescence intensity. Luminescence measurements are very sensitive to defects. Impurities of a concentration as low as $10^{10}$ to $10^{12} / \mathrm{cm}^{3}$ can be detected [14]. Thus, luminescence measurement is a suitable method for analysis of the sample quality.

\subsection{Luminescence of gallium nitride}

In fig. 3.2 typical photoluminescence of GaN samples is shown, picture taken from [76]. Gallium nitride is a semiconductor with a direct band gap of $3.5 \mathrm{eV}$ [77]. The luminescence spectrum is dominated by an intense peak at $358 \mathrm{~nm}(3.464 \mathrm{eV})$. This line results from recombination of free excitons $\left(\mathrm{FX}_{A}, \mathrm{FX}_{B}\right)$ or excitons bound to a shallow donor $\left(\mathrm{D}^{0} \mathrm{X}\right)$ [78, 77]. Also visible is a broad band located at $550 \mathrm{~nm}$, referred to as the yellow band. The near band-edge luminescence is shown in detail in an inset. Two longitudinal optical phonon replicas associated to the band-edge luminescence are visible, located at $367 \mathrm{~nm}(3.379 \mathrm{~nm})$ and $377 \mathrm{~nm}(3.289 \mathrm{eV})$. The appearance of these phonon replicas is an evidence for high crystal quality. After 
implantation with $300 \mathrm{keV}$ Ge-ions, the intensity of the near band-edge luminescence decreases. After the lowest implantation fluence of $1 \times 10^{12} \frac{\mathrm{ions}}{\mathrm{cm}^{2}}$, the phonon replicas are not detectable. Luminescence vanishes after high fluence implantation.

After Mg-doping of GaN and successful removal of defects, spectra shown in fig. 2.5 or fig. 3.3 should appear. These spectra show beside a peak due to the band-edge transition Mg-related luminescesce, such as a donor-acceptor pair transition with a zero phonon line at $379 \mathrm{~nm}(3.27 \mathrm{eV})$ and or a blue band located in the range of $420 \mathrm{~nm}$ to $496 \mathrm{~nm}(2.5 \mathrm{eV}$ to $2.95 \mathrm{eV})$. When the defects caused by implantation are not removed, the luminescence intensity is reduced.

\subsection{Luminescence of diamond}

Diamond has an indirect band gap of about $5.45 \mathrm{eV}$ [79]. About 500 optical centers have been found in absorption and/or luminescence spectra of diamond [80]. Many of them are related to nitrogen impurities. Some of them have similar positions of their zero-phonon lines, such as the H3 center, a vacancy bound to two subtitutional nitrogen atoms [81] and the $3 \mathrm{H}$ center, observed after irradiation of diamond [53]. It would go beyond the scope of this thesis to describe all optical centers, only selected lines will be presented. Synthetic diamond grown by the high temperature, high pressure (HTHP) method often exhibit nickel as contamination. These nickel impurities form optical centers in the visible range. The so-called $2.56 \mathrm{eV}$ center is shown in fig. 3.4, taken from [80]. This center shows two intense lines at $484 \mathrm{~nm}$ $(2.56 \mathrm{eV})$ and $489 \mathrm{~nm}(2.536 \mathrm{eV})$. The zero-phonon line shows a fine structure, which is expected to result from excited states of the $484 \mathrm{~nm}$ center [82, 83], shown in fig. 3.5 from [82.

The most common naturally occurring color center related to nitrogen and vacancies is the so-called N3 center, three substitutional nitrogen atoms surrounding a vacancy [84]. Two substitutional nitrogen atoms and a vacancy form the H3 center. Both centers are shown in fig. 3.6, showing irradiated $\mathrm{Ib}$ diamond after annealing, taken from [84]. The N3 center has a zero-phonon line at $415.2 \mathrm{~nm}(2.985 \mathrm{eV})$, the zerophonon line of the $\mathrm{H} 3$ center is located at $503.2 \mathrm{~nm}(2.463 \mathrm{eV})$. Also visible in fig. 3.6 is a line at $574.9 \mathrm{~nm}(2.156 \mathrm{eV})$, which is attributed to the neutral nitrogen vacancy center $(\mathrm{N}-\mathrm{V})^{0}$.

During this work, diamond was irradiated with argon ions. Argon is not expected to form optical centers [80, but the vacancies caused by implantation may form optical centers. However, if the crystal structure is damaged due to implantation, the luminescence intensity is reduced. 


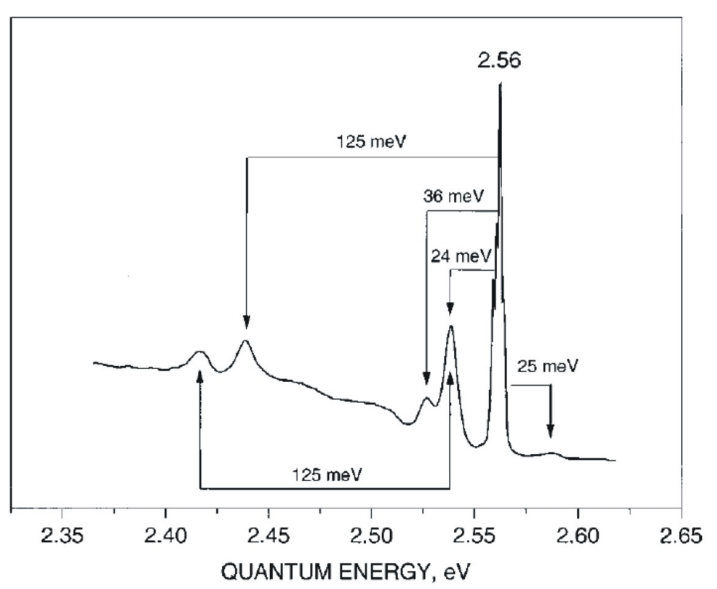

Figure 3.4: Luminescence of the nickel- Figure 3.5: Luminescence of the $2.56 \mathrm{eV}$ related 2.56 center, taken from [80].

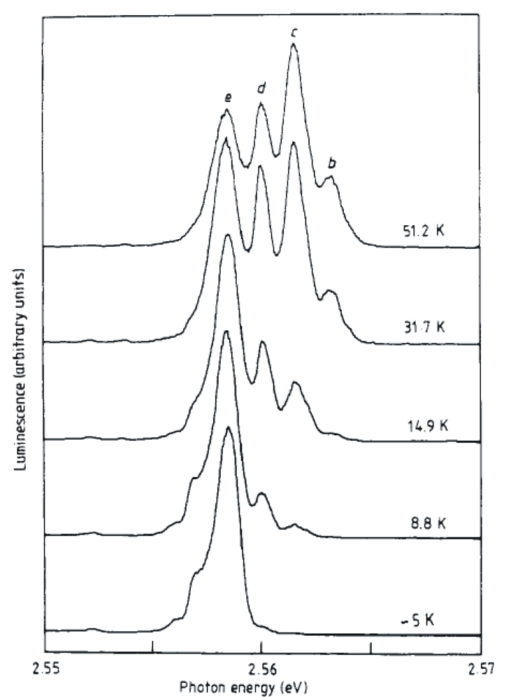
nickel related line recorded at different temperatures, from [82].

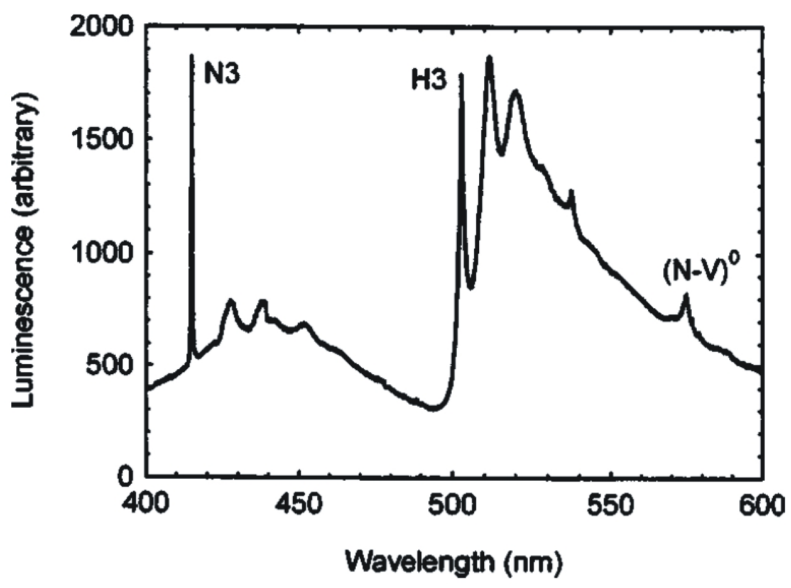

Figure 3.6: Luminescence of a Ib diamond sample, showing the N3 and the H3 center [84]. Also, a line attributed to a single nitrogen-vacancy center is seen. 


\subsection{Luminescence of silicon carbide}

$\mathrm{SiC}$ in the 6H-polytype has an indirect band gap of $3 \mathrm{eV}$ [61]. For this work, ndoped $6 \mathrm{H}-\mathrm{SiC}$, doped with nitrogen, was analyzed. The luminescence of nitrogen doped $6 \mathrm{H}-\mathrm{SiC}$ is seen in fig. 3.7 [85]. The zero-phonon lines of exctions bound to nitrogen are visible, labeled as $\mathrm{R}_{0}, \mathrm{~S}_{0}$ and $\mathrm{P}_{0}$. These lines result from the different inequivalent $\mathrm{Si}$ sited in a $6 \mathrm{H}-\mathrm{SiC}$ crystal which may be occupied by a nitrogen atom. A free exciton may only recombine with an emission of a phonon, so only the phonon replicas appear in the spectrum, labeled as I with the energy difference as index. The lines labeled with $\mathrm{P}, \mathrm{S}$ and $\mathrm{R}$ with an energy difference as index are the phonon replicas to the $\mathrm{P}_{0}, \mathrm{~S}_{0}$ and $\mathrm{R}_{0}$ lines. Photoluminescence survey spectra of $6 \mathrm{H}-\mathrm{SiC}$ is seen in fig. 3.8 [86. A broad band at $2.65 \mathrm{eV}(468 \mathrm{~nm})$ is seen, which results from $\mathrm{N}-\mathrm{Al}$ donor-acceptor transitions. Also, the nitrogen related luminescence is visible. After irradiation and annealing, many lines related to defects may be found, such as the D1 center, shown in fig. 3.9 [65]. Another set of defect lines after electron irradiation of $6 \mathrm{H}-\mathrm{SiC}$ is seen in fig. 3.10, the so-called alphabet lines [87].

The $6 \mathrm{H}-\mathrm{SiC}$ samples were implanted with argon ions for the same reasons as the diamond samples. If the defects from implantation are removed, the nitrogen related luminescence should be visible, alongside with the plethora of phonon replicas. Also no defect lines should be visible. 


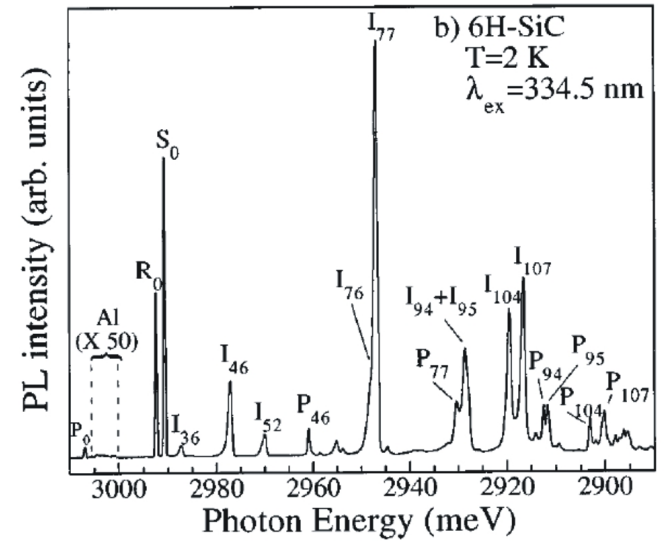

Figure 3.7: Nitrogen related luminescence in $6 \mathrm{H}-\mathrm{SiC}$ at the band-edge region [85]. The zero-phonon lines of the excitons bound to nitrogen are labeled with $R_{0}, S_{0}$ and $P_{0}$. is seen Many phonon replicas are visible in this high quality crystal.

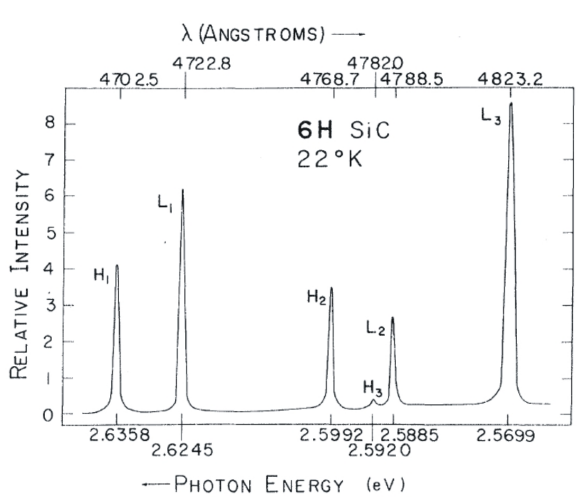

Figure 3.9: Luminescence lines of the D1 center [65].

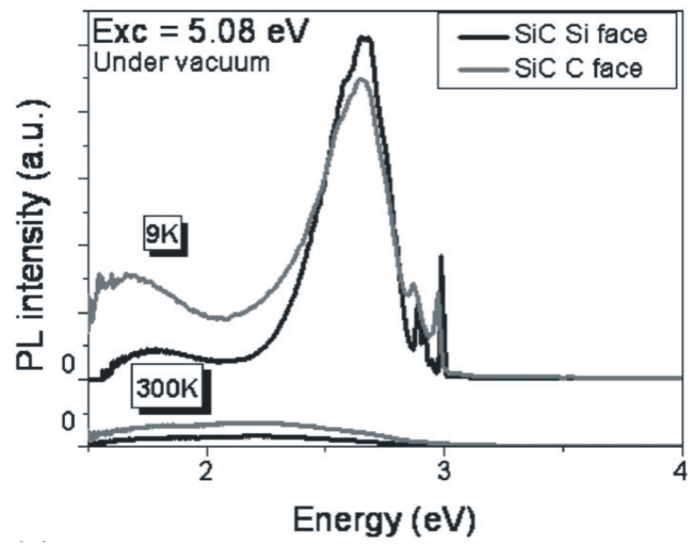

Figure 3.8: Photoluminescence of n-type $6 \mathrm{H}-\mathrm{SiC}$ [86]. Beside the nitrogen related luminescence, a broad band located at $2.65 \mathrm{eV}$

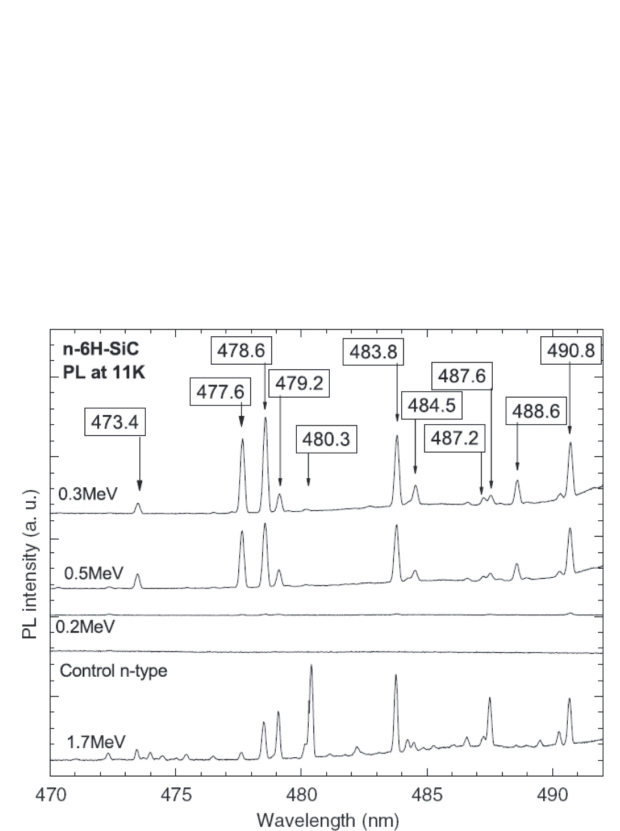

Figure 3.10: Defect lines in $\mathrm{SiC}$ found after electron irradiation [87], the alphabet lines, recoded at different temperatures. 


\section{Chapter 4}

\section{Experimental methods}

In this chapter, the characterization methods used for this work will be presented. A brief overview of the apparatuses used for sample preparation will be given as well. Several samples analyzed in this work, such as diamond and GaN, were commercially produced. The tetrahedral amorphous carbon films were fabricated by our group. This method will be described in the following section.

\subsection{Mass selected ion beam deposition $M S I B D$}

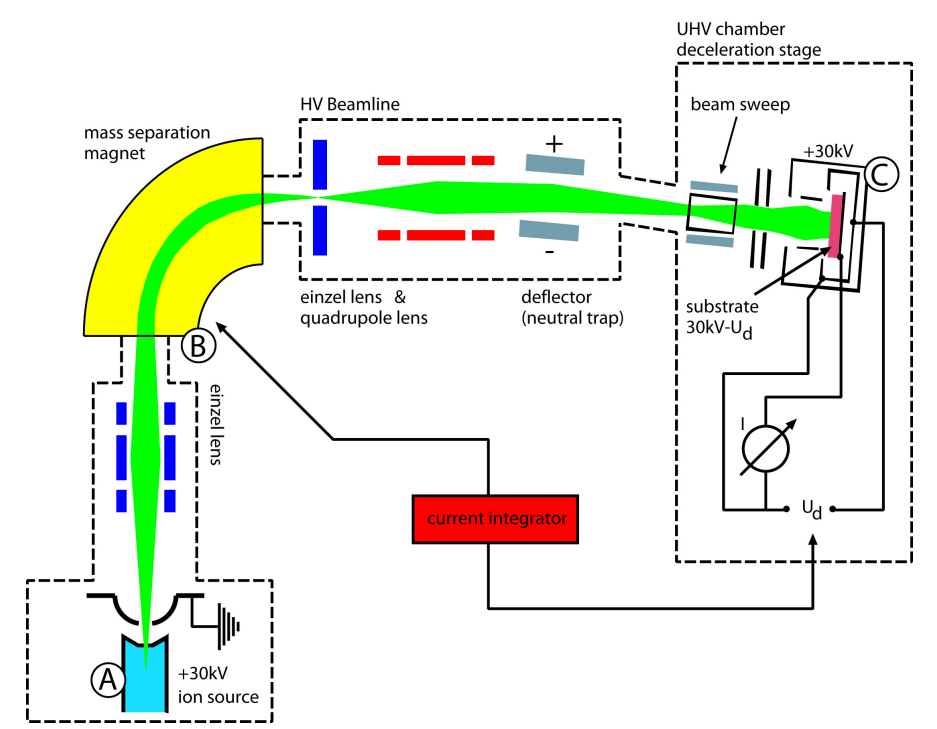

Figure 4.1: Schematic illustration of ADONIS: The ions (ion source at (A)) are accelerated to $30 \mathrm{kV}$, the mass separation magnet (B) ensures a monoisotopic ion beam, which is decelerated to the desired deposition energy in front of the substrate (C). 
The samples were produced by means of low energy ion deposition on a substrate. The apparatus used for mass selected ion beam deposition, called ADONIS, is schematically drawn in Fig. 4.1. The ions for deposition are extracted from the hot filament plasma ion source (A), which is described in [88]. The source is equipped with two gas inlets and an oven, a hollow rod which can be placed at the hot filament. The ions are accelerated with $30 \mathrm{kV}$ and the beam is filtered with the mass separation magnet (B). Thus, a monoisotopic ion beam can be produced. The controller of the mass separation magnet is able to store four different values of magnet current, thus a deposition with up to four ion species is possible. In front of and behind the separation magnet, two einzel lenses and a quadrupole lens are installed for beam focusing. In order to reduce recombination and space charge effects, the ion beam is decelerated not until in front of the substrate (C). The maximum irradiation energy is $60 \mathrm{keV}$, but also irradiation with a $10 \mathrm{eV}$ beam is possible. To ensure homogeneous films, the ion beam is scanned over the substrate with a beam sweep. Before decelerating, the beam is tilted by an angle of about $5^{\circ}$ using a deflector, two opposing contrary charged plates. This forms a trap for neutral particles. This is mandatory for the measurement of the deposited charge. The current at the substrate is recorded and integrated to a total charge using a current integrator. With the deposited charge, the density and the film diameter, which can be varied with a broadening lens, the film thickness can be calculated. The sputter effect of the impinging ions ${ }^{1}$ has to be included into this calculation. After deposition, the film can be analyzed by means of electron energy loss spectroscopy EELS and X-ray photoelectron spectroscopy XPS without breaking the vacuum. More details of the apparatus are given in ref. [89].

In order to obtain carbon ions for ta-C production, carbon dioxide is injected into the source, the molecules are broken and the fragments are ionized. Usually, a charge of $0.4 \mathrm{C}$ is deposited, which corresponds to a film thickness of $100 \mathrm{~nm}$ with a diameter of $13 \mathrm{~mm}$. The deposition is performed under UHV-conditions $\left(10^{-8} \mathrm{mbar}\right)$, and due to the mass separation, a pure, hydrogen free film is ensured. As mentioned in 2.4.1, doped ta-C films were produced. For this purpose, the desired dopant has to be injected into the ion source. In the case of

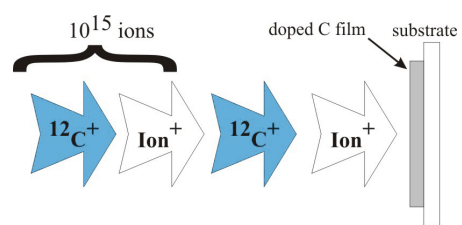

Figure 4.2: Sketch of deposition of doped ta-C films: After a certain amount of carbon ions, the beam is bent away, the mass separation magnet switches to the desired dopant and the beam is bent to the sample. After the desired concentration in a deposition cycle is reached, deposition with carbon continues. nitrogen, the nitrogen outgassing from the boron nitride insulators inside the source was used. The dopant concentration low enough that this small amount of nitrogen suffices. For boron, iron and copper doping, a powder consisting of these dopant

\footnotetext{
${ }^{1}$ calculated with SRIM
} 
compounds is filled in a hollow rod and put into the source. The rod is placed at the filament during irradiation, thus the powder is molten, evaporated and ionized and the ions are extracted. For this work, copper chloride, iron chloride and boron oxide were used. The deposition follows a procedure to obtain homogeneous samples, sketched in Fig. 4.2. The whole deposition is monitored by a computer system. Deposition cycles of about $10^{15}$ ions per cycle are run, which corresponds to a thickness in the order of Angstroms. When the selected amount of carbon in one deposition cycle is reached, the deposition pauses. The controller of the mass separation magnet switches to the dopant ion and the deposition continues until the deposition cycle is finished. The deposition cycles are repeated usually over a 1000 times to the desired charge. The dopant concentration is about $1 \%$, this concentration is too low to cause a significant change in the $\mathrm{sp}^{3}$ bond structure. This was analyzed for copper as a dopant by GERHARDS et al. in ref. [90]. The $\mathrm{sp}^{3}$ content of the doped films were analyzed by the means of XPS directly after deposition to ensure their high $\mathrm{sp}^{3}$ content. XPS analysis was performed using $\mathrm{Mg}$ $\mathrm{K} \alpha$ radiation $(1253.6 \mathrm{eV})$ and the kinetic energy of the photo-emitted electrons was measured. The $\mathrm{sp}^{3}$ content can be estimated by measuring the position of the $\mathrm{C} 1 \mathrm{~s}$ peak, the s-orbital of the first shell of carbon, as in [90. Graphite shows the C1s peak at $284.0 \mathrm{eV}$ binding energy and ta-C at $284.8 \mathrm{eV}$. The $\mathrm{sp}^{3}$ content can also be estimated by additionally analyzing the plasmon energy loss [91, 92]. When oscillations of the electrons in the sample, so-called plasmons, are excited, the kinetic energy of the electrons is reduced by the plasmon energy. Therefore, a peak close to the $\mathrm{C} 1 \mathrm{~s}$ peak is detected, the plasmon peak. Measuring the plasmon energy loss gives evidence for the $\mathrm{sp}^{3}$ fraction. With the plasmon energy for diamond $(100 \%$ $\mathrm{sp}^{3}$ bonding, $33 \mathrm{eV}$ ) and for graphite $\left(0 \% \mathrm{sp}^{3}\right.$ bonding, $\left.24 \mathrm{eV}\right)$ the $\mathrm{sp}^{3}$ content of the samples can be calculated by linear interpolation [34]. The second method has the advantage that measuring relative positions is not affected by charging effects, which causes shifting of the spectrum.

The conductivity of the ta-C samples was characterized by measuring the current flowing from sample surface to the substrate. In this work, highly doped silicon with a specific resistivity of about $0.005 \Omega \mathrm{cm}$ was used. The substrate is much more conductive than ta-C, thus it can be neglected during measurements. However, there is a native oxide layer on top of the substrate, which would affect the conduction measurement. This layer is removed before deposition by the means of sputtering. For this purpose, the substrate is irradiated with argon ions with an energy of $1 \mathrm{keV}$. Due to the impact, the silicon ions are removed from the substrate. After a charge of about $15 \mathrm{mC}$, which corresponds to a depth of about $20 \mathrm{~nm}$ (calculated with SRIM), the process is stopped. Directly after this, film deposition is started.

With the MSIBD method, hydrogen free samples can be produces. However, the growth rate with about $10 \mathrm{~nm} / \mathrm{h}$ is very low compared to other methods like filtered cathodic arc deposition [93] or chemical vapor deposition CVD [94], which can cover 
Experimental methods

a whole silicon wafer in reasonable times. Nonetheless, the hydrogen content is important regarding electrical transport measurements since it affects the conductivity of the samples and the ion tracks [2].

\subsection{Implantation for doping and defect production}

For low energy implantation, the accelerator IONAS located at the University of Göttingen [95] is used. This Cockkroft-Walton type implanter has a maximum acceleration voltage of $500 \mathrm{kV}$. This accelerator is equipped with an ion source similar to ADONIS, described in [88]. During the implantation of single crystals, channeling may occur. This may result in irreproducible implantation profiles. To avoid this, all samples were mounted on a tilted sample holder. Its surface has an angle of $9^{\circ}$ to the ion beam.

\subsection{Swift heavy ion irradiation at the GSI}

The swift heavy ion irradiation was either performed at the Helmholtzzentrum für Schwerionenforschung $\left.\right|^{2}$ (GSI) in Darmstadt or at the now closed Ionenstrahllabor (ISL) at the Helmholtzzentrum Berlin für neue Materialien und Energi $\left.\right|^{3}$ in Berlin. To perform irradiations at temperatures above room temperature, a new chamber was established at the M-branch at GSI within the framework of this thesis. Figure 4.3 shows a photograph of the new M3-branch. On the left of the beam line, a multi purpose irradiation chamber is seen (1). It is equipped with a sample manipulator which allows rotating the sample additionally to up-downward movements. The heating chamber is located in front of this multi purpose chamber (2). The feedthroughs for temperature measurement and heater power supply are mounted on the large flange. The right part of the beam line is used for beam monitoring (3). An average ion flux is $10^{8} \frac{\text { ions }}{\mathrm{cm}^{2} \cdot \mathrm{s}}$ but it can exceed $10^{9} \frac{\mathrm{ions}}{\mathrm{cm}^{2} \cdot \mathrm{s}}$. The samples are mounted on a heater plate perpendicular to the beam, shown in Fig. 4.4, which is fixed on a linear stage. By moving the stage, different areas of the heater plate can be irradiated. The heater plate is made up of three parts. On the right in fig. 4.4, a part without heating option is seen. This part is used for irradiation at room temperature for reference measurements. The two heater plates consist of pyrolytic boron nitride heaters. The heaters are framed in tantalum sheets to avoid losses due to heat radiation. Small pockets are formed with the tantalum sheets for sample clamping. The samples are also glued onto the tantalum using a carbon based liquid. To ensure the beam position on the heater plate, small pieces of a ceramic

\footnotetext{
${ }^{2}$ www.gsi.de

$3_{\text {www.helmholtz-berlin.de }}$
} 


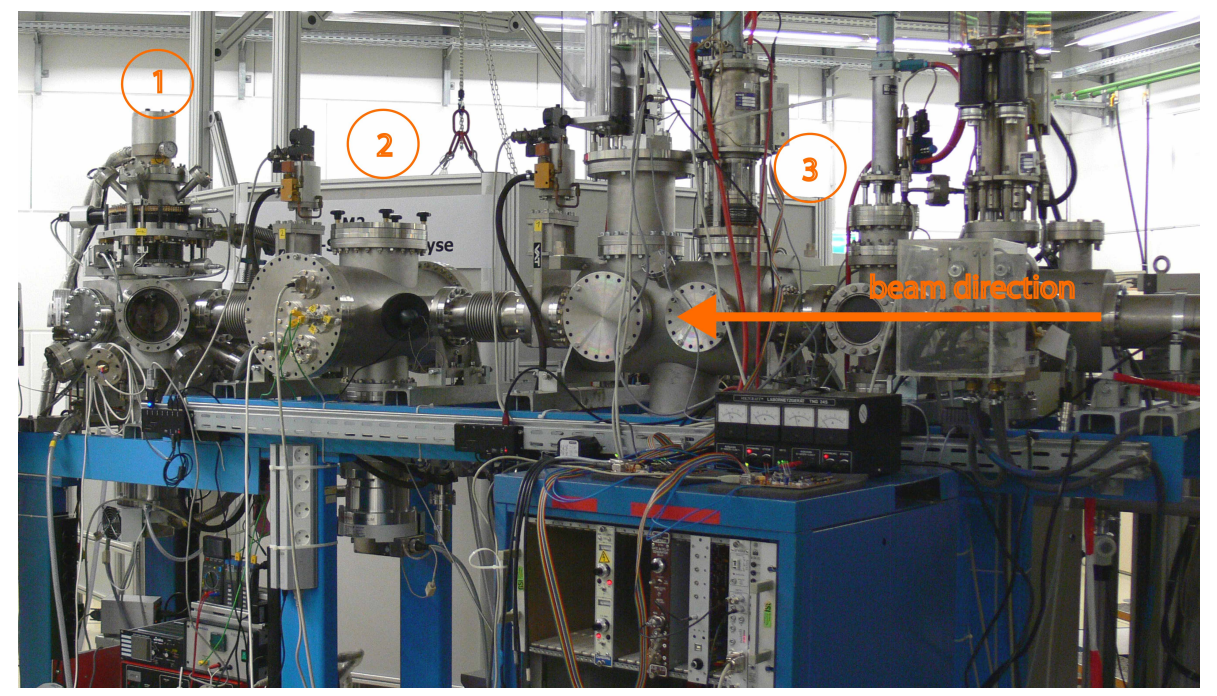

Figure 4.3: Photograph of M-branch at the GSI. In front, the M3-branch is visible. The right part of the beam line to the flexible hose in the middle of the picture is used for beam focusing and detection (3). The heating chamber is located directly after this setup (2), the chamber with the large windowless flange.

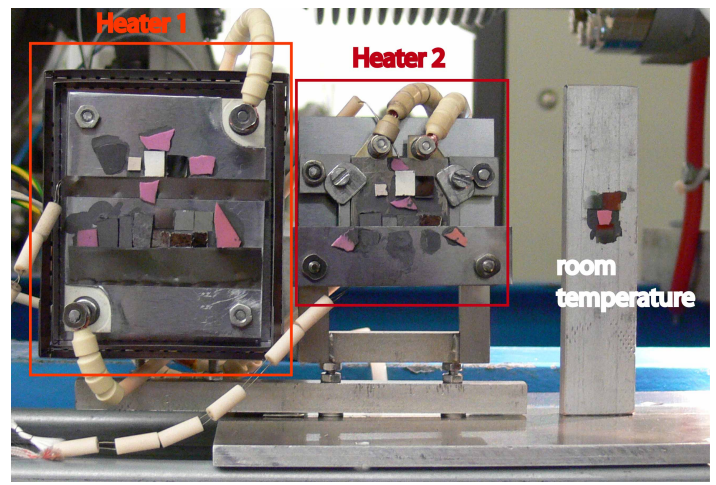

Figure 4.4: Photograph of heater plate. The plate consists of three parts, two pyrolytic boron nitride heaters and a part without heating. Several samples are mounted on the plate. The pink mineral is used for beam detection.

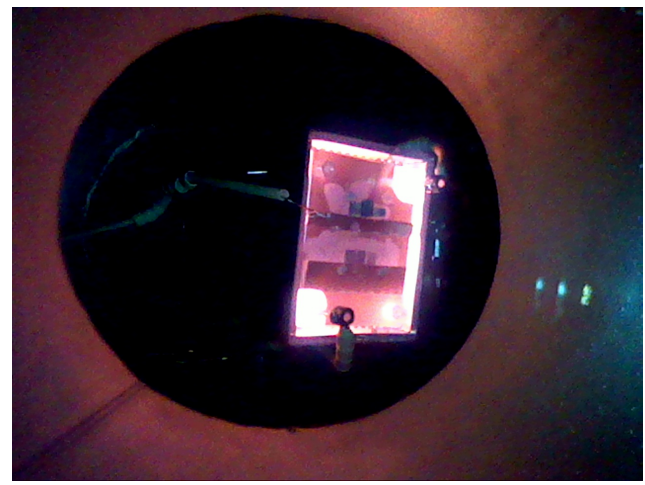

Figure 4.5: View inside the heating chamber. The left heater in Fig. 4.4 (heater 1) is in use and glowing. 
based on Cr-doped aluminium oxide are fixed beside the samples, visible as pink fragments. This mineral is glowing under ion irradiation. For temperature sensing, type $\mathrm{K}$ thermocouples, $\mathrm{Ni} / \mathrm{CrNi}$-wire, were used. The heater plate is capable to perform irradiations at temperatures up to $1000{ }^{\circ} \mathrm{C}$.

\subsection{Electrical transport measurements}

The ta-C samples have been characterized by means of conductivity measurements. Two methods were applied, which will be described in the following.

\subsubsection{AFM with conductive cantilever}

The atomic force microscopy (AFM) [96] is a widely used technique for surface analysis. A cantilever with a small tip is scanned over a sample surface. All measurements were performed in contact mode, this means the tip is pressed on the sample surface with certain pressure. When scanning the tip over the sample, the cantilever is bend due to mechanical repulsion. A laser beam reflecting from the reverse side of the cantilever can be used for curvature measurements and thus height measurements. First introduced in 1986, AFM was much developed since then. For example, using a conductive cantilever and applying a voltage between sample and cantilever, simultaneously local conductivity and topography can be measured. This method allows the measurement of small-sized conductivity variations on the sample, such as single ion tracks in ta-C. For this work, an AFM with the classification XE-100 manufactured by PSIA is used. Conductive cantilevers coated with a Pt/Ir-film (Budget Sensors ContE) with a spring constant of $0.2 \mathrm{~N} / \mathrm{m}$ were used. All measurements were performed by Johann Krauser at the Hochschule Harz in Wernigerode.

\subsubsection{Measurements with macroscopic contact pad}

The apparatus used for electrical transport characterization is sketched in Fig 4.6. This setup was arranged within the framework of my diploma thesis [97]. Mounted on a closed-cycle helium cryostat under high-vacuum conditions, the conductivity can be measured at temperatures down to $15 \mathrm{~K}$. Voltage was applied to the sample using a 273 high voltage source measure unit SMU by Keithley. This SMU is able to detect currents down to picoampères with proper shielding. The temperature is measured with a silicon diode, model name DT-470-CU-12, which is read out by a 331 temperature controller fabricated by LakeShore. A second silicon diode is used for monitoring the cryostat temperature. The heating wire is a nickel-chromium wire, its current flowing through is adjusted by the temperature controller. Both 


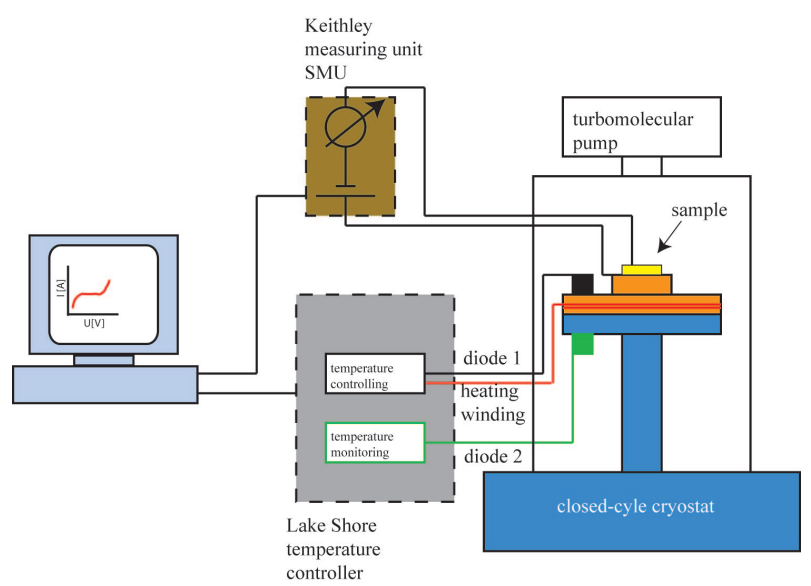

Figure 4.6: Schematic illustration of electrical measurement setup. See text for detailed description of single components.

SMU and temperature controller are controlled by a computer, the measurement runs automatically.

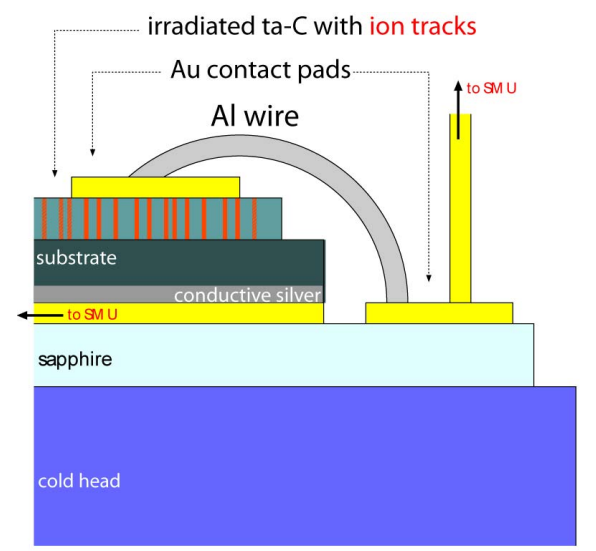

Figure 4.7: Sketch of contact pad on sample. The contact pad on top of the sample is first connected to the sapphire for thermal anchoring. The back contact is realized by conductive silver.
Mostly, two-probe measurement, with one contact on the top and one on the back, as seen in fig. 4.7, were performed. This is suitable for samples with high resistivity. For the analyzed material ta-C, a typical resistivity of about $10^{10} \Omega \mathrm{cm}[79$ is given. It is also possible to perform four-probe measurements by fixing two wires on top of the sample and two on the back contact. Thus, the wiring resistance can be neglected. However, the resistance of the conductive silver drop, which forms the second contact, see fig. 4.7, varies. To avoid measurement artifacts, the resistivity of the conductive silver drop has to be tested. A detailed procedure is given in [98].

In Fig,4.7, a detailed view of the contact pad on the sample is given. To form circular contact pads the samples are masked and $10 \mathrm{~nm}$ chromium and about $100 \mathrm{~nm}$ gold are deposited by thermal evaporation. The chromium buffer layer is necessary for the durability and adhesion of the contact pad. Using only gold contacts yields poor results. A sapphire with gold contacts serves as thermal conductor and electrical insulator between the cryostat and sample. The 


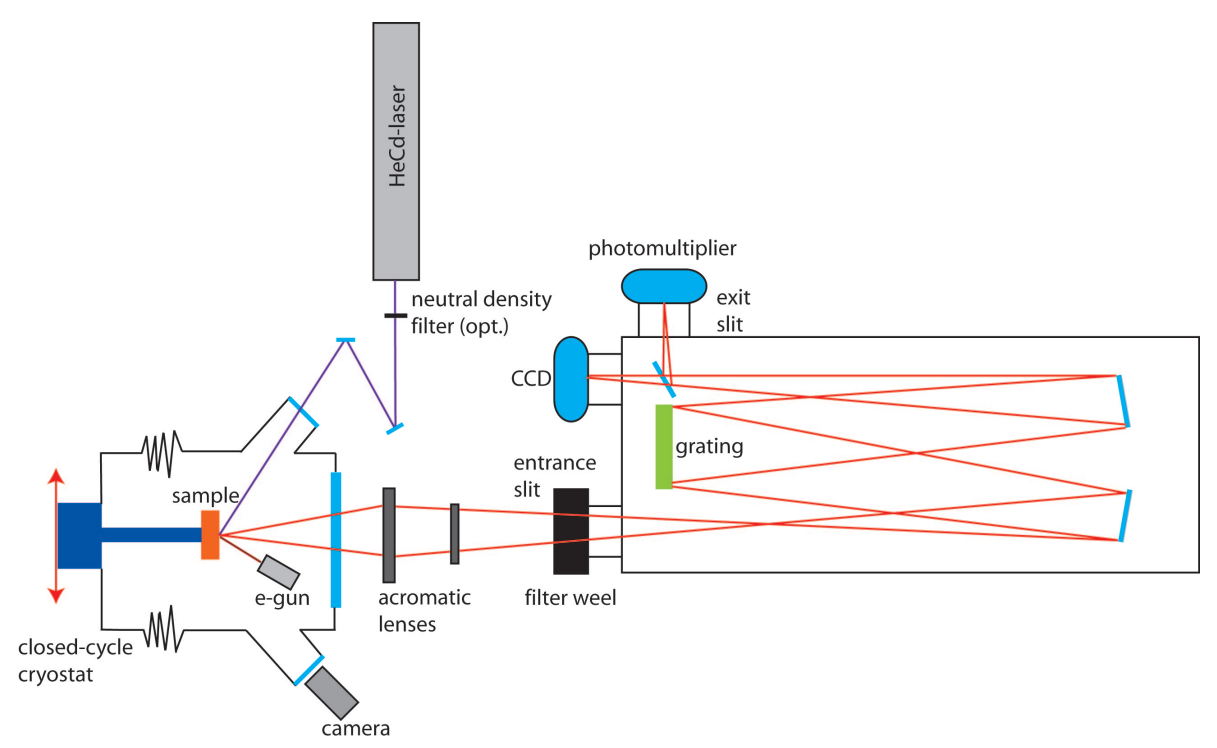

Figure 4.8: Sketch of luminescence analysis chamber. The laser is guided into the chamber with dielectric high performance mirrors. The emitting light is focused on a grating and recorded by either a liquid nitrogen cooled CCD camera or a photomultiplier.

contact between sapphire and top of the sample is realized with an aluminum wire. Using a WedgeBonder provided by Kulicke \& Soffa, the wire is pressed onto the gold contacts by ultrasonic vibrations. The duration, amplitude and static force can be adjusted for best possible adhesion and low damage on sample. The contact between sapphire and substrate is realized with conductive silver.

Assuming an irradiation fluence of $10^{11} \frac{\mathrm{ions}}{\mathrm{cm}^{2}}$ and a track diameter of $10 \mathrm{~nm}$, only about $8 \%$ of the sample surface are irradiated, neglecting double hits. Thus, electrical measurements on irradiated and unirradiated samples are mandatory. Previous work has shown, that, regarding undoped ta-C, the conductivity increases about two orders of magnitude due to this irradiation fluence [4].

\subsection{Luminescence measurements}

In this thesis, luminescence was analyzed and used for indirect determination of crystal quality. Incident light can generate electron-hole pairs inside a semiconductor. When recombining, a photon may be emitted. The intensity and wavelength depend on crystal quality and dopant concentration. A sketch of the luminescence analysis chamber is given in fig. 4.8. The apparatus located at the II. Institute of Physics of the university of Göttingen and also described in [99] is capable to stimulate luminescence in three ways. If the luminescence is stimulated by laser light, one speaks of photoluminescence. The luminescence analysis chamber is equipped 
with a pulsed Nd:YAG-laser emitting at $532 \mathrm{~nm}(2.33 \mathrm{eV})$ and $266 \mathrm{~nm}(4.66 \mathrm{eV})$ and a continuous wave HeCd-laser, emitting at $325 \mathrm{~nm}(3.81 \mathrm{eV})$. The laser beam is guided in the luminescence analysis chamber with dielectric high performance mirrors and hits the sample surface under an angle of $60^{\circ}$. As diamond is a wide band-gap semiconductor (about $5 \mathrm{eV}$ ), near band-edge luminescence could not be activated with the laser available. Instead, an electron beam source was used, labeled as e-gun in fig. 4.8. The e-gun is embedded into the analysis chamber with an incident angle to the sample surface of 60 degrees. The maximum electron energy is $5 \mathrm{keV}$ with a maximum current of $50 \mu \mathrm{A}$. Due to the lower penetration depth of electrons compared to the penetration depth of light, the maximum depth 4 for analysis is about $200 \mathrm{~nm}$. This was taken into account during implantation. The electrons are extracted from a hot filament, a non linear background, the black body radiation, is observed in the spectra. The apparatus is also capable to perform electroluminescence analysis. Here, luminescence is activated by applying a voltage at the sample. The samples are mounted on a closed cycle cryostat glued with conductive silver under high-vacuum conditions. Thus, temperatures down to $12 \mathrm{~K}$ can be achieved. The heating wire, temperature diodes and temperature controller are identical in construction to the ones used for electrical transport characterization. The sample holder can be moved with the aid of two electric motors, which drive two worm gears. An area of about $2 \mathrm{~cm} \times 2 \mathrm{~cm}$ can be scanned and analyzed. The light emitting from the sample is focused on a grating in a monochromator with a set of achromatic lenses, a convex and a concave lens. The monochromator, type Jobin Yvon Horiba 1000M in Czerny-Turner geometry, can be equipped with three different gratings. Beside a different amount of grooves per millimeter, the gratings differ in their blaze wavelength $\lambda_{\text {blaze }}$. The three gratings are $100 \frac{\text { grooves }}{\mathrm{mm}}\left(\lambda_{\text {blaze }}=\right.$ $450 \mathrm{~nm}), 600 \frac{\text { grooves }}{\mathrm{mm}}\left(\lambda_{\text {blaze }}=1000 \mathrm{~nm}\right)$ and $1200 \frac{\text { grooves }}{\mathrm{mm}}\left(\lambda_{\text {blaze }}=250 \mathrm{~nm}\right)$. The signal can either be recorded with a liquid nitrogen cooled CCD camera or with a photomultiplier. Under an angle of about $60^{\circ}$ to the sample, a camera is placed in front of a window for sample observation. Thus, the position of the beam spot on the samples can be controlled.

For this work, photoluminescence was stimulated using the HeCd-laser. As marked in fig. 4.8, the output power can be adjusted using a neutral density filter. The maximum output power of the laser available is $65 \mathrm{~mW}$. When measurements were performed with varying power, the output power used for the measurements will be mentioned with the respective spectra.

The diamond samples were analyzed by cathodoluminescence, using the maximum energy of $5 \mathrm{keV}$.

Performing electroluminescence measurements requires some modifications of the

${ }^{4}$ This was calculated with the simulation software CASINO. 
sample holder to apply a voltage on the sample. These modifications are described in [100]. 


\section{Chapter 5}

\section{Results}

In this chapter, the results obtained in the framework of this thesis are presented. These results will be discussed in detail in chapter 6. At first, the results derived from swift heavy ion irradiation of $t a-C$ are presented, followed by the sections $G a N$, diamond and $S i C$. In the beginning of each section, the analysis of the pristine material will be given. Then, the details of swift heavy ion irradiation, or $\mathrm{C}_{60}$ irradiation respectively, are described, followed by the results obtained from the irradiated samples.

\subsection{Doping and irradiation of ta-C}

As mentioned in section 2.4.1, ta- $\mathrm{C}$ forms conductive ion tracks after swift heavy ion irradiation. The aim of this work is to increase the conductivity of these ion tracks and retain the insulating properties of the surrounding matrix. Two approaches were made. First, ta-C films doped with nitrogen, boron, copper and iron were produced. Nitrogen and boron impurities are expected to increase the number of localized states at the Fermi-level and thus increase the number of hopping sites. This should lead to an increase of conductivity. After swift heavy ion irradiation of metal doped ta-C, the ion tracks should contain iron or copper and thus should show ohmic current-voltage characteristics. The conductivity of the ion tracks was analyzed by AFM-

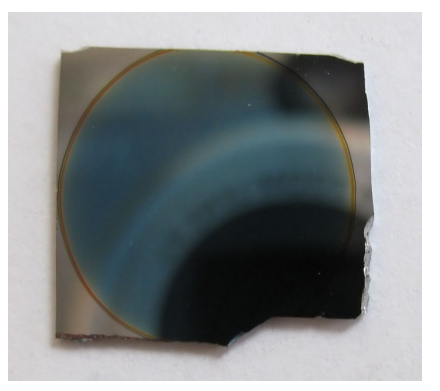

Figure 5.1: Photograph of undoped ta- $C$ deposited on silicon. The film has a thickness of $100 \mathrm{~nm}$. The substrate has a size of $15 \mathrm{~mm} \times 15 \mathrm{~mm}$. measurements and macroscopic electrical transport measurements.

Second, as the conductivity of ion tracks increases with increasing electronic energy 


\begin{tabular}{lll}
$\begin{array}{l}\text { Carbon energy } \\
\mathrm{eV}\end{array}$ & $\begin{array}{l}\text { Dopant \& energy } \\
\mathrm{eV}\end{array}$ & $\begin{array}{l}\text { Fluence ratio } \\
\text { carbon:dopant }\end{array}$ \\
\hline \hline 100 & $\mathrm{~N}, 100$ & $99: 1$ \\
100 & $\mathrm{~B}, 100$ & $98: 2$ \\
100 & $\mathrm{Cu}, 100$ & $99: 1$ \\
100 & $\mathrm{Fe}, 100$ & $99: 1$ \\
\hline
\end{tabular}

Table 5.1: Deposition parameters of doped ta-C. The deposition temperature was room temperature.

loss during irradiation, ta-C samples were irradiated with $\mathrm{C}_{60}$ molecules which show a higher electronic energy loss than uranium ions.

Fig. 5.1 shows a photograph of a typical ta-C sample deposited on silicon. The film has a diameter of about $13 \mathrm{~mm}$ and a thickness of $100 \mathrm{~nm}$. Due to interference of light reflected from sample and substrate surface, the film appears blue.

As described in section 4.1, ta-C films were produced by deposition of $100 \mathrm{eV}$ carbon atoms on a silicon substrate. The doped ta-C samples were produced by codepositing of nitrogen, boron, copper or iron. The deposition fluence ratio of carbon and dopant is given in table 5.1. Directly after deposition, the $\mathrm{sp}^{3}$-content of the samples was measured by XPS using the $\mathrm{Mg}-\mathrm{K} \alpha$ radiation $(1253.6 \mathrm{eV})$. To determine this content, the position of the plasmon ${ }^{1}$ loss peak with respect to the C1s peak maximum, the s-orbital of the first shell of carbon, was determined and compared to the plasmon loss peak of undoped ta-C, as described in, for example, [91, 92]. It was found that the plasmon loss energy exceeds $31 \mathrm{eV}$ for all samples, comparable to undoped ta-C.

To ensure the absence of clusters, the ta-C:Fe and ta-C:Cu samples were analyzed by transmission electron microscopy (TEM). These measurements were performed by Hayo Zutz (former collaborator of the II. Institute of Physics, university of Göttingen) at the Philips CM200-FEG-UT microscope in the workgroup of Prof. Dr. Michael Seibt at the IV. Institute of Physics (university of Göttingen). No clusters could be found.

All samples were irradiated at room temperature, the parameters are given in table 5.2. Swift heavy ion irradiation with gold or uranium was performed at the Helmholzzentrum für Schwerionenforschung in Darmstadt, $\mathrm{C}_{60}$ irradiation was performed at the Institut de Physique Nucleaire D'Orsay. The swift heavy ions used for irradiation have a range of several micrometers, thus, the ions are stopped inside the substrate. For the $\mathrm{C}_{60}$ irradiation, the coherence length, the range, in which the molecule is intact, is of importance. The coherence length is about $100 \mathrm{~nm}$ [101], and thus, the maximum sample thickness should not exceed $100 \mathrm{~nm}$. The electronic

${ }^{1}$ oscillation of electrons 
and nuclear energy loss was calculated using SRIM2008. To obtain the energy loss for the $\mathrm{C}_{60}$ molecules, the values for a single carbon ion with same velocity, which means an energy of $\frac{30}{60} \mathrm{MeV}=0.5 \mathrm{MeV}$, was calculated and multiplied by 60 . The validity of this assumption was confirmed by other experiments [102, 103].

The conductivity of the ion tracks was analyzed in two ways. First, the results

\begin{tabular}{lll}
$\begin{array}{l}\text { Ion species \& energy } \\
\mathrm{MeV}\end{array}$ & $\begin{array}{l}\text { Electronic energy loss } \\
\mathrm{keV} / \mathrm{nm}\end{array}$ & $\begin{array}{l}\text { Nuclear energy loss } \\
\mathrm{keV} / \mathrm{nm}\end{array}$ \\
\hline \hline $\mathrm{U}, 1000$ & 42 & $7.8 \times 10^{-2}$ \\
$\mathrm{Au}, 1000$ & 33 & $5 \times 10^{-2}$ \\
$\mathrm{C}_{60}, 30$ & $72^{*}$ & $1.33^{*}$ \\
\hline
\end{tabular}

${ }^{*}$ The energy loss was calculated using carbon ions with $\frac{30}{60} \mathrm{MeV}=0.5 \mathrm{MeV}$ and multiplying the energy loss with 60 .

Table 5.2: Irradiation parameters used for ta-C. The energy loss was calculated using SRIM2008.

obtained from the AFM measurements will be presented. These measurements were performed by J. Krauser at Hochschule Harz, Wernigerode. Second, the electrical conductivity was analyzed by macroscopic measurements.

\section{AFM measurements on ion irradiated ta-C:}

Undoped ta-C: The AFM current mapping of undoped ta-C after Au-irradiation is shown in fig $5.2(\mathrm{a})$, the applied voltage was $0.1 \mathrm{~V}$. Each conducting spot in this image corresponds to one ion track. These ion tracks have different conductivities, which is seen by the different color. The irradiation fluence was $5 \times 10^{9} \frac{\text { ions }}{\mathrm{cm}^{2}}$, derived from the image. The statistical analysis of the measured current at $0.1 \mathrm{~V}$ is given in fig. 5.2(b). For this, the conductivity of 76 tracks was taken into account. To obtain these values, the following procedure was performed for all samples. With the AFM imaging software XEI, the conductive spots of several AFM images were detected. A lower threshold value for the current was selected, which corresponds to the highest current measured on the unirradiated material. Here a value of about $0.05 \mathrm{nA}$ was chosen. The average current of the remaining grains, the ion tracks, was calculated. The data obtained this way was binned with a size of $0.2 \mathrm{nA}$. A broad variation in conductivity can be clearly seen, the values do not show a normal distribution. The average resistivity of the ion tracks is $231 \mathrm{M} \Omega$. Its value is derived from the arithmetic mean current value.

ta-C:N: In fig. 5.3(a), the AFM-current image of Au-irradiated ta-C:N is shown. The applied voltage was $0.3 \mathrm{~V}$, three times higher than the applied voltage in fig. 5.2. Currents up to $4 \mathrm{nA}$ were measured. Counting the spots in this image, the irradiation fluence should be $3 \times 10^{9} \frac{\mathrm{ions}}{\mathrm{cm}^{2}}$. The frequency of the measured current with 


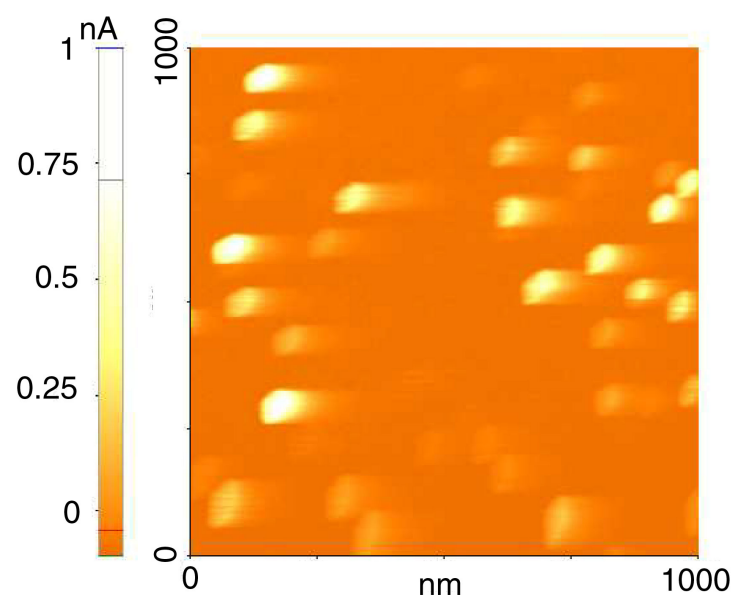

(a) AFM-current mapping, bias voltage $0.1 \mathrm{~V}$

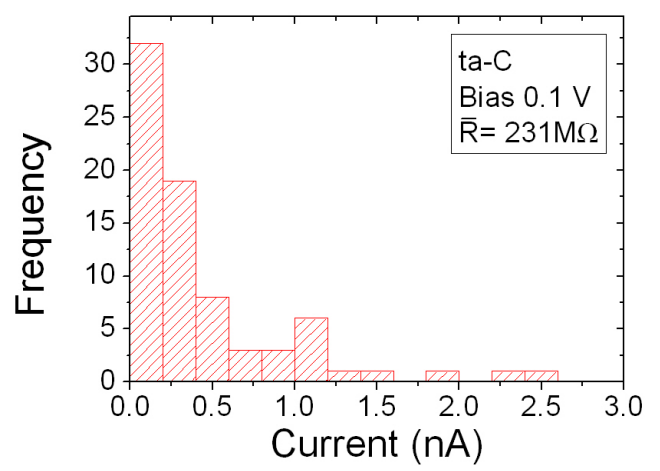

(b) Frequency of measured current at $0.1 \mathrm{~V}$

Figure 5.2: $A F M$-current mapping and current frequency of ion irradiated ta- $C$ with an applied voltage of $0.1 \mathrm{~V}$.

a bin size of $0.5 \mathrm{nA}$ is given in fig. 5.3(b), regarding 107 ion tracks. The "cut-off" current was $0.075 \mathrm{nA}$. A broad distribution of conductivity comparable to pure ta-C is noticeable. With the average current, the average resistivity could be calculated to $104 \mathrm{M} \Omega$. The average resistivity of irradiated ta-C:N is reduced compared to the resistivity of irradiated ta-C.

ta-C:B: The conductivity of ion tracks in ta-C:B after gold irradiation can be derived from the AFM-current mapping, shown in fig. 5.4(a) bias voltage was $0.3 \mathrm{~V}$. The irradiation fluence is about $3.5 \times 10^{10} \frac{\mathrm{ions}}{\mathrm{cm}^{2}}$. Again, the average resistivity derived from the current frequency, see fig. $5.4(\mathrm{~b})$ is used for comparison. Its value equals $119 \mathrm{M} \Omega$, which is lower than the resistivity of tracks in pure ta-C. The current histogram was drawn with the current measured on 82 tracks and a binning size of $0.5 \mathrm{nA}$. Here, the current threshold value was $0.25 \mathrm{nA}$.

ta-C:Fe: The most conductive ion tracks were found in ta-C:Fe. Currents up to $16 \mathrm{nA}$ were found with an applied voltage of $0.05 \mathrm{~V}$, fig. 5.5(a). Here, the irradiation fluence can be estimated to $3.4 \times 10^{10} \frac{\mathrm{ions}}{\mathrm{cm}^{2}}$. However, the track conductivity varies, as seen in fig. 5.5(b). A total sum of 53 tracks with a current threshold value of $0.25 \mathrm{nA}$ was used for the histogram with a binning size of $2 \mathrm{nA}$. The value of the average resistivity is the lowest of all samples, namely $4.4 \mathrm{M} \Omega$.

ta-C:Cu: Copper doped ta-C forms tracks with higher conductivity compared to the ones in ta-C after U-irradiation, see fig. 5.6(a). With an applied voltage of $0.3 \mathrm{~V}$, currents of $50 \mathrm{nA}$ flowing through the ion tracks were recorded. Irradiation fluence is calculated to $3.7 \times 10^{10} \frac{\text { ions }}{\mathrm{cm}^{2}}$. A broad variation in track conductivity was recognized again, fig. 5.6(b). The histogram contains the current of 77 ion tracks, 


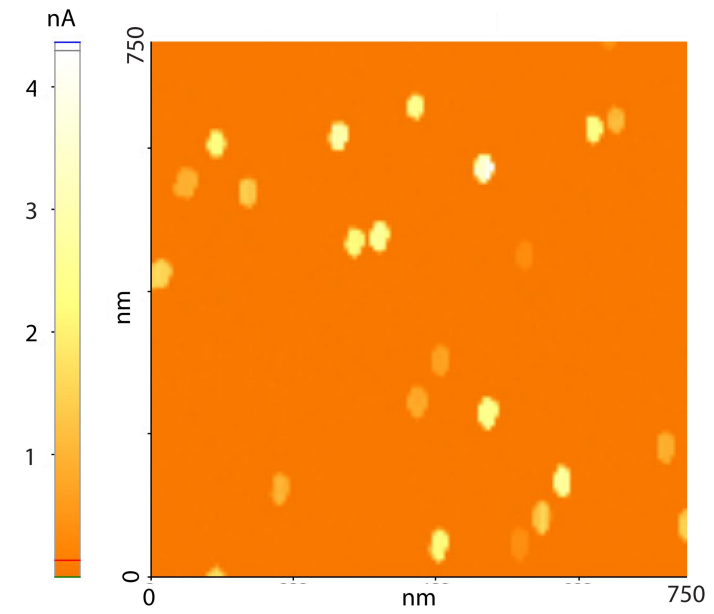

(a) AFM-current mapping, bias voltage $0.3 \mathrm{~V}$

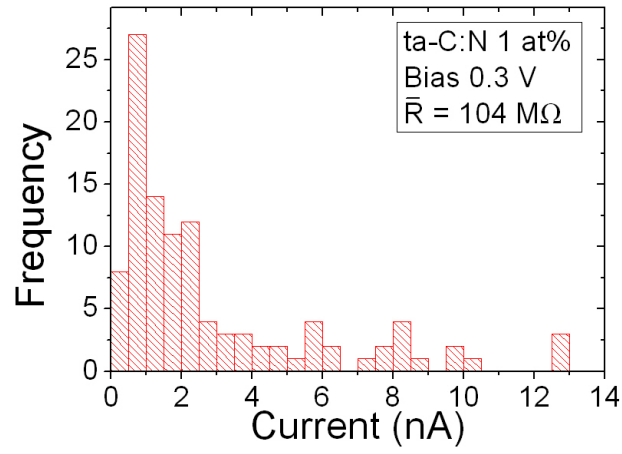

(b) Frequency of measured current at $0.3 \mathrm{~V}$

Figure 5.3: AFM-current mapping and current frequency of ion irradiated ta-C:N with an applied voltage of $0.3 \mathrm{~V}$.

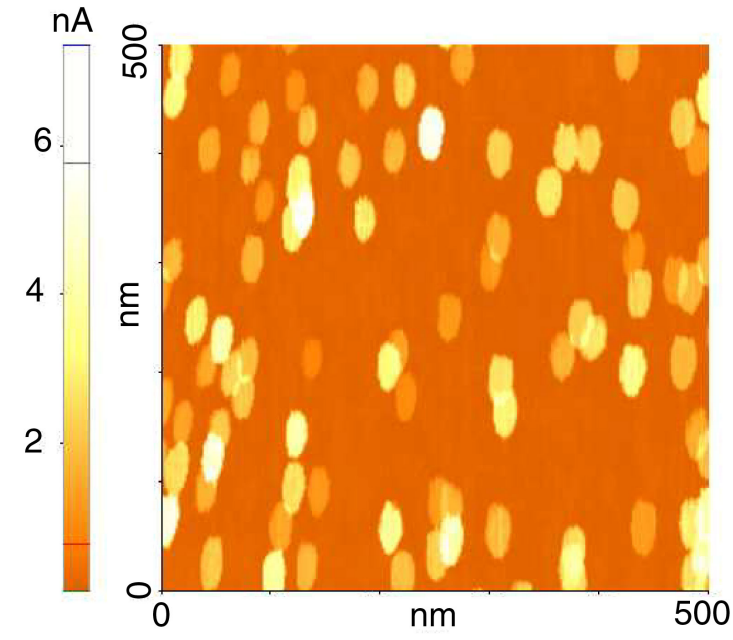

(a) AFM-current mapping, bias voltage $0.3 \mathrm{~V}$

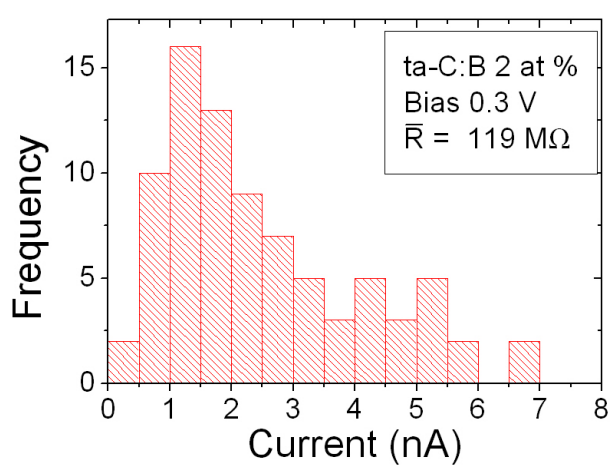

(b) Frequency of measured current at $0.3 \mathrm{~V}$

Figure 5.4: $A F M$-current mapping and current frequency of ion irradiated ta-C:B with an applied voltage of $0.3 \mathrm{~V}$. 
binning size was $5 \mathrm{nA}$ and current threshold value $0.1 \mathrm{nA}$. The average resistivity of $14 \mathrm{M} \Omega$ is comparable low as the resistivity of irradiated ta-C:Fe.

\section{AFM measurements on $\mathrm{C}_{60}$ irradiated ta-C:}

All samples were irradiated with $10^{9} \frac{\mathrm{C}_{60}}{\mathrm{~cm}^{2}}$. Thus, about ten tracks should be visible in area of $1 \mu \mathrm{m} \times 1 \mu \mathrm{m}$. The conductive spots in the AFM images correspond well with this number.

undoped ta-C: The conductivity of tracks in ta-C after $\mathrm{C}_{60}$ irradiation can be seen in fig. 5.7. AFM current mapping was recorded with an applied voltage of $0.1 \mathrm{~V}$. All ion tracks in fig. 5.7(a) seem similar in conductivity. Statistical analysis was performed regarding the measured current of 145 ion tracks. With a binning size of $0.2 \mathrm{nA}$ and a "cut-off" value similar to the one for ion irradiated ta-C (0.06 nA), the histogram shown in fig. 5.7(b) is observed. The most striking difference to fig. $5.2(\mathrm{~b})$ is the narrow distribution of measured current. To obtain the mean current value, a Gaussian line shape was fitted. The average resistivity could be calculated to $22 \mathrm{M} \Omega$.

ta-C:N: The AFM current image of $\mathrm{C}_{60}$ irradiated ta-C:N is seen in fig. 5.8, applied voltage was $0.1 \mathrm{~V}$. Conductive tracks were found, see fig. $5.8(\mathrm{a})$, but their conductivity seems not to be equal contrary to $\mathrm{C}_{60}$ irradiated ta-C. The histogram in fig. 5.8(b) involves the measured current of 45 ion tracks using a threshold value of $0.025 \mathrm{nA}$, the binning size is $1 \mathrm{nA}$. With the average current of $0.57 \mathrm{nA}$, the average resistivity is calculated to $17.7 \mathrm{M} \Omega$. No Gaussian line shape was fitted to the data due to the broad distribution. The average resistivity is reduced compared to the resistivity of tracks in ion irradiated ta-C:N or $\mathrm{C}_{60}$ irradiated ta-C.

ta-C:B:As one may expect from fig. 5.2(b), ta-C:B forms very conductive tracks after $\mathrm{C}_{60}$ irradiation. The AFM-current mapping fig. 5.9(a) was recorded with a bias voltage of $0.1 \mathrm{~V}$, currents up to $10 \mathrm{nA}$ were found. The current of 65 tracks (threshold $0.075 \mathrm{nA}$ ) were used for statistical analysis. With a binning size of $0.5 \mathrm{nA}$, the histogram shown in fig. 5.9(b) is calculated. A narrow current distribution, which was also recorded after $\mathrm{C}_{60}$ irradiation of ta-C, is observed. The average resistivity derived from the histogram by fitting a Gaussian line shape is $10.3 \mathrm{M} \Omega$.

ta-C:Fe:Similar to the results of swift heavy ion irradiation of ta-C:Fe, the most conductive tracks were found after $\mathrm{C}_{60}$ irradiation of ta-C:Fe. With an applied voltage of $0.1 \mathrm{~V}$, currents up to $50 \mathrm{nA}$ were measured, see fig. 5.10(a). All tracks seem to have a similar conductivity. To test this, a total sum of 104 ion tracks were analyzed ("cut-off" at $0.1 \mathrm{nA}$ ). The measured current was binned using a size of $5 \mathrm{nA}$, shown in fig. $5.10(\mathrm{~b})$, The average resistivity is derived from the Gaussian line fit of the narrow distribution, its value equals $1.9 \mathrm{M} \Omega$.

No $\mathrm{C}_{60}$ irradiation was performed on ta-C: $\mathrm{Cu}$ samples. 


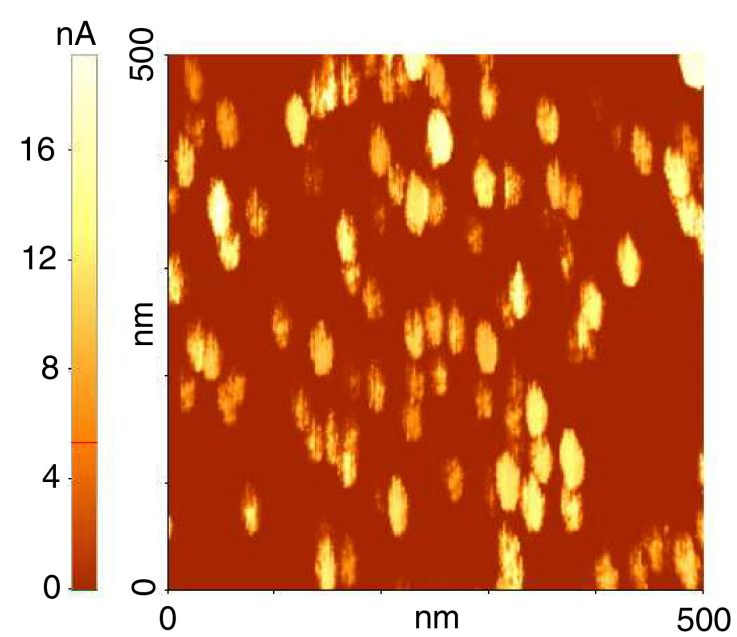

(a) AFM-current mapping, bias voltage $0.05 \mathrm{~V}$

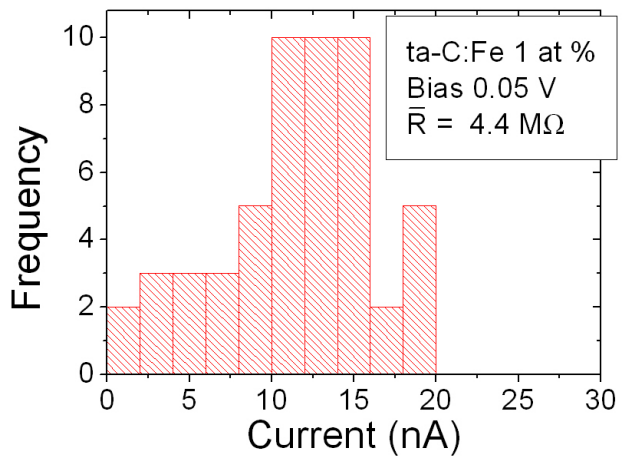

(b) Frequency of measured current at $0.05 \mathrm{~V}$

Figure 5.5: AFM-current mapping with $0.05 \mathrm{mV}$ and current frequency with $0.05 \mathrm{~V}$ of irradiated ta-C:Fe.

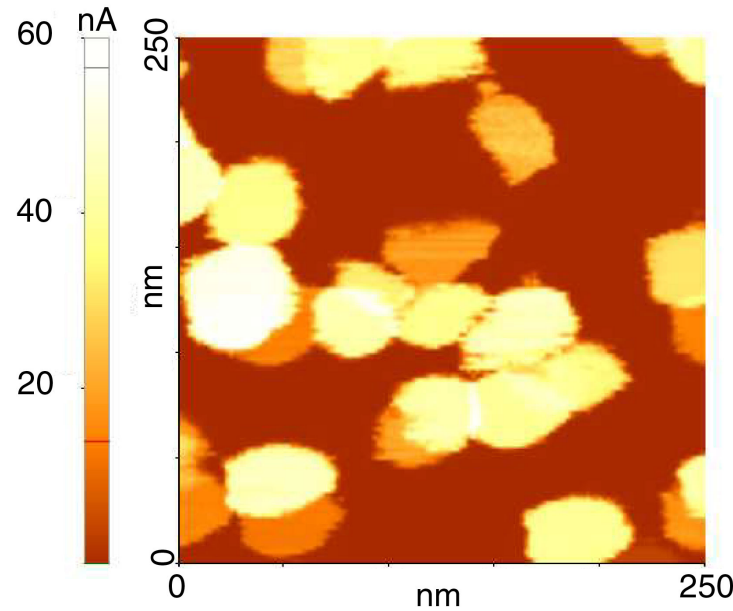

(a) AFM-current mapping, bias voltage $0.3 \mathrm{~V}$

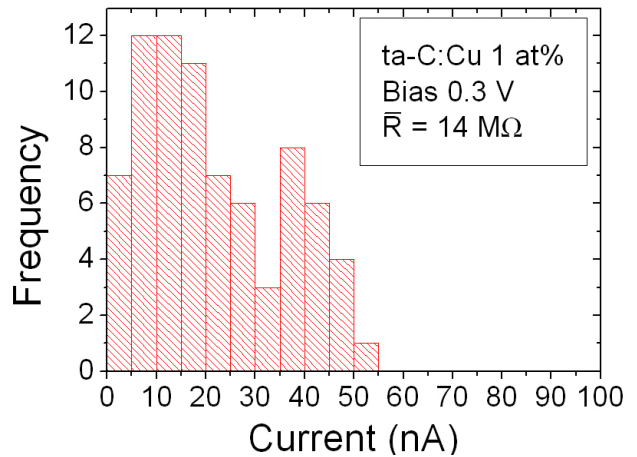

(b) Frequency of measured current at $0.3 \mathrm{~V}$

Figure 5.6: AFM-current mapping and current frequency of irradiated ta-C:Cu with an applied voltage of $0.3 \mathrm{~V}$. 


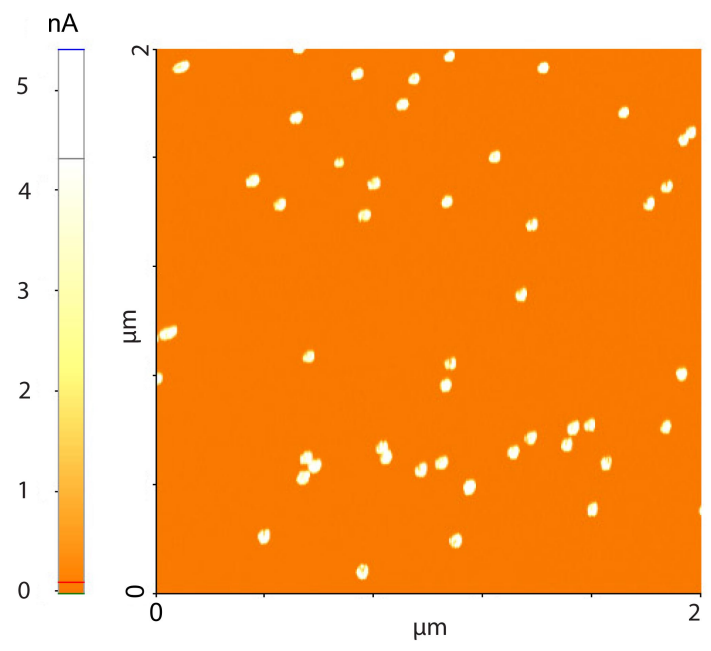

(a) AFM-current mapping, bias voltage $0.1 \mathrm{~V}$

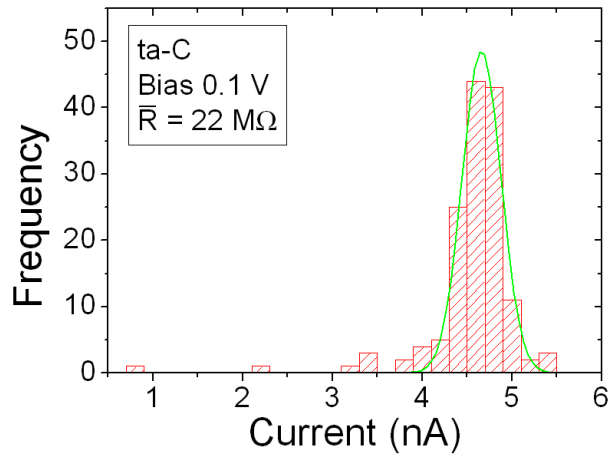

(b) Frequency of measured current at $0.1 \mathrm{~V}$

Figure 5.7: AFM-current mapping and current frequency of $C_{60}$ irradiated ta- $C$ with an applied voltage of $0.1 \mathrm{~V}$.

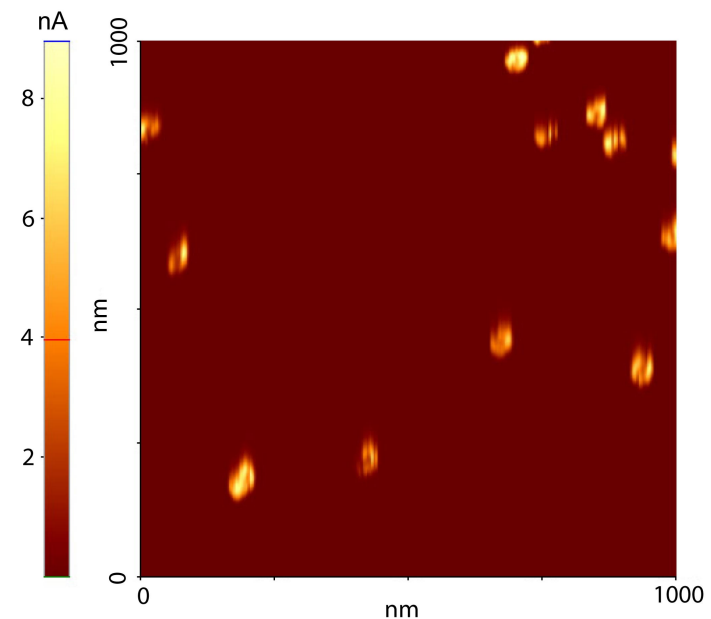

(a) AFM-current mapping, bias voltage $0.1 \mathrm{~V}$

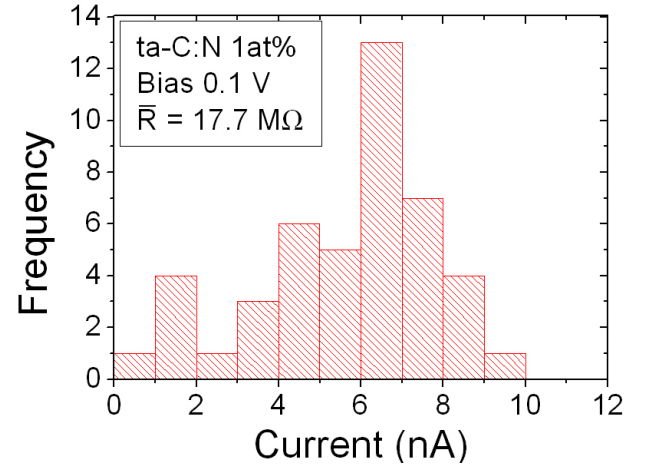

(b) Frequency of measured current at $0.1 \mathrm{~V}$

Figure 5.8: AFM-current mapping and current frequency of $C_{60}$ irradiated ta-C:N with an applied voltage of $0.1 \mathrm{~V}$. 


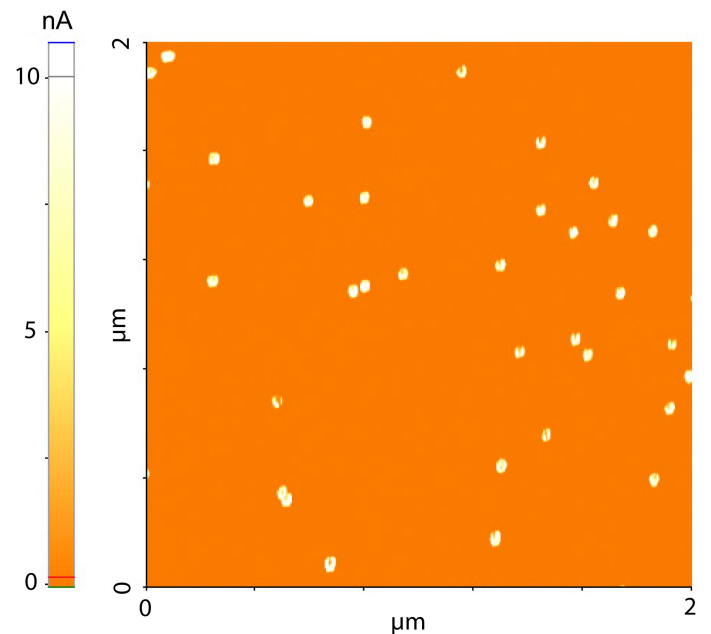

(a) AFM-current mapping, bias voltage $0.1 \mathrm{~V}$

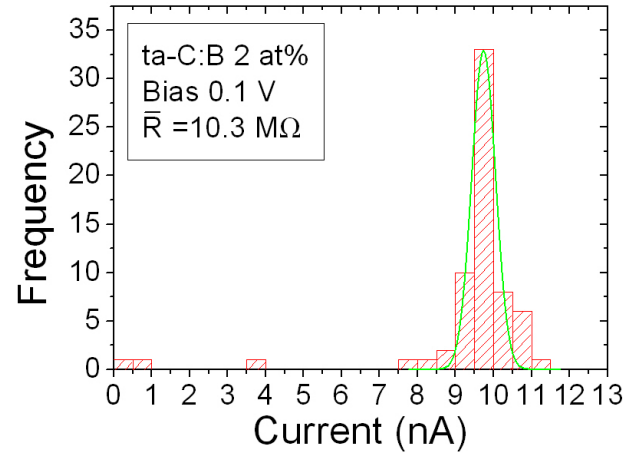

(b) Frequency of measured current at $0.1 \mathrm{~V}$

Figure 5.9: AFM-current mapping and conductivity frequency of $C_{60}$ irradiated ta-C:B with an applied voltage of $0.1 \mathrm{~V}$.

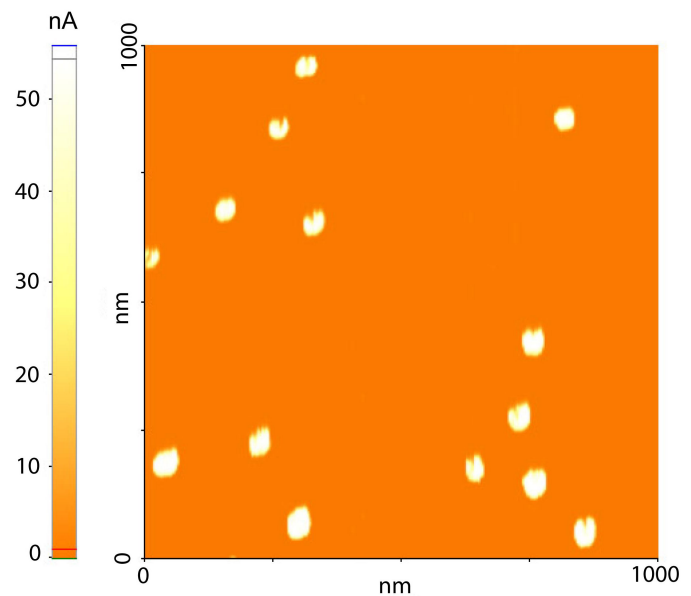

(a) AFM-current mapping, bias voltage $0.1 \mathrm{~V}$

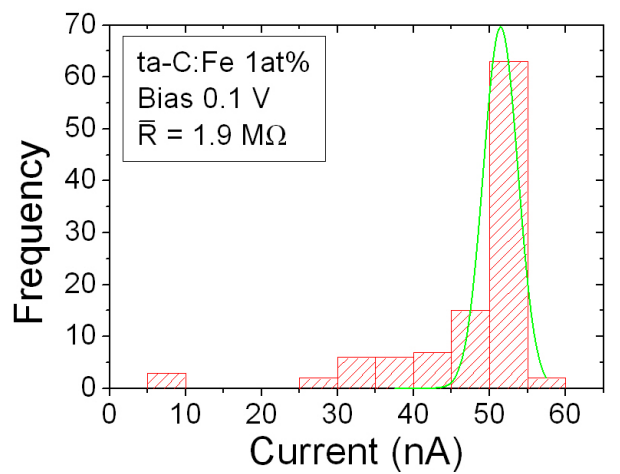

(b) Frequency of measured current at $0.1 \mathrm{~V}$

Figure 5.10: AFM-current mapping and current frequency of $C_{60}$ irradiated ta-C:Fe with an applied voltage of $0.1 \mathrm{~V}$. 


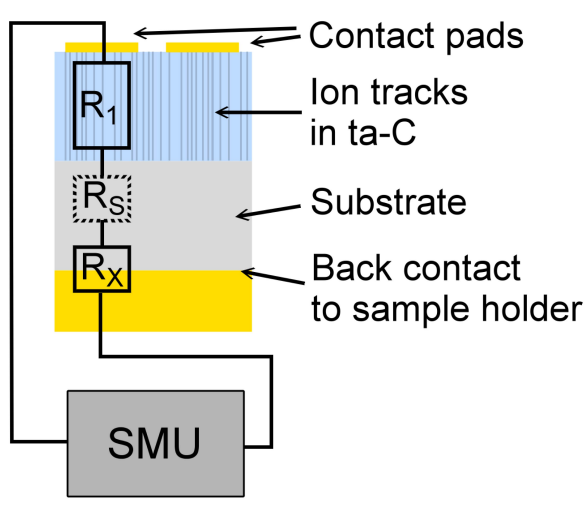

(a) Measurement of $R_{1}$

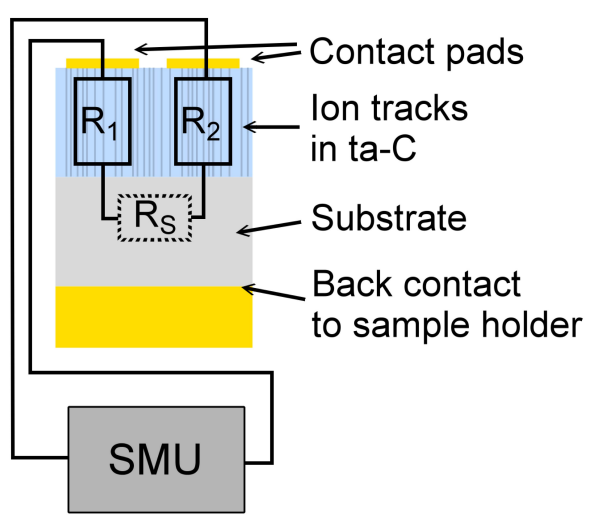

(b) Measurement of $\mathrm{R}_{12}$

Figure 5.11: Schematic drawing of transport measurement setup to calculate $R_{X}$, taken from [98]. In (a), the standard setup is seen, in which track resistivity $R_{1}$ is in series with $R_{X}$. The substrate resistance $R_{S}$ can be neglected. The lateral resistivity is measured using the setup drawn in (b).

\section{Transport measurements on ion irradiated ta-C:}

Beside the conductivity of the ion tracks, the conductivity contrast to the surrounding material is of interest. The measurements of ta- $\mathrm{C}$ and ta- $\mathrm{C}: \mathrm{Cu}$ were performed by Hans-Gregor Gehrke (II. Institute of Physics, university of Göttingen). For the irradiated samples, the resistivity of the conductive silver droplet was taken into account. The same procedure described in [98 was applied. At least two measurements yielding linear I-U-curves at different contact pads were performed for each sample. The resistivity of the current-voltage curves was calculated for each contact pad, see fig. 5.11(a). Then, the lateral resistivity $R_{12}$ was estimated, fig. 5.11(b). Assuming the current flows through the ion tracks during lateral measurements, the back contact resistance and thus the adjusted voltage and adjusted current can be calculated to:

$$
\begin{gathered}
R_{X}=\frac{\left(R_{1}-R_{2}\right)-R_{12}}{2} \\
U_{\text {adjust }}=U-R_{X} I \\
I_{\text {adjust }}=\frac{U I}{U-R_{X} I}
\end{gathered}
$$

The adjusted voltage is the voltage which is applied on the film and the adjusted current is the extrapolated current which would be measured, if $\mathrm{R}_{X}$ is zero, assum- 
ing the current-voltage curves are linear. However, this can not be concluded for the unirradiated samples, so $\mathrm{R}_{X}$ can not be estimated using this procedure. Therefore, no correction was applied, although the resistivity may not be negligible. It was found that the resistivity resulting from the contacts can be neglected for temperatures under $200 \mathrm{~K}$.

In the following, the current-voltage curves between $-0.3 \mathrm{~V}$ and $0.3 \mathrm{~V}$ of the irradiated and unirradiated ta-C samples are presented. The contact pad had a diameter of $0.4 \mathrm{~mm}$, or, regarding the measurement on ta-C and ta-C:Cu, the current was adjusted. In this voltage regime, the samples show linear curves at $300 \mathrm{~K}$. Measurements at lower temperatures show non-linear current-voltage curves. Therefore, the conductivity contrast becomes voltage dependent, especially at lower temperatures.

The conductivity contrast of unirradiated and irradiated ta-C was derived from the macroscopic transport measurements. To calculate this contrast, a superposition of the two components, ion tracks and matrix, was assumed. The irradiation fluence is similar for all samples within the margin of error, in the order of $3.7 \times 10^{10} \frac{\mathrm{ions}}{\mathrm{cm}^{2}}$, which was derived from the AFM images, thus, only about $2 \%$ of the sample surface are converted to ion tracks assuming a diameter of $8 \mathrm{~nm} \mathrm{[2].} \mathrm{The} \mathrm{current} \mathrm{measured}$ on irradiated samples was assumed to be $\mathrm{I}_{\text {irr }}=0.02 \mathrm{I}_{\text {tracks }}+0.98 \mathrm{I}_{\text {matrix }}$. The current flowing through the matrix was subtracted using the measurements performed on unirradiated samples. The conductivity contrast is the ratio of the current densities $\rho_{\text {tracks }}$ over $\rho_{\text {matrix }}$. Sample thickness is the same for all samples, thus, this ratio equals the ratio of the conductivities $\sigma_{\text {tracks }} / \sigma_{\text {matrix }}$.

undoped ta-C: The conductivity contrast over temperature for undoped ta-C is given in fig. 5.12. At room temperature, this ratio is $4 \times 10^{4}$, so the current through the insulating ta-C may even be neglected. This ratio even increases with decreasing temperature. At $100 \mathrm{~K}$, the conductivity contrast is $10^{6}$.

ta-C:N: The conductivity contrast of ta-C:N is shown in fig. 5.13, No correction regarding the contact resistivity was done, thus, only the values for measurements below $200 \mathrm{~K}$ are shown. The contrast is in the order of $1 \times 10^{3}$. Unirradiated ta$\mathrm{C}: \mathrm{N}$ shows nonlinear current-voltage curves at room temperature, thus, the contrast varies with the applied voltage.

ta-C:B: The conductivity contrast for ta-C:B is shown in fig. 5.14. The unirradiated ta-C:B has a higher conductivity compared to the one of pristine ta- $\mathrm{C}$, so the contrast is reduced. The contrast has a value of 48 at room temperature and decreases toward lower temperatures. At about $150 \mathrm{~K}$, the I-U-curves of both irradiated and unirradiated ta-C:B become nonlinear.

ta-C:Fe: The current-voltage-curves of unirradiated ta-C:Fe and irradiated ta-C:Fe hardly differ without resistivity correction. The conductivity contrast is low, see fig. 5.15. The ratio has a value of about 33 at room temperature. It decreases with decreasing temperature. 


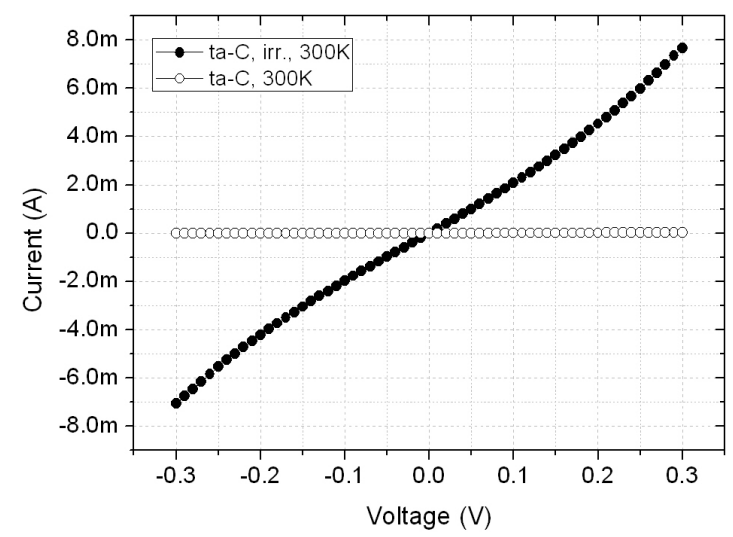

(a) Irradiated and unirradiated ta-C at $300 \mathrm{~K}$, $\mathrm{R}_{X}$ was $15 \pm 1 \Omega$

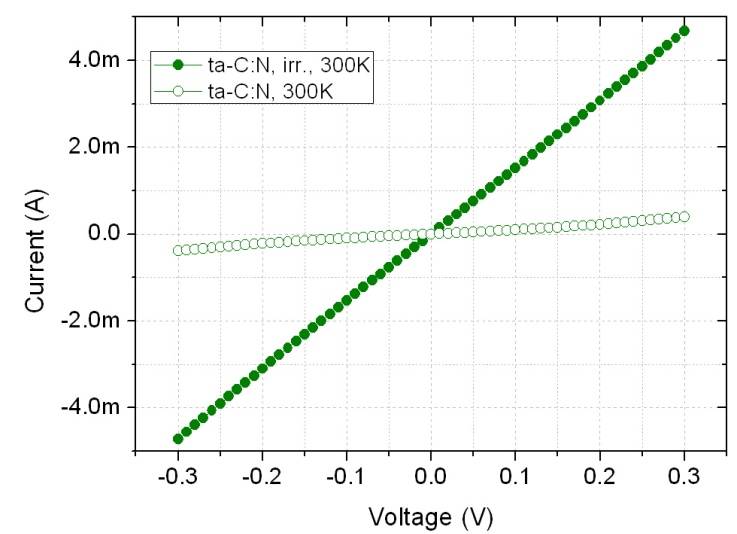

(c) Irradiated and unirradiated ta-C:N at $300 \mathrm{~K}$. Here, no correction was performed, thus, the current of the irradiated sample is likely underestimated.

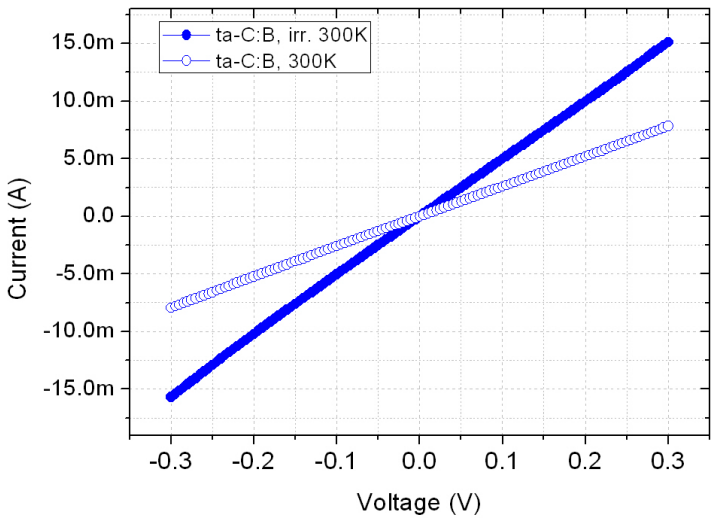

(e) Irradiated and unirradiated ta-C:B at $300 \mathrm{~K}$, (f) Irradiated and unirradiated ta-C:B at $100 \mathrm{~K}$. $\mathrm{R}_{X}$ was $7.41 \pm 0.02 \Omega$.

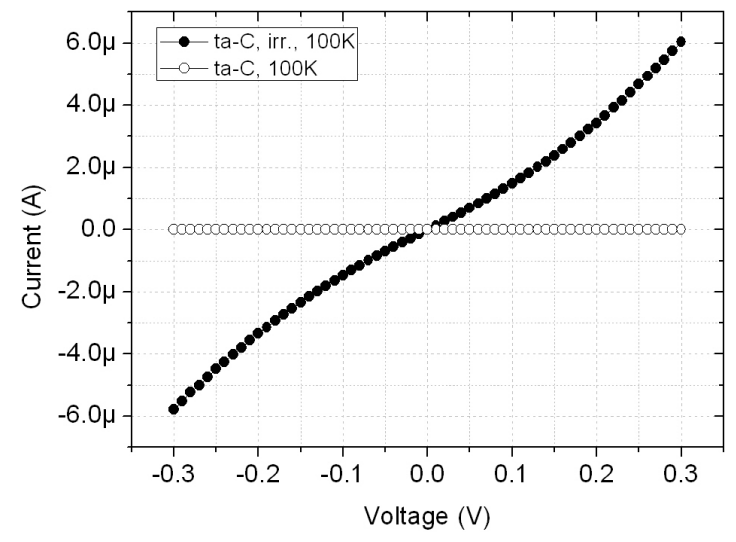

(b) Irradiated and unirradiated ta-C at $100 \mathrm{~K}$.

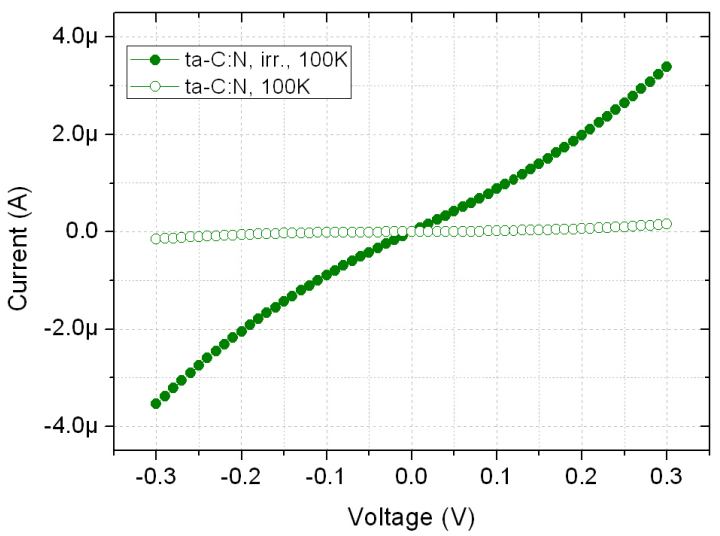

(d) Irradiated and unirradiated ta-C:N at $100 \mathrm{~K}$.

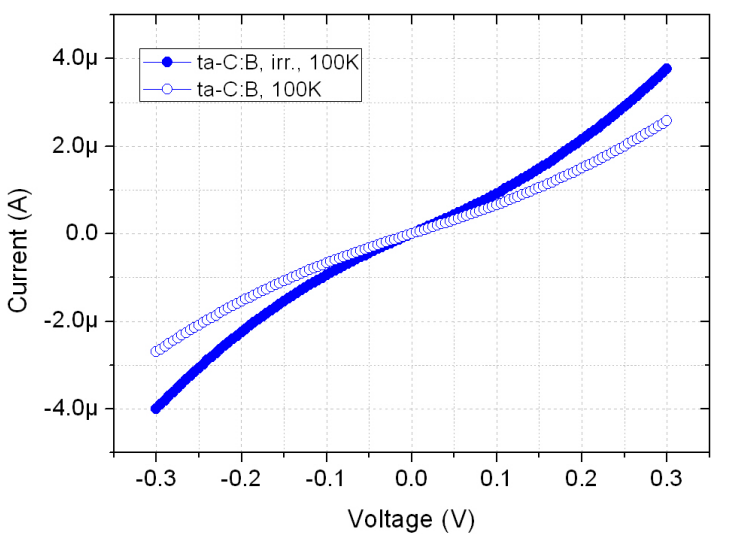



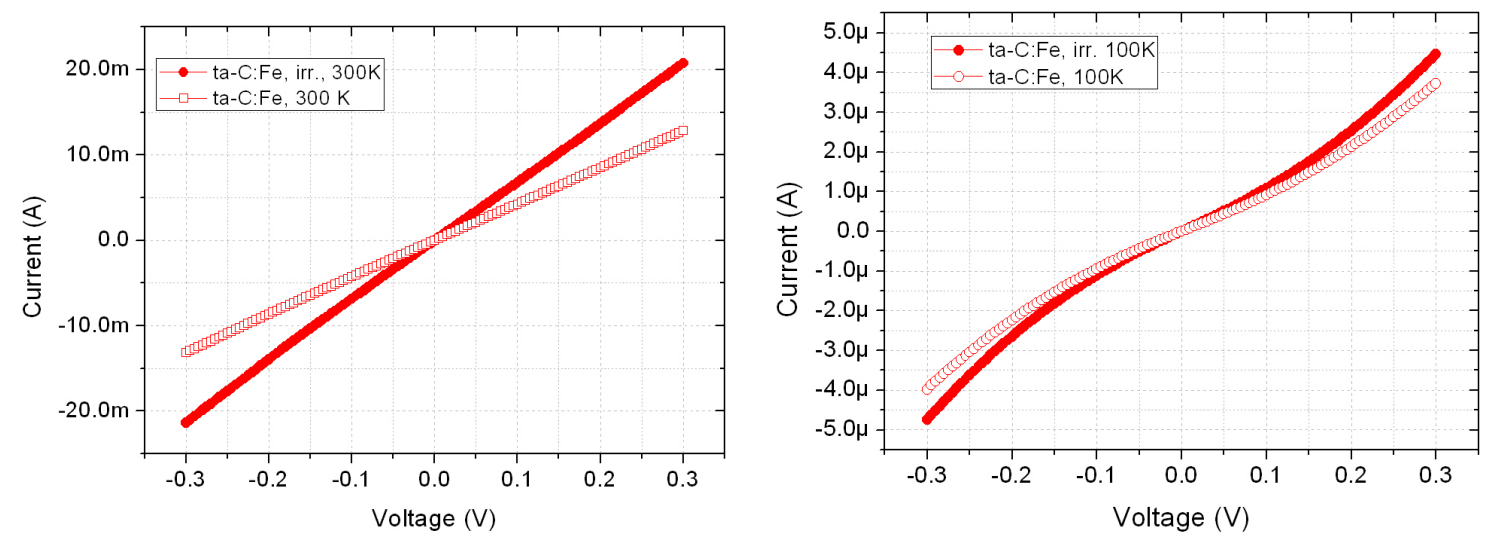

(g) Irradiated and unirradiated ta-C:Fe at $300 \mathrm{~K}, \mathrm{R}_{X}$ was $7.62 \pm 0.08 \Omega$.

(h) Irradiated and unirradiated ta-C:Fe at $100 \mathrm{~K}$.
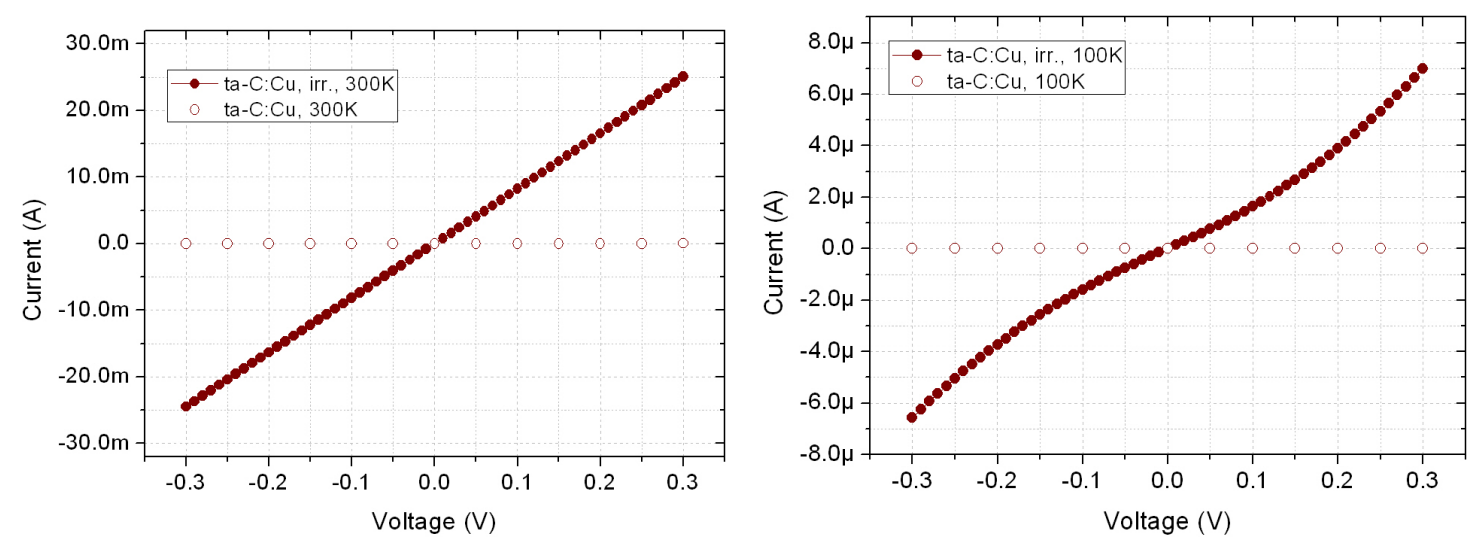

(i) Irradiated and unirradiated ta- $\mathrm{C}: \mathrm{Cu}$ at $300 \mathrm{~K}, \mathrm{R}_{X}$ was $2.30 \pm 0.05 \Omega$.

(j) Irradiated and unirradiated ta-C:Cu at $100 \mathrm{~K}$. 


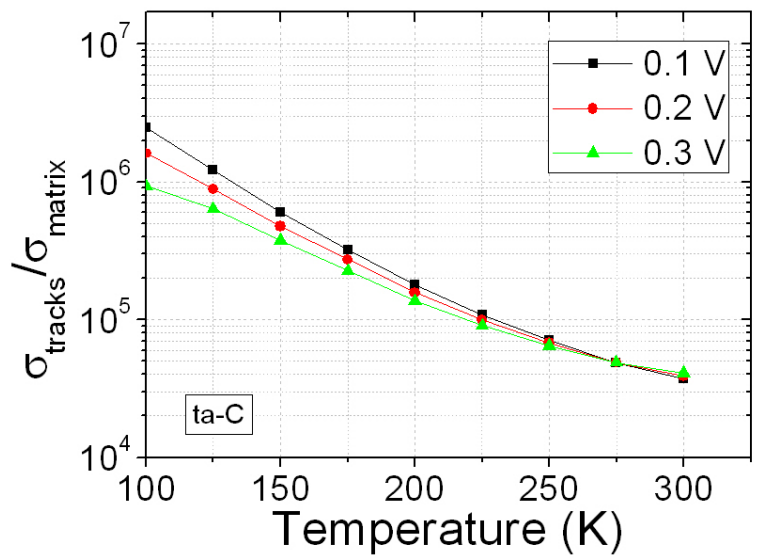

Figure 5.12: Conductivity contrast of pure ta-C. The contrast increases to $10^{6}$ toward lower temperatures.

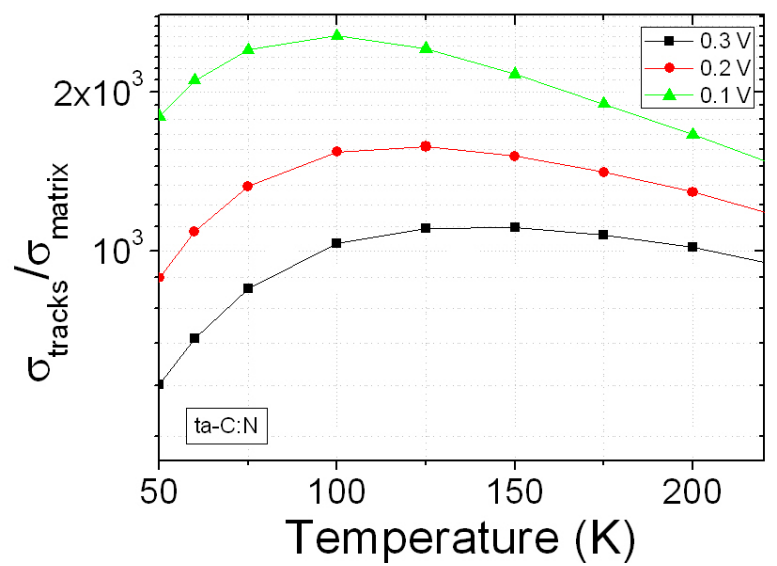

Figure 5.13: Conductivity contrast of ta-C:N. The contrast is on the order of $1 \times 10^{3}$. 


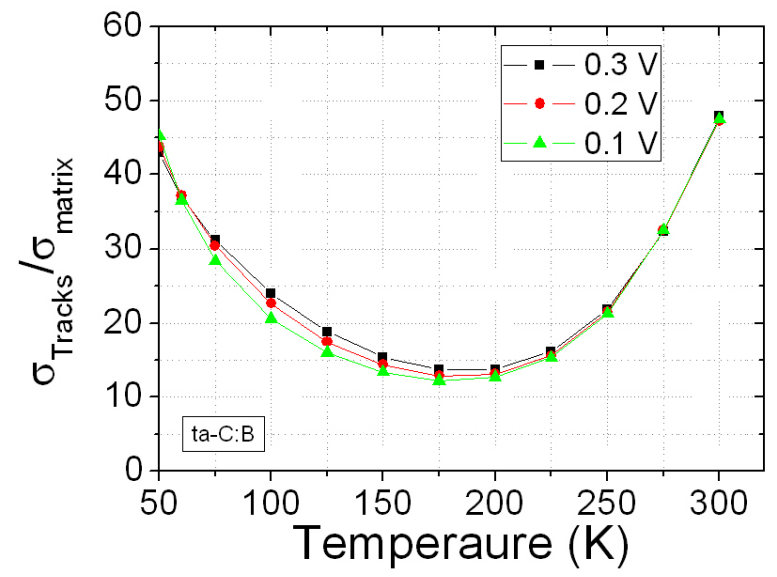

Figure 5.14: Conductivity contrast of ta-C:B. The contrast is reduced compared to pure ta-C.

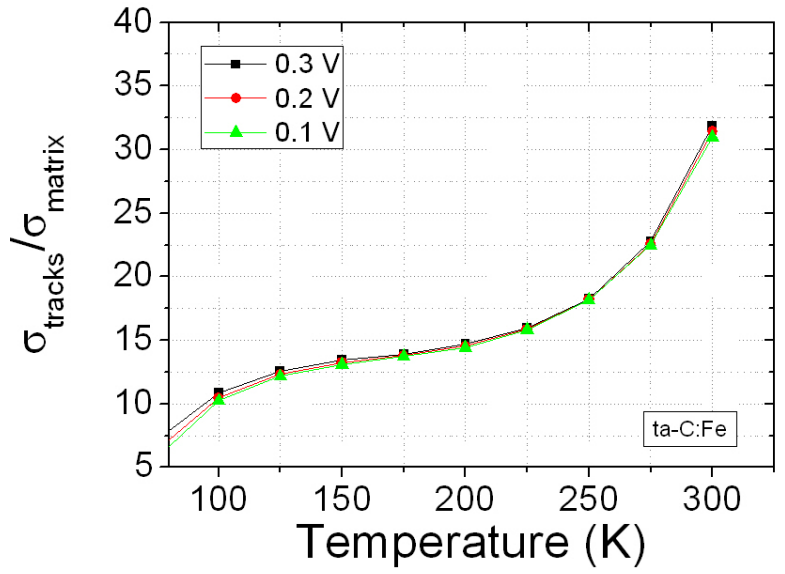

Figure 5.15: Conductivity contrast of ta-C:Fe. The contrast is low. 


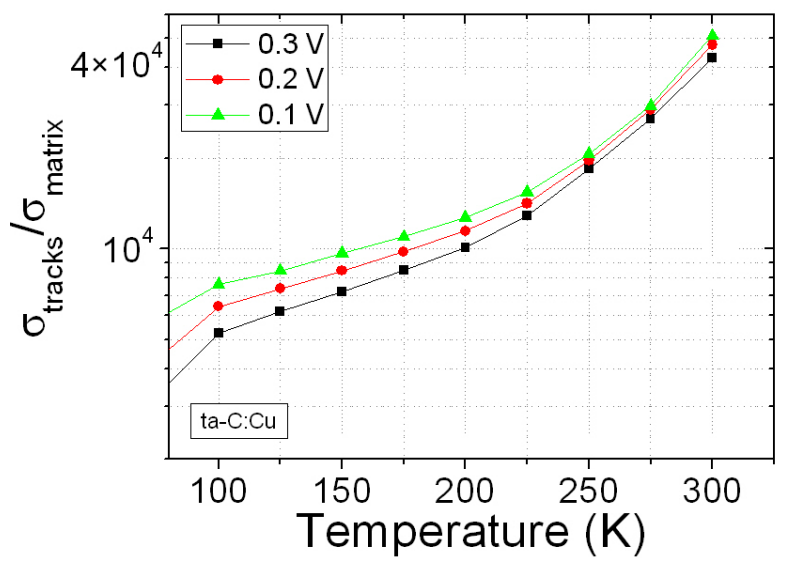

Figure 5.16: Conductivity contrast of ta-C:Cu. The conductivity contrast decreases toward lower temperature.

ta-C:Cu: The ta-C:Cu samples show a good conductivity contrast of $4 \times 10^{4}$ at room temperature, see fig. 5.16. The current through the surrounding matrix cab be neglected. The contrast decreases with decreasing temperature.

The results which can be derived from irradiation of undoped and doped ta-C are summarized in table 5.3 .

Sample $\quad \mathrm{R} \mathrm{M} \Omega$ ion irr. $\mathrm{R} \mathrm{M} \Omega \mathrm{C}_{60}$ irr. Conductivity contrast at $300 \mathrm{~K}$

\begin{tabular}{cccc}
\hline \hline ta-C & 231 & 22 & $4 \times 10^{4}$ \\
ta-C:N & 104 & 17.7 & $10^{3}(200 \mathrm{~K})$ \\
ta-C:B & 119 & 10.3 & $\sim 48$ \\
ta-C:Fe & 4.4 & 1.9 & $\sim 32$ \\
ta-C:Cu & 14 & - & $4 \times 10^{4}$ \\
\hline
\end{tabular}

Table 5.3: Summarized results of ta-C irradiation. 


\subsection{Irradiation of gallium nitride}

Gallium nitride has to be annealed after doping with ion implantation to remove the implantation defects. Problems occur during furnace annealing such as sample decomposition. Ion beam induced annealing could be a good alternative annealing method, because the sample is just locally heated for a short time span. Here, GaN damaged by Mg-implantation was irradiated with a variety of ions to analyze the dependence of the electronic energy loss on a possible annealing effect. Mg ions were chosen for implantation because the effect of $\mathrm{Mg}$ on the luminescence of $\mathrm{GaN}$ is widely investigated. If the implantation damage is removed, one expect the wellknown Mg-related luminescence. The samples were investigated with luminescence measurements because it is a very sensitive method for defect analysis.

Commercially available GaN samples, nominally undoped, with a thickness of $3 \mu \mathrm{m}$ grown on sapphire provided by TDI inc., USA, were used for this work. These samples were grown by hydride vapor phase epitaxy HVPE. The crystal quality was monitored by photoluminescence, all spectra were recorded at about $12 \mathrm{~K}$. In fig. 5.17 photoluminescnece of pristine GaN recorded at $12 \mathrm{~K}$ with a Laser output power ${ }^{2}$ of $40 \mathrm{~mW}$ is seen. The near band-edge luminescence, $\mathrm{D}^{0} \mathrm{X}$, dominates the spectrum. A broad band is seen between $400 \mathrm{~nm}$ and $480 \mathrm{~nm}$, which is referred to as the blue band.

The GaN samples were implanted with magnesium ions for doping. An example of the well known luminescence of GaN:Mg is given in fig.2.5 in section 2.4.2, page 13 . The implantation energy was $100 \mathrm{keV}$, resulting in an implantation depth of $100 \mathrm{~nm}$. The fluences chosen for implantation were $3 \times 10^{13} \frac{\mathrm{ions}}{\mathrm{cm}^{2}}$ and $10^{14} \frac{\mathrm{ions}}{\mathrm{cm}^{2}}$. With this, the maximum peak concentration is $3 \times 10^{18} \frac{\text { ions }}{\mathrm{cm}^{3}}$ and $10^{19} \frac{\mathrm{ions}}{\mathrm{cm}^{3}}$, respectively. After successful removal of the implantation damage, one may expect the DAP-transition (donor-acceptor-pair) with a zero phonon line at $379 \mathrm{~nm}(3.27 \mathrm{eV})$ described in section 2.4.2 in the luminescence of the samples implanted with the low fluence and a broad blue band between $420 \mathrm{~nm}$ and $496 \mathrm{~nm}(2.5 \mathrm{eV}$ and $2.95 \mathrm{eV})$ for the samples with the high implantation fluence [45]. Note that the blue band resulting from Mg-doping is different from the blue band found in the untreated material. A blue band in undoped GaN films grown by HVPE was found before and is described in [45]. The authors RESHCHIKOV and MORKOÇ suggest Zn contamination during film growth to cause blue band emission.

Photoluminescence was recorded directly after implantation. The intensity of the luminescence is heavily quenched; no luminescence is detected using the same parameters as used for pristine GaN. Opening the entrance slit by a factor of 30 and increasing the accumulation time by a factor of 16 , a spectrum shown in fig. 5.18

\footnotetext{
${ }^{2}$ The power is measured directly in front of the laser before the beam enters the chamber through a window.
} 


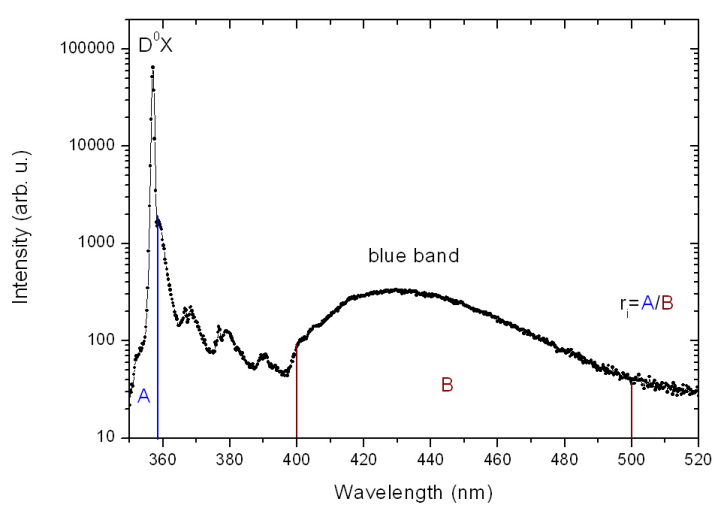

Figure 5.17: Photoluminescence of pristine GaN, recorded at $12 \mathrm{~K}$ with an output power of $40 \mathrm{~mW}$. The spectrum is dominated by the near band-edge luminescence $D^{0} X$. A broad band located at $430 \mathrm{~nm}$ is also visible, the intrinsic blue band. As a figure of merit for crystal quality, the area ratio $r_{i}$ is calculated.

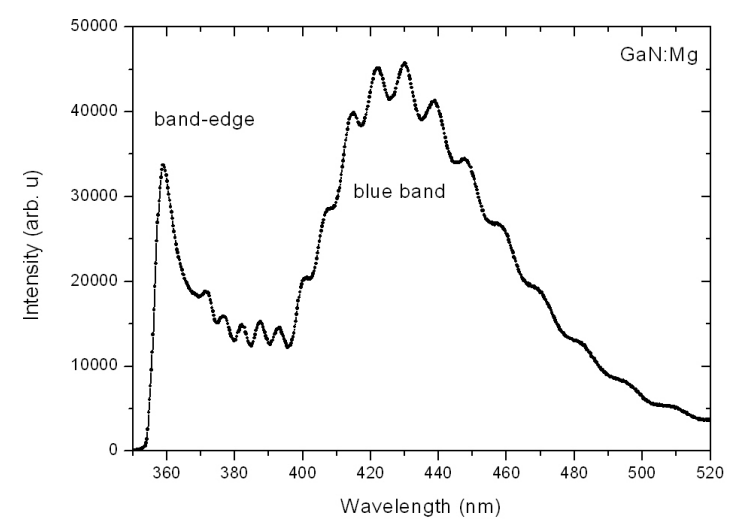

Figure 5.18: Photoluminescence of GaN:Mg, as implanted, at 12 with an output power of $40 \mathrm{~mW}$. The implantation $\mathrm{flu}-$ ence was $3 \times 10^{13} \frac{\mathrm{ions}}{\mathrm{cm}^{2}}$. The band-edge luminescence is heavily quenched.

is observed. The near band-edge luminescence is broadened, which may also be a result of opening the entrance slit, and its height is reduced. To obtain an empirical figure of merit for the crystal quality, the area ratio $\mathrm{r}_{i}$ of the near-band-edge intensity over the blue band intensity was calculated. For this, the intensity between $350 \mathrm{~nm}$ and $357 \mathrm{~nm}$ was integrated (labeled as A in fig. 5.17) and divided by the integral of the intensity between $495 \mathrm{~nm}$ and $500 \mathrm{~nm}$ (labeled as B in fig. 5.17). For pristine GaN, this ratio can be calculated as 2.83. For implanted GaN as seen in fig. 5.18 this ratio equals 0.01 . The relative intensities of signatures in a GaN spectrum vary with varying output power [41, 104]. Power-dependent measurements on pristine GaN showed that the intensity ratio is decreased by a factor of about 2 when decreasing the output power from $40 \mathrm{~mW}$, the highest output power used, to $6.5 \mathrm{~mW}$, the lowest output power used.

Shown in fig. 5.18 several lines appear between $375 \mathrm{~nm}$ and $400 \mathrm{~nm}$. One might attribute these lines to Mg-related luminescence. To test this, an empty sample holder was measured, shown in fig. 5.19. One can clearly see that these lines appear in this spectrum. This structure will be referred to as the background signal.

After Mg-implantation, the samples were irradiated with a variety of ions to analyze an ion beam induced annealing effect. The overview of the ions used for irradiation along with there electronic (eel) and nuclear energy loss (nel) is given in table 5.4 alongside with the ratio of electronic and nuclear energy loss. All irradiations were performed at room temperature. Fluences of $5 \times 10^{11} \frac{\text { ions }}{\mathrm{cm}^{2}}$ and $5 \times 10^{12} \frac{\text { ions }}{\mathrm{cm}^{2}}$ were used. 


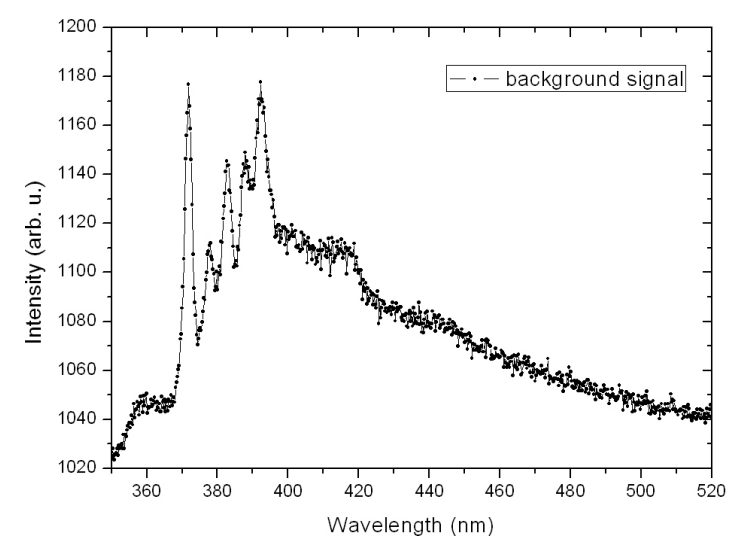

Figure 5.19: Luminescence of an empty sample holder, output power was $40 \mathrm{~mW}$. Five lines between $375 \mathrm{~nm}$ and $400 \mathrm{~nm}$ are visible. This structure is referred to as the background signal.

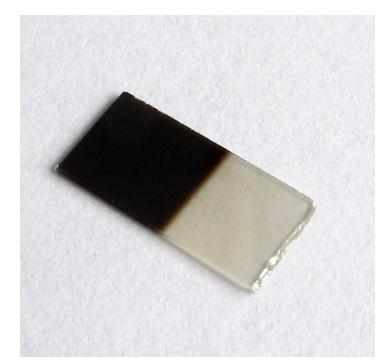

Figure 5.20: Photograph of implanted GaN after $593 \mathrm{MeV} A u$ irradiation. The lower right part of the sample was shielded from the beam.

For irradiation with carbon ions, fluences up to $10^{13} \frac{\mathrm{ions}}{\mathrm{cm}^{2}}$ were applied. The nickel irradiation was performed with two additional fluences between $5 \times 10^{11} \frac{\text { ions }}{\mathrm{cm}^{2}}$ and $5 \times$ $10^{12} \frac{\mathrm{ions}}{\mathrm{cm}^{2}}$. The ion range exceeds the sample thickness, thus, they are stopped inside the sapphire substrate. The samples or the sample holder might get activated during irradiation. In this case, measurements were performed after decay. Irradiation with $593 \mathrm{MeV}$ Au-ions could result in track formation in GaN [49]. This experiment was performed to confirm the critical value of the electronic energy loss of $24 \mathrm{keV} / \mathrm{nm}$, which can be derived from the results presented in [48, see section 2.4.2.

During swift heavy ion irradiation, some of the GaN samples darken. After irradiation with an electronic energy loss of $42 \mathrm{keV} / \mathrm{nm}$, the sample completely turned black, see fig. 5.20. This is a clear evidence for damage accumulation. As a matter of course, this sample was analyzed by luminescence measurements. Some samples broke during irradiation ${ }^{3}$ and thus, could not be analyzed. This happened during gold and xenon irradiation with high fluences.

\section{Irradaition of unimplanted GaN:}

Before analyzing the effect of swift heavy ion irradiation on doped GaN samples, the results derived from the measurements on the pristine material will be given. Ion beam induced annealing should occur, when the pristine material is not damaged during irradiation. In fig. 5.21(a) the luminescence recorded on $\mathrm{GaN}$ after swift heavy ion irradiation with the lowest irradiation fluence, $5 \times 10^{11} \frac{\mathrm{ions}}{\mathrm{cm}^{2}}$, is seen. The

\footnotetext{
${ }^{3}$ The sapphire substrate broke due to the irradiation damage.
} 


\begin{tabular}{llll}
$\begin{array}{l}\text { Ion species \& energy } \\
\mathrm{MeV}\end{array}$ & $\begin{array}{l}\text { Electronic energy loss } \\
\mathrm{keV} / \mathrm{nm}\end{array}$ & $\begin{array}{l}\text { Nuclear eneregy loss } \\
\mathrm{keV} / \mathrm{nm}\end{array}$ & ratio $\frac{\text { eel }}{\text { nel }}$ \\
\hline \hline $\mathrm{C}, 137$ & 0.53 & $2.7 \times 10^{-4}$ & 1963 \\
$\mathrm{~N}, 9^{* *}$ & 2.78 & $4.52 \times 10^{-3}$ & 615 \\
$\mathrm{Si}, 6^{* *}$ & 4.2 & 0.02 & 210 \\
$\mathrm{Cr}, 587$ & 8 & $4 \times 10^{-3}$ & 2000 \\
$\mathrm{Ni}, 668$ & 9 & $5.6 \times 10^{-3}$ & 1607 \\
$\mathrm{Xe}, 55$ & 17 & 0.31 & 55 \\
$\mathrm{Kr}, 140$ & 19 & $4.7 \times 10^{-2}$ & 383 \\
$\mathrm{Xe}, 1450$ & 27 & $2 \times 10^{-2}$ & 1350 \\
$\mathrm{Au}, 593$ & 42 & 0.14 & 300 \\
\hline
\end{tabular}

** Irradiation was performed with the accelerator MaRPel described in [95].

Table 5.4: Overview of irradiation parameters used for GaN-samples. The energy loss was calculated using SRIM2008. Irradiation was performed at room temperature.

observed spectra were normalized to their maximum, thus, the total intensity is not comparable. Here, the difference in the observed lines is of interest. The spectra were recorded with an output power of $8 \mathrm{~mW}$ except as noted otherwise. After 137 $\mathrm{MeV} \mathrm{C}$ irradiation $(0.53 \mathrm{keV} / \mathrm{nm})$, the spectrum is dominated by the near bandedge luminescence. Near band-edge luminescence was also found after $9 \mathrm{MeV} \mathrm{N}$ $(2.78 \mathrm{keV} / \mathrm{nm}), 6 \mathrm{MeV} \mathrm{Si}(4.2 \mathrm{keV} / \mathrm{nm}), 587 \mathrm{MeV} \mathrm{Cr}(8 \mathrm{keV} / \mathrm{nm})$ and $668 \mathrm{MeV} \mathrm{Ni}$ $(9 \mathrm{keV} / \mathrm{nm})$ irradiation. The intensity ratio of near band-edge $(355 \mathrm{~nm}$ to $357 \mathrm{~nm})$ to blue band luminescence (400 nm to $500 \mathrm{~nm}$ ) is 0.05 after $9 \mathrm{MeV} N$ irradiation and 0.02 after $6 \mathrm{MeV}$ Si irradiation, the values calculated after $587 \mathrm{MeV} \mathrm{Cr}$ and $668 \mathrm{MeV}$ $\mathrm{Ni}$ irradiation are 0.84 and 0.7 , respectively. After irradiation with an energy loss exceeding $9 \mathrm{keV} / \mathrm{nm}$, a structure consisting of five broad lines between $375 \mathrm{~nm}$ and $400 \mathrm{~nm}$ occurs. This structure is similar to the background signal, see fig. 5.19. Thus, these samples show no luminescence. This finding is an evidence for heavy damage accumulation. Ion beam induced annealing is not expected to occur after irradiation with an energy loss exceeding $9 \mathrm{keV} / \mathrm{nm}$. This value is way below the value expected for track formation in gallium nitride $(37 \mathrm{keV} / \mathrm{nm})$ and below the critical value of $24 \mathrm{keV} / \mathrm{nm}$.

The highest fluence applied for the plurality of the samples is $5 \times 10^{12} \frac{\mathrm{ions}}{\mathrm{cm}^{2}}$. The luminescence recorded after irradiation with this fluence is shown in fig. 5.21(b). After $137 \mathrm{MeV} \mathrm{C}(0.53 \mathrm{keV} / \mathrm{nm})$ irradiation, near band-edge luminescence is still visible. After $9 \mathrm{MeV} \mathrm{N}(2.78 \mathrm{keV} / \mathrm{nm})$ irradiation, the near band-edge luminescence is dominant in the spectrum. It should be noted that this spectrum, and also the spectrum of silicon irradiated GaN, was recorded using a higher output power. However, near band-edge luminescence is hardly visible after $6 \mathrm{MeV} \mathrm{Si}(4.2 \mathrm{keV} / \mathrm{nm})$ 


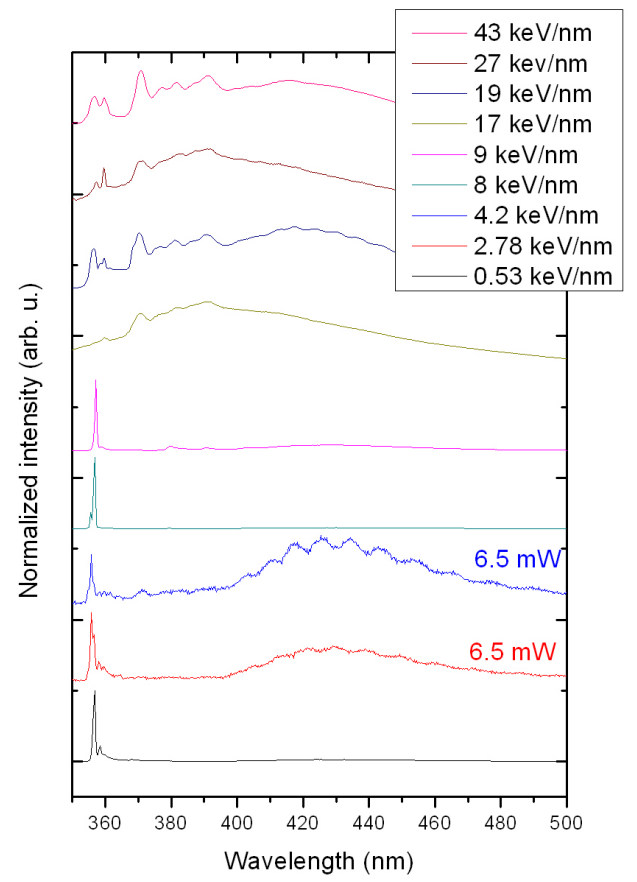

(a) Photoluminescence of irradiated pristine GaN, irradiation fluence was $5 \times 10^{11} \frac{\mathrm{ions}}{\mathrm{cm}^{2}}$

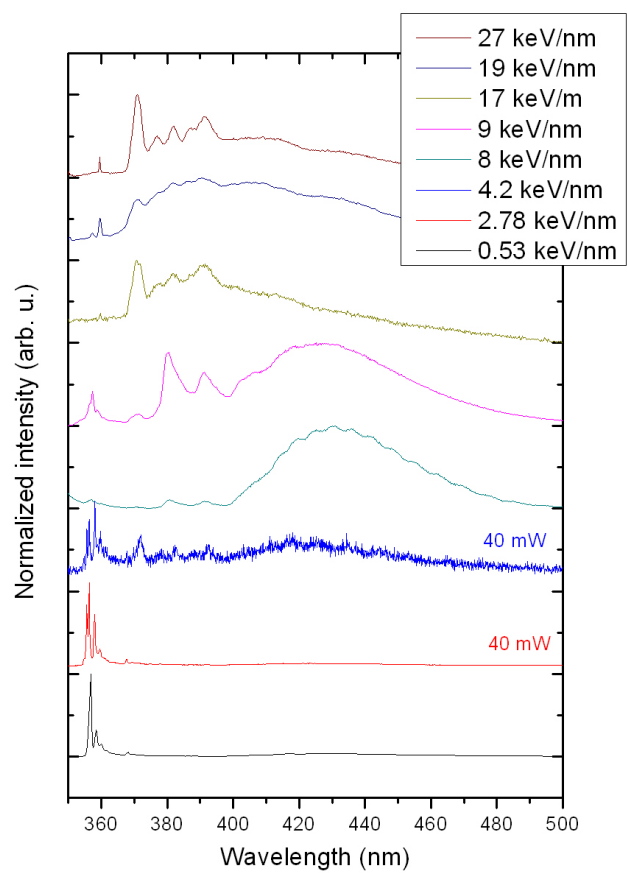

(b) Photoluminescence of irradiated pristine GaN, irradiation fluence was $5 \times 10^{12} \frac{\mathrm{ions}}{\mathrm{cm}^{2}}$

Figure 5.21: Photoluminescence spectra of GaN samples after SHI irradiation. The spectra were normalized to their maximum in order to compare luminescence line and shifted vertically for clarity. All spectra were recorded with an output power of about $8 \mathrm{~mW}$ except as noted otherwise. See table 5.4 for ion species and energy.

irradiation, the peak at about $370 \mathrm{~nm}$, which can be attributed to the background signal, arises. Although the samples are damaged after $587 \mathrm{MeV} \mathrm{Cr}(8 \mathrm{keV} / \mathrm{nm})$ and $668 \mathrm{MeV} \mathrm{Ni}(9 \mathrm{kev} / \mathrm{nm})$ irradiation, the background luminescence is not observed. Here, the near-band edge luminescence disappears, which seems as an increase of the blue band.

Detailed analysis of carbon irradiation: With these results in mind, irradiation with $137 \mathrm{MeV}$ carbon ions could lead to ion beam induced annealing. To test this, the irradiation fluence was varied over a broader range. The luminescence of pristine GaN after $137 \mathrm{MeV} \mathrm{C}(0.53 \mathrm{keV} / \mathrm{nm})$ is shown in fig. 5.22. Here, the samples were analyzed under the same conditions, which means that they were mounted on the same sample holder, to ensure comparability of intensity. Luminescence is slightly quenched, even at a high fluence of $2.5 \times 10^{13} \frac{\mathrm{ions}}{\mathrm{cm}^{2}}$. Assuming a diameter of the ther- 


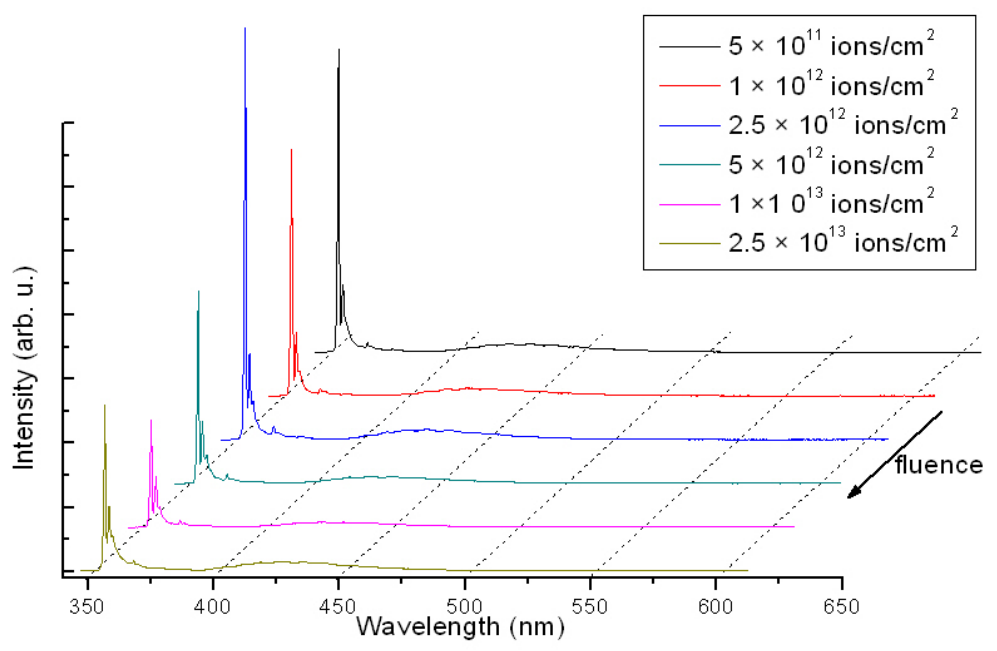

Figure 5.22: Photoluminescence spectra of pristine GaN after $137 \mathrm{MeV} C$ irradiation with varying fluences. The samples were analyzed under the same conditions, thus, the intensity is comparable. Spectra were recorded with an output power of $8 \mathrm{~mW}$.

mal spike of about $10 \mathrm{~nm}$, the whole surface of the sample would be covered with a fluence of $10^{12} \frac{\mathrm{ions}}{\mathrm{cm}^{2}}$. Thus, the sample was severalfold locally molten by impinging ions. The intensity ratio $\mathrm{r}_{i}$ decreases from $0.6\left(5 \times 10^{11} \frac{\mathrm{ions}}{\mathrm{cm}^{2}}\right)$ to $0.3\left(2.5 \times 10^{13} \frac{\mathrm{ions}}{\mathrm{cm}^{2}}\right)$. Increasing the irradiation fluence by a factor of 50 , the intensity ratio is decreased by a factor of two. These results show that irradiation with $137 \mathrm{MeV} \mathrm{C}$ ions could lead to ion beam induced annealing.

Detailed analysis of nickel irradiation: Irradiation with an energy loss of about $9 \mathrm{keV} / \mathrm{nm}$ could also lead to possible annealing effects. Photoluminescence of GaN irradiated with $668 \mathrm{MeV} \mathrm{Ni}(9 \mathrm{keV} / \mathrm{nm})$ ions is seen in fig. 5.23. The samples were analyzed under the same conditions, except for the sample irradiated with the highest fluence. The integration time was twice as high as compared to the other samples. Already shown in fig. 5.21(a), near band-edge luminescence is clearly visible after irradiation with $5 \times 10^{11} \frac{\mathrm{ions}}{\mathrm{cm}^{2}}$. The intensity ratio $\mathrm{r}_{i}$ equals 0.7 . With increasing fluence, the near band-edge luminescence decreases. After an irradiation fluence of $10^{12} \frac{\text { ions }}{\mathrm{cm}^{2}}$, the intensity ratio is calculated to 0.1 . By increasing the irradiation fluence to $2.5 \times 10^{12} \frac{\mathrm{ions}}{\mathrm{cm}^{2}}$, the ratio decreases to a value of 0.024 . This ratio is even more decreased after irradiation with $5 \times 10^{12} \frac{\text { ions }}{\mathrm{cm}^{2}}$ to 0.015 . This value is almost as low as the value calculated for implanted samples, however, a background signal was not recorded. With these results one may suggest that ion beam induced 


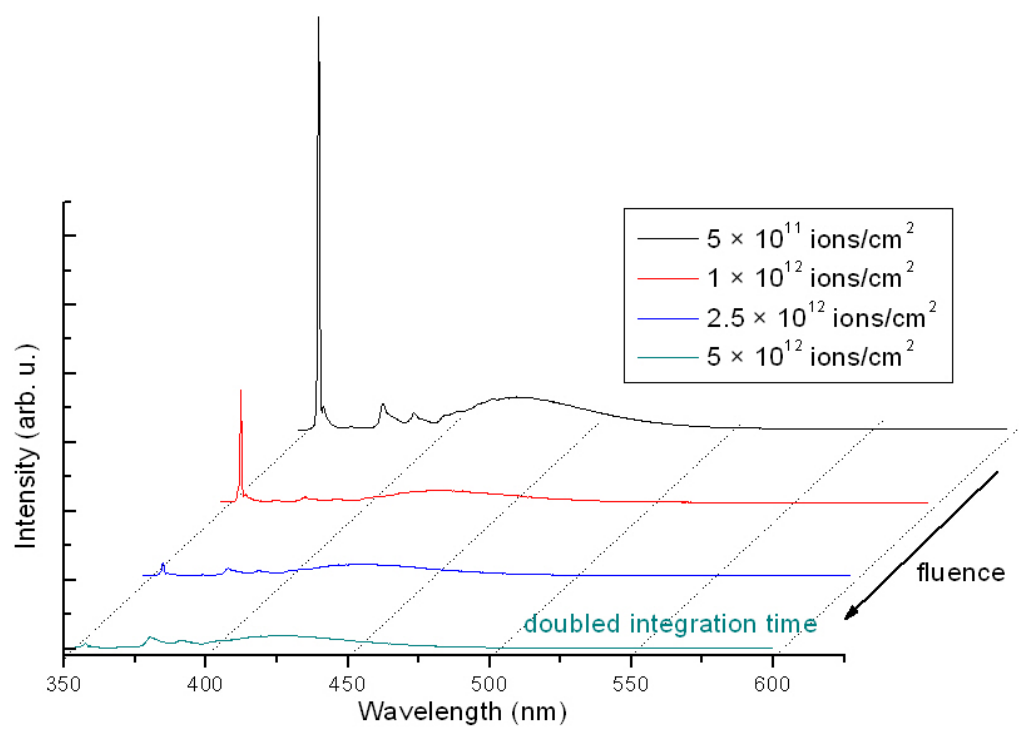

Figure 5.23: Photoluminescence spectra of pristine $\mathrm{GaN}$ after $668 \mathrm{MeV} \mathrm{C}$ irradiation with varying fluences. The samples were analyzed under the same conditions with an output power of about $8 \mathrm{~mW}$, except for the spectrum with the highest fluence. Here, the integration time was twice as high compared to the other spectra.

irradiation can occur after irradiation with low fluences.

\section{Irradiation of implanted $\mathrm{GaN}$}

The luminescence of GaN implanted with $3 \times 10^{13} \frac{\text { ions }}{\mathrm{cm}^{2}}$ Mg-ions, the low implantation fluence, after swift heavy ion irradiation is seen in fig. 5.24. Again, all spectra were normalized to their maximum value in order to compare the observed lines and shifted vertically. The output power used of excitation was $8 \mathrm{~mW}$ except as noted otherwise. The left part, fig. 5.24(a) shows the luminescence recorded after irradiation with $5 \times 10^{11} \frac{\text { ions }}{\mathrm{cm}^{2}}$. Near band-edge luminescence and a blue band are observed after $137 \mathrm{MeV} \mathrm{C}(0.53 \mathrm{keV} / \mathrm{nm})$ irradiation, this spectrum is similar to the spectrum of GaN directly after implantation, see fig. 5.18. After nitrogen $(2.78 \mathrm{keV} / \mathrm{nm})$ and silicon $(4.2 \mathrm{keV} / \mathrm{nm})$ irradiation, only the background signal could be recorded. After chromium $(8 \mathrm{keV})$ irradiation, a dominant near band-edge luminescence is observed. The ratio $\mathrm{r}_{i}$ equals 0.8 . This sample showed no noteworthy luminescence after implantation, thus, the crystal structure recovered from implantation defects. The background signal was found in the spectra of all other samples irradiated with a higher electronic energy loss. 


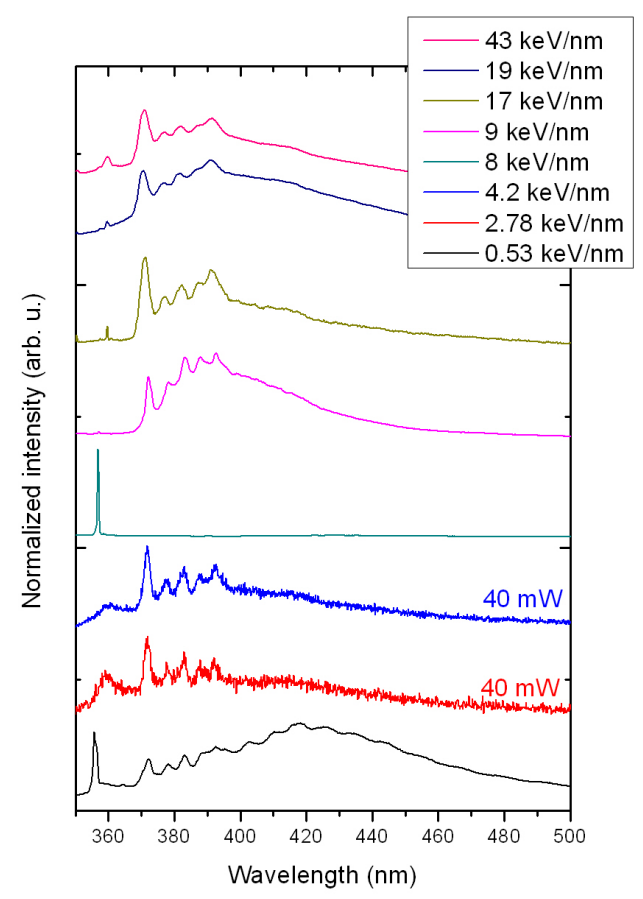

(a) Photoluminescence of irradiated GaN:Mg (low implantation fluence), irradiation fluence was $5 \times 10^{11} \frac{\text { ions }}{\mathrm{cm}^{2}}$

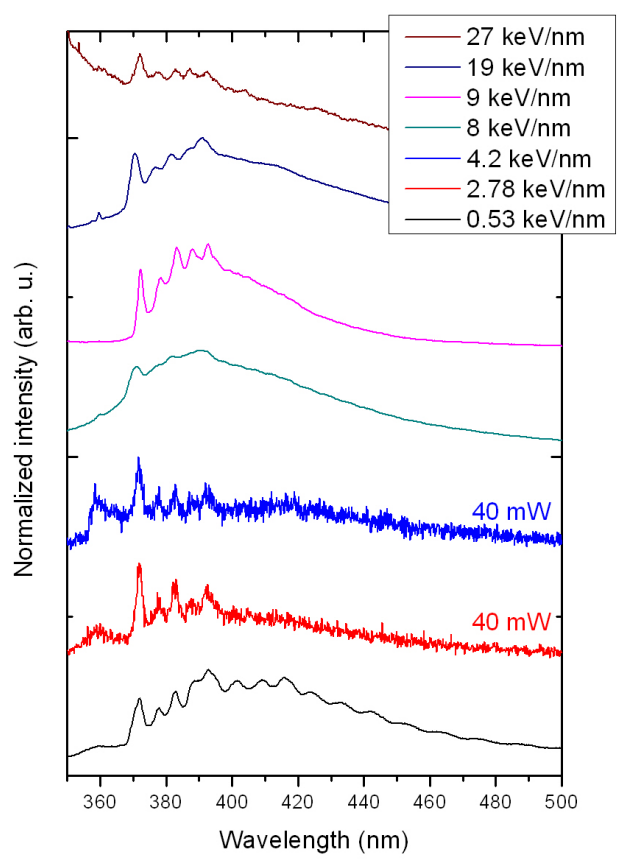

(b) Photoluminescence of irradiated GaN:Mg (low implantation fluence), irradiation fluence was $5 \times 10^{12} \frac{\text { ions }}{\mathrm{cm}^{2}}$

Figure 5.24: Photoluminescence spectra of GaN:Mg (low implantation fluence) after SHI irradiation, output power was about $8 \mathrm{~mW}$ except as noted otherwise. All spectra were normalized to their maximum value in order to compare luminescence lines. See table 5.4 for ion species and energy. Again, spectra were shifted vertically.

Photoluminescence of implanted GaN after irradiation with $5 \times 10^{12} \frac{\text { ions }}{\mathrm{cm}^{2}}$ is shown in fig. $5.24(\mathrm{~b})$. After carbon $(0.53 \mathrm{keV} / \mathrm{nm})$ irradiation, a slight contribution of the intrinsic blue band to the spectrum can be seen. All other samples showed the background signal. Thus, the samples were further damaged during high fluence irradiation. The increase toward lower wavelength in the upper spectrum $(27 \mathrm{keV} / \mathrm{nmn})$ can be attributed to the laser positioned at $325 \mathrm{~nm}$.

Photoluminescence of GaN implanted with high Mg-fluence, $10^{14} \frac{\mathrm{ions}}{\mathrm{cm}^{2}}$, after swift heavy ion irradiation is given in fig. 5.25. Again, the spectra were normalized to their maximum value for line comparison. Laser output power was $8 \mathrm{~mW}$ except as noted otherwise. Similar to the results of GaN implanted with the low fluence, a contribution of the intrinsic blue band in the spectrum is found after carbon 


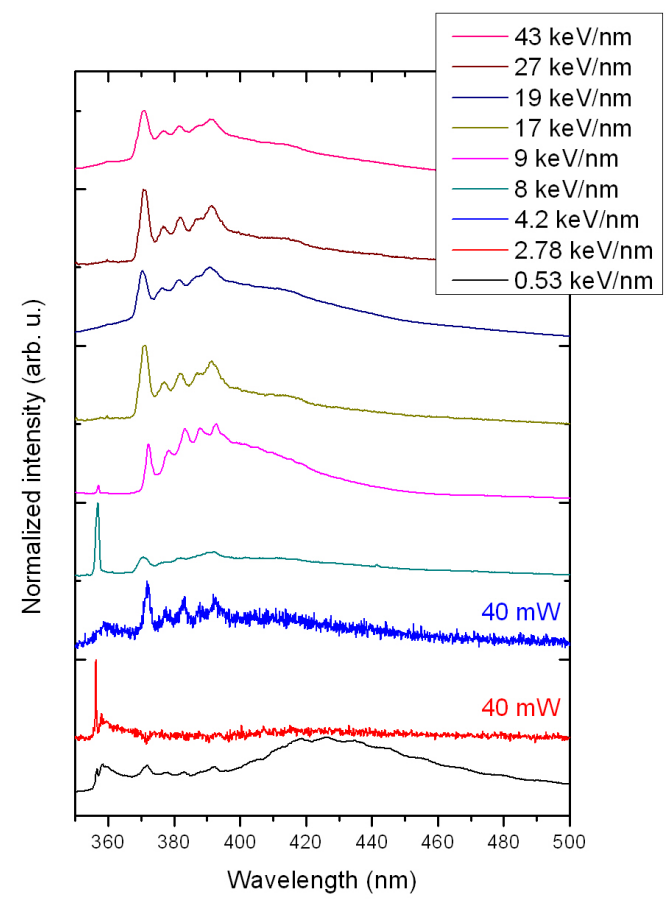

(a) Photoluminescence of irradiated GaN:Mg (high implantation fluence), irradiation fluence was $5 \times 10^{11} \frac{\text { ions }}{\mathrm{cm}^{2}}$

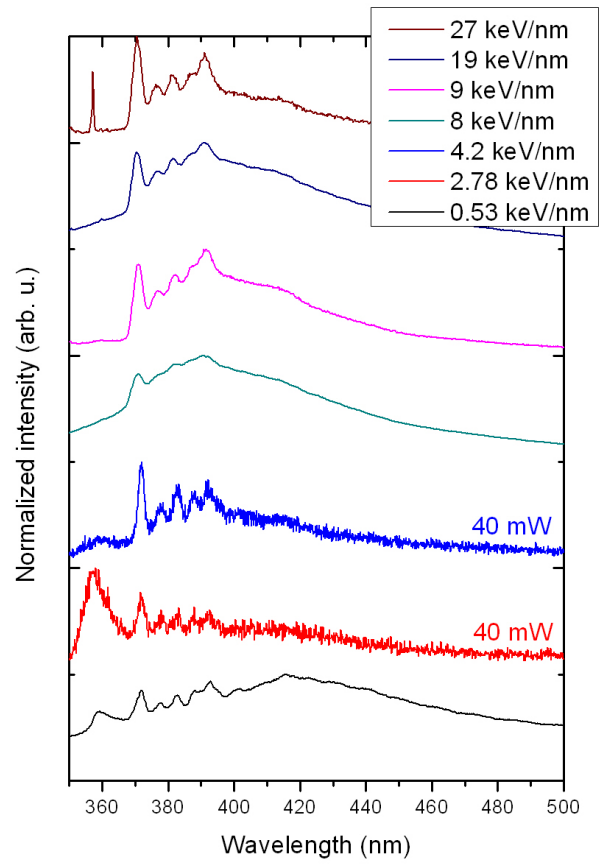

(b) Photoluminescence of irradiated GaN:Mg (high implantation fluence), irradiation fluence was $5 \times 10^{12} \frac{\text { ions }}{\mathrm{cm}^{2}}$

Figure 5.25: Photoluminescence spectra of GaN:Mg (high implantation fluence) after SHI irradiation, output power was about $8 \mathrm{~mW}$ except as noted otherwise. Again, all spectra were normalized to their maximum value in order to compare luminescence lines and shifted vertically. See table 5.4 for ion species and energy.

$(0.53 \mathrm{keV} / \mathrm{nm})$ irradiation with low irradiation fluence, see fig. 5.25(a). After nitrogen $(2.78 \mathrm{keV} / \mathrm{nm})$ irradiation, slight near band-edge luminescence was found, which was also found directly after implantation in a similar intensity. Thus, the irradiation did not result in heavy damage accumulation. The sample irradiated with $587 \mathrm{MeV} \mathrm{Cr}(8 \mathrm{keV} / \mathrm{nm})$ ions showed a noticeable near band-edge luminescence, but a bright near band-edge luminescence was found directly after implantation. Apparently, this sample was not heavily damaged after ion implantation 4 and thus, comparable to pure GaN, not heavily damaged during irradiation. For all other irradiated samples, the background signal was found. After high irradiation fluence, similar results were found, see fig. 5.25(b). Blue band luminescence was found af-

\footnotetext{
${ }^{4}$ This sample was likely implanted in channeling direction.
} 


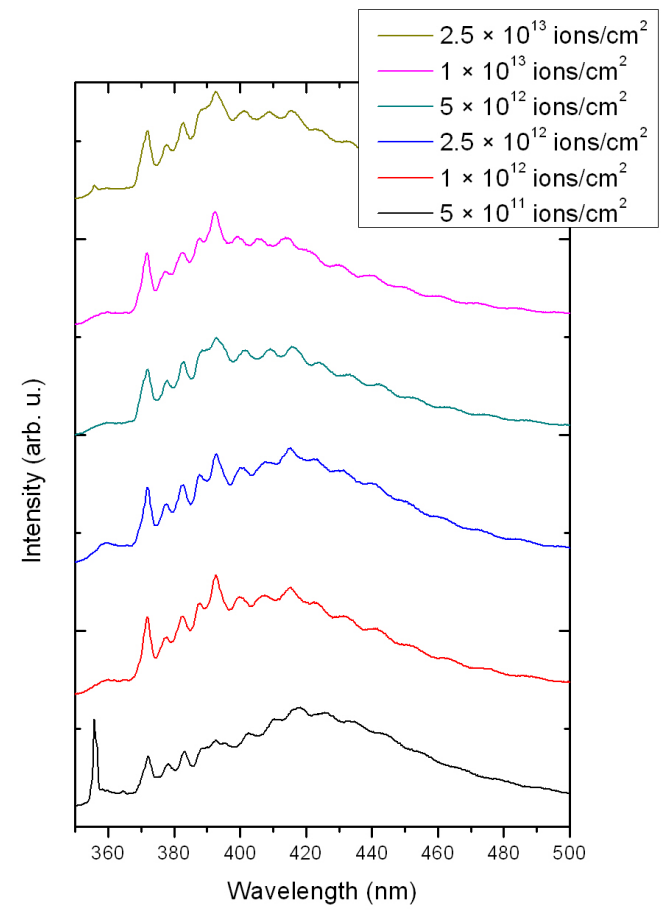

(a) Photoluminescence spectra of GaN:Mg (low implantation fluence) after $137 \mathrm{MeV} \mathrm{C}$ irradiation.

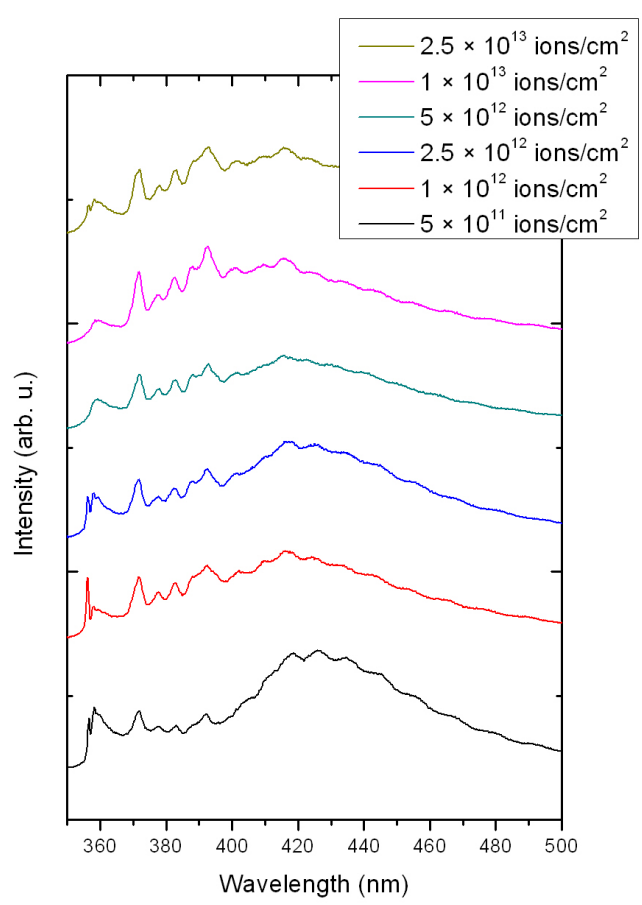

(b) Photoluminescence spectra of GaN:Mg (high implantation fluence) after $137 \mathrm{MeV} \mathrm{C}$ irradiation.

Figure 5.26: Photoluminescence spectra of implanted GaN after $137 \mathrm{MeV} C$ irradiation. Output power was $8 \mathrm{~mW}$. The spectra were shifted vertically.

ter carbon irradiation. The background signal was found in all other samples. No annealing effect was found.

Detailed analysis of carbon irradiation: A detailed view on the luminescence measured after carbon irradiation is given in fig. 5.26. Fig. 5.26(a) shows luminescence spectra of GaN implanted with the low fluence. In all spectra, the structured intrinsic blue band is visible. Near band-edge luminescence is only found after irradiation with the lowest irradiation fluence. The spectra obtained after high fluence irradiation are seen in fig. 5.26(b). The results are similar to the results found after low fluence irradiation. One can conclude that no significant annealing effect was found after $137 \mathrm{MeV} \mathrm{C}$ irradiation, but also no heavy damage accumulation occurred.

After nickel irradiation with varying fluences of implanted GaN, only background luminescence was found. 


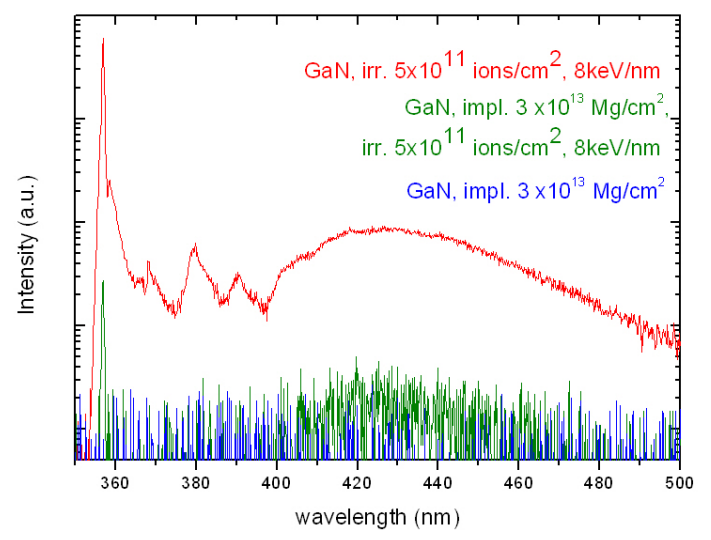

Figure 5.27: Photoluminescence spectra of pristine (red) and implanted (green) GaN after $587 \mathrm{MeV}$ Cr irradiation with $5 \times 10^{11} \frac{\text { ions }}{\mathrm{cm}^{2}}$, intensity is comparable. The luminescence spectrum of implanted GaN (blue) was added for comparison. Output power was $40 \mathrm{~mW}$.

An annealing effect was observed after chromium $(8 \mathrm{keV} / \mathrm{nm})$ irradiation. To analyze the efficiency of the annealing effect, luminescence of unimplanted and implanted GaN after chromium irradiation was measured with the same conditions to compare the intensity with an output power of $40 \mathrm{~mW}$, see fig. 5.27. An exemplary spectrum of implanted GaN (green) is also shown. It can be seen that the near-band edge luminescence line of implanted and irradiated $\mathrm{GaN}$ is about two orders of magnitude lower compared to irradiated undoped GaN. Thus, the crystal is not totally recovered. However, Mg-related luminescence was not found.

The values for $\mathrm{r}_{i}$ are summarized in table 5.5. Only the values for spectra without lines from the background spectrum were included. Almost every implanted sample is damaged due to swift heavy ion irradiation, therefore, $\mathrm{r}_{i}$ was calculated for the sample which showed an annealing effect.

\begin{tabular}{cccc} 
Sample & $\mathrm{dE} / \mathrm{dx}_{\text {el. }} \mathrm{keV} / \mathrm{nm}$ & $\mathrm{r}_{i}$ low irr. fluence & $\mathrm{r}_{i}$ high irr. fluence \\
\cline { 2 - 4 } pristine GaN & 0.53 & 0.6 & 0.45 \\
\cline { 2 - 4 } & 2.78 & 0.05 & - \\
\cline { 2 - 4 } & 4.72 & 0.02 & - \\
\cline { 2 - 4 } & 8 & 1.2 & 0.005 \\
\hline low fluence impl. GaN & 9 & 0.7 & 0.015 \\
\hline
\end{tabular}

Table 5.5: Summarized results of SHI irradiated GaN. 


\subsection{Irradiation of diamond}

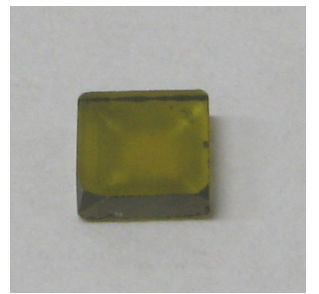

Figure 5.28: Photograph of synthetic diamond provided by Element Six. The sample size is about $4 \mathrm{~mm}$ $\times 4 \mathrm{~mm} \times 1 \mathrm{~mm}$.
Diamond is easily graphitized during ion implantation. If a graphite layer is formed during implantation, only high temperature high pressure annealing methods can be applied for re-arrangement of the diamond phase. Ion beam induced annealing was tested as an alternative annealing method, because an annealing effect of diamond was found after irradiation with light ions [17, 18]. The possibility of ion beam annealing using swift heavy ions is analyzed. Track formation after swift heavy ion irradiation as found in ta- $\mathrm{C}$ is not observed in diamond, which is an evidence for prompt annealing of swift heavy ion irradiation damage. As luminescence measurements

are sensitive to defects, the crystal quality of the diamond samples was investigated with cathodoluminescence measurements.

For this work, two different types of nitrogen containing synthetic diamond were used, namely type Ia and type Ib, second provided by Element Six. Both types of diamond appear yellow, indicating a relatively high nitrogen concentration, see fig 5.28. The difference between these types of diamond is the embedding of the nitrogen contamination. In Ia diamond, nitrogen is mainly bound in aggregates, for example the A- or B-aggregate, a substitutional nitrogen pair or a quad of nitrogen atoms surrounding a vacancy, respectively. A single substitutional nitrogen atom is called C-aggregate and a diamond with nitrogen mainly in this state is called Ib diamond [53]. The cathodoluminescence of Ia diamond recorded at $14 \mathrm{~K}$ is shown in fig. 5.29. The luminescence was recorded using the grating with 100 grooves per millimeter, see section 4.5 for details. The luminescence spectra appear different from each (100) sides. One side, and a (111) edge on the other side which is seen in fig. 5.29, showed two intense lines at $484 \mathrm{~nm}$ and $489 \mathrm{~nm}$. The line at $489 \mathrm{~nm}$ has a shoulder toward higher wavelength. A triplet is seen at $503 \mathrm{~nm}, 509 \mathrm{~nm}$ and $513 \mathrm{~nm}$. No luminescence in the UV-regime could be detected. The lines at $484 \mathrm{~nm}$, $489 \mathrm{~nm}, 509 \mathrm{~nm}$ and $513 \mathrm{~nm}$ found in diamond can be attributed to nickel [80, 82]. The line at 503 can not be clearly identified, two optical centers in diamond are known to form a line at about $503 \mathrm{~nm}$, the H3 center, a vacancy bound to two subtitutional nitrogen atoms [81], and the 3H center, observed after irradiation of diamond, both lines are described in ref. [53]. The H3 center was observed on the other side of the diamond sample5 thus, it seems plausible that the line at $503 \mathrm{~nm}$ is weak H3 luminescence. The (111) side which shows the nickel-related luminescence

\footnotetext{
${ }^{5}$ The presence of the H3 center in the offered diamond samples was also confirmed by an employee of Element Six by e-mail.
} 


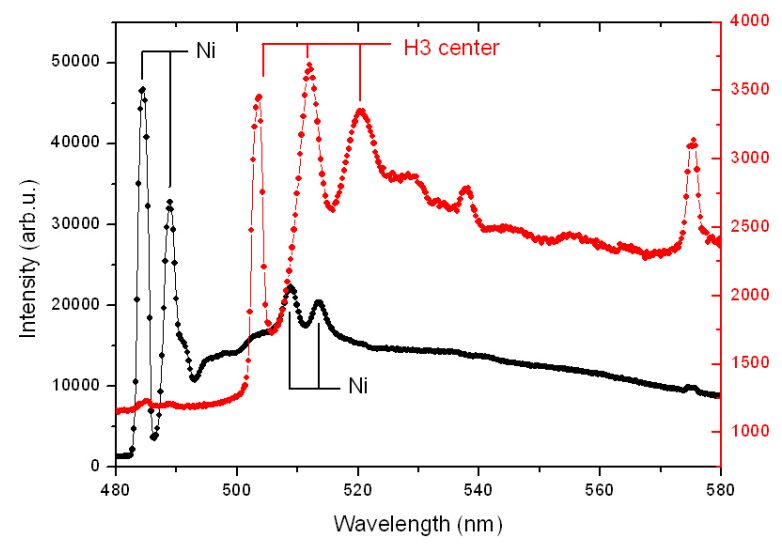

Figure 5.29: Cathodoluminescence of synthetic Ia diamond recorded on different positions. Some spots ( $\{111\}$ sides) showed a spectrum which is dominated by nickel-related defects. The plane (100) face shows H3-related luminescence. The other side of the sample showed Ni-related luminescence.

is used as reference spectrum in fig 5.30 (black curve). Also seen in fig. 5.30 is the luminescence of samples damaged by implantation with $100 \mathrm{keV}$ argon ions using 3 $\times 10^{13} \frac{\text { ions }}{\mathrm{cm}^{2}}$ (red curve) and $10^{14} \frac{\text { ions }}{\mathrm{cm}^{2}}$ (blue curve). This corresponds to an implantation depth of $53 \mathrm{~nm}$. The sample faces showing the nickel-related luminescence were used for implantation. Both sides of the diamond can be used for analysis, because the electron beam used for luminescence activation has a maximum penetration depth of about $200 \mathrm{~nm} 6$. After low fluence implantation, all five lines can be detected, no additional lines occur. After high fluence implantation, no luminescence lines could be detected. The increasing curve may be attributed to the black body radiation of the filament of the electron source.

Similar to the Ia diamonds, the luminescence of the Ib diamonds differs from front

\begin{tabular}{llll}
$\begin{array}{l}\text { Ion species \& } \\
\text { energy }\end{array}$ & $\begin{array}{l}\text { Electronic energy } \\
\text { loss } \\
\mathrm{MeV}\end{array}$ & $\begin{array}{l}\text { Nuclear eneregy } \\
\text { loss } \\
\mathrm{keV} / \mathrm{nm}\end{array}$ & $\begin{array}{l}\text { irradiation } \\
\text { temperature } \\
{ }^{\circ} \mathrm{C}\end{array}$ \\
\hline \hline $\mathrm{Xe}, 1400$ & 23.2 & $8.99 \times 10^{-3}$ & 500 \\
$\mathrm{Ag}, 945$ & 39 & $6 \times 10^{-2}$ & $\begin{array}{l}500 \text { and room } \\
\text { temperature }\end{array}$ \\
\hline
\end{tabular}

Table 5.6: Irradiation parameters used for diamond. The energy loss was calculated using SRIM2008.

${ }^{6}$ calculated with the simulation software CASINO 


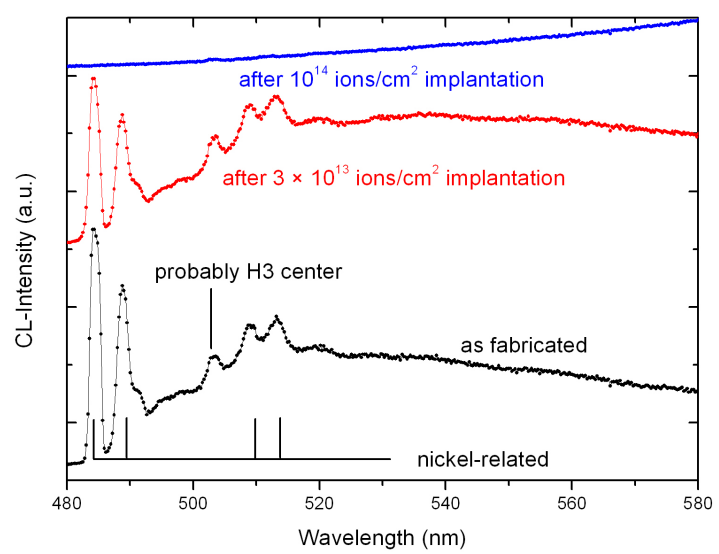

Figure 5.30: Cathodoluminescence of treated synthetic Ia diamond before (black) and after implantation (red,blue). The spectrum of the pristine diamond is dominated by nickel-related defects. The intensity is quenched due to implantation. The spectra are shifted vertically for the sake of clarity.

(100) side to back (100) side. Their luminescence recorded at $12 \mathrm{~K}$ is shown in fig. 5.31, using a grating with 1200 grooves per millimeter. The front side shows the nickel-related luminescence. Here, it can be clearly seen that the shoulder at the line at $489 \mathrm{~nm}$ is an additional line. Also, the $484 \mathrm{~nm}$ line shows a substructure, seen as an inset in fig. 5.31. This fine structure is attributed to excited states of the $484 \mathrm{~nm}$ system [82, 83]. On the back side, luminescence attributed to the H3 center is recorded. For implantation experiments, the side showing the nickel-related luminescence is used. Although these diamonds are classified as Ia and Ib, their luminescence spectra do not differ.

The irradiation parameters for the diamond samples are given in table 5.6. The Ia diamonds were irradiated with xenon ions, the Ib diamonds were irradiated with gold ions to analyze the annealing effect of irradiation. In order to increase a possible ion beam induced annealing effect, as seen in ref. [18], irradiation was performed at temperatures above room temperature. Vacancies in diamond start to propagate at temperatures about $500{ }^{\circ} \mathrm{C}$ [105], so this temperature was chosen for irradiation.

\section{Irradiation of Ia diamond:}

The result derived from the irradiated Ia diamonds will be shown at first. No visible change, such as sample darkening, was found after irradiation. To analyze the effect of swift heavy ion irradiation on untreated diamond, luminescence of the high temperature irradiated diamond sample was measured at different positions. The 


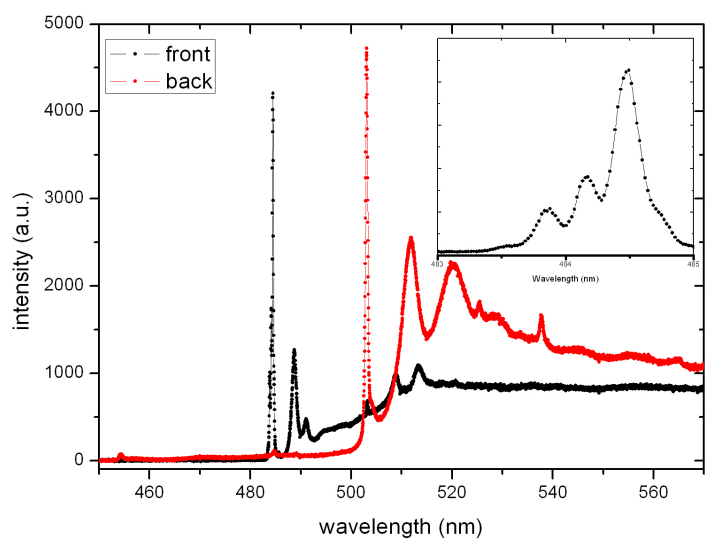

Figure 5.31: Cathodoluminescence of synthetic Ib diamond. The front side shows Nirelated luminescence which was also observed in the spectrum of the Ia diamond. The back side shows luminescence which can be attributed to the H3 center. The inset shows the $484 \mathrm{~nm}$ line of the nickel-related center.

sample was irradiated at $500{ }^{\circ} \mathrm{C}$ for $1.5 \mathrm{~h}$. An e-beam spot of $1 \mathrm{~mm} \times 1 \mathrm{~mm}$ (current $2 \mu \mathrm{A}$ ) was scanned over the sample. The obtained spectra are shown in fig 5.32. The positions are color-coded in the right part of the figure, showing a photograph of the sample. The spectra of the $\{111\}$ sides were not included; they show the Ni-related luminescence. It can be seen that the intensity of the $\mathrm{H} 3$ center does not vary over the whole sample. This is important, as a portion of the sample was shielded from the beam in order to fix the diamond on the heating plate. This observation shows that the diamond is not affected by swift heavy ion irradiation.

The cathodoluminescence of Ia diamond after temperature treatment and swift heavy ion irradiation is shown in fig. 5.33. The luminescence recorded on different positions after low implantation fluence and swift heavy ion irradiation at $500{ }^{\circ} \mathrm{C}$ is shown in fig. 5.33(a), Again, a part of the sample face was shielded from the beam. The irradiated area is larger than the shielded area. The majority of the curves in fig. 5.33(a) show the nickel-related luminescence which reduced intensity compared to fig. 5.30. The peak at $575 \mathrm{~nm}$ can be attributed to a nitrogen-vacancy center [106, 107]. Some parts of the diamond show H3-related luminescence, for example the center position (light pink curve). No luminescence mapping was recorded before irradiation. Thus, it can neither be confirmed nor excluded that the diamond showed inhomogeneous luminescence spectra before irradiation. Luminescence recorded on different positions after high implantation fluence and temperature treatment at $500{ }^{\circ} \mathrm{C}$ for $1.5 \mathrm{~h}$ is shown in fig. 5.33(b). The nickel related luminescence can be seen with low intensity. However, hardly any luminescence could be recorded at the 


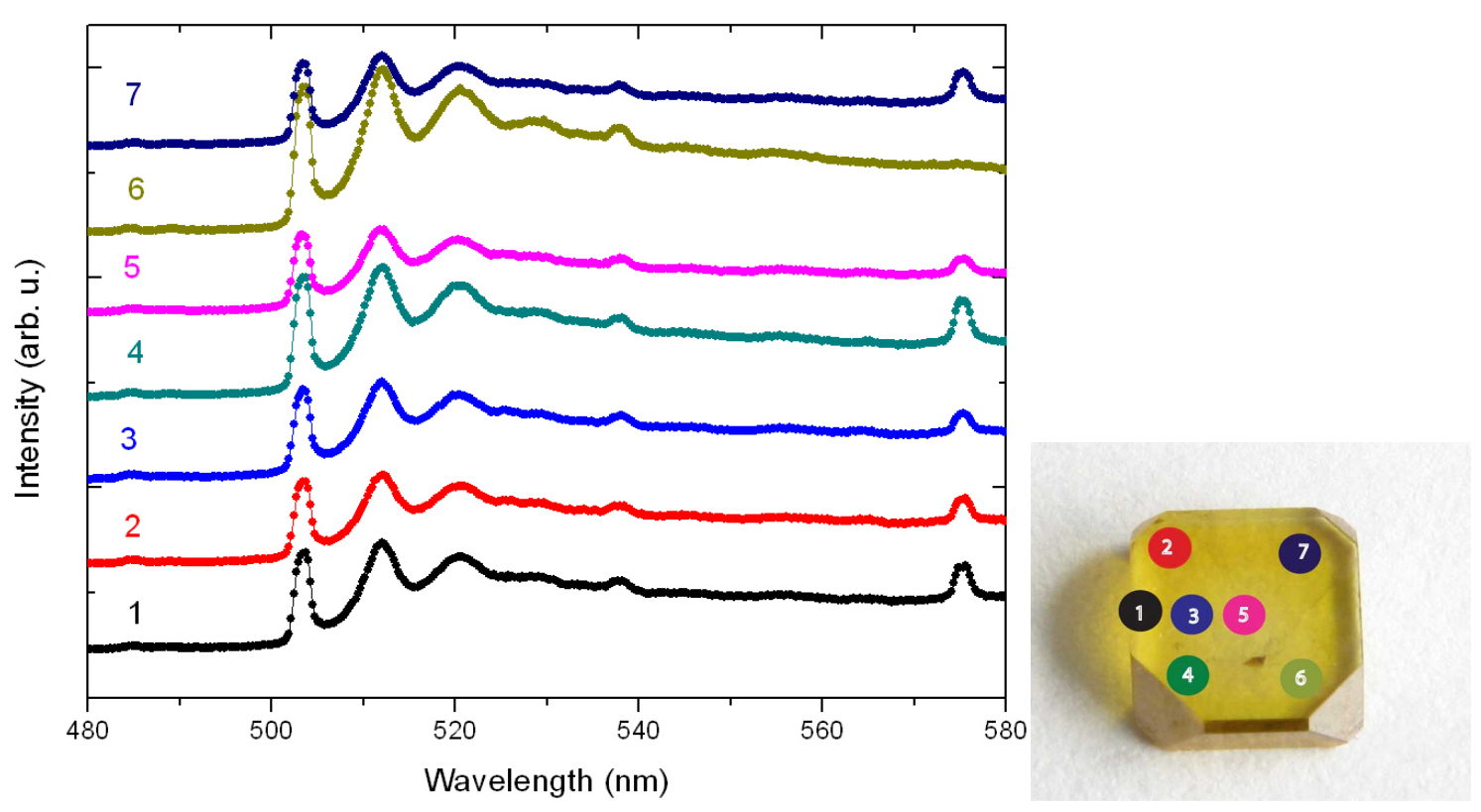

Figure 5.32: Cathodoluminescence of synthetic Ia diamond after high temperature SHI irradiation measured at different positions. The positions are marked in the photograph on the right side. The sample was kept at $500{ }^{\circ} \mathrm{C}$ for $1.5 \mathrm{~h}$.

center position (blue curve). A peak at $575 \mathrm{~nm}$ arises, the nickel-vacancy center (N$\mathrm{V})^{0}$. Luminescence spectra recorded at the four edges ((111) sides) are not included, they show strong Ni-luminescence. This sample is the backside of the sample shown in fig. 5.32, right side, thus, it was pressed on the heater plate during irradiation. To summarize the results, swift heavy ion irradiation damages the implanted samples. Many vacancies are produced which gives rise to the $575 \mathrm{~nm}$ line. However, unimplanted diamond is not affected by swift heavy ion irradiation.

\section{Irradiation of Ib diamond:}

The luminescence of the Ib diamonds before and after implantation is shown in fig. 5.34. All spectra in this section were recorded at the center position of the (100) side. The implantation fluence and energy are identical to the fluence used for the Ia diamonds, which are $100 \mathrm{keV}$ Ar-ions with $3 \times 10^{13} \frac{\text { ions }}{\mathrm{cm}^{2}}$ (blue curves, low implantation fluence) and $10^{14} \frac{\text { ions }}{\mathrm{cm}^{2}}$ (green curves, high implantation fluence). Before implantation, all diamonds showed luminescence with identical lines but varying intensity. To obtain a figure of merit for the implantation damage, the integrated intensity of the $484 \mathrm{~nm}$ line was calculated and compared to the integrated intensity of the untreated samples. After implantation with the low fluence, the cyan spectrum shows $27 \%$ of the line intensity and the blue spectrum $34 \%$. The green 


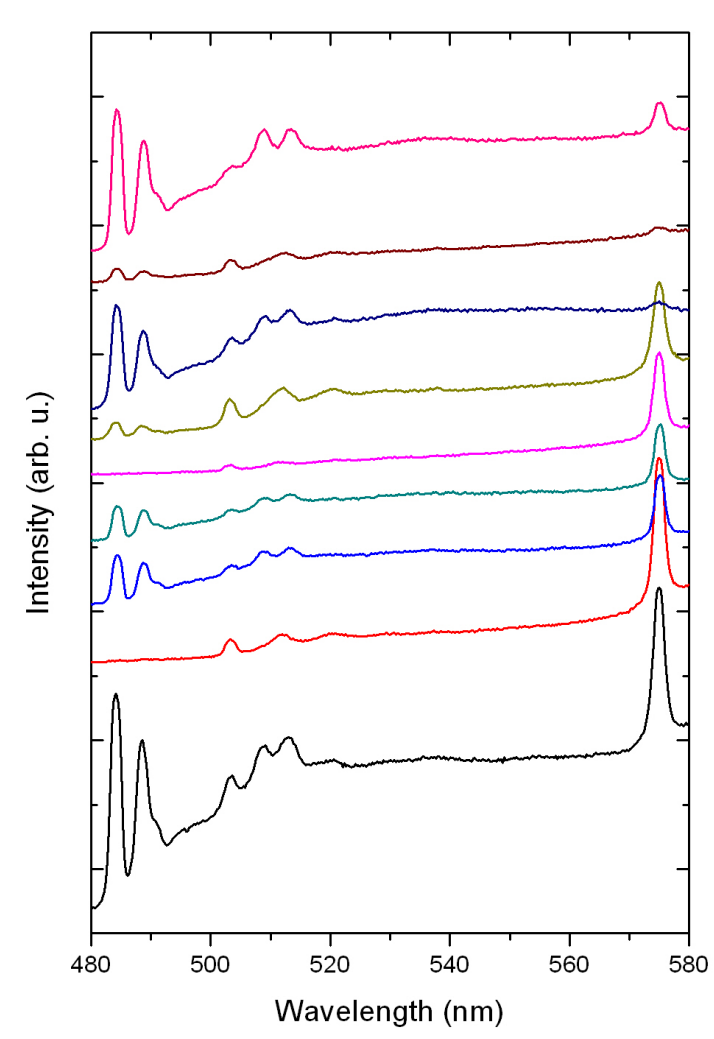

(a) Cathodouminescence spectra of Ia diamond implanted with $3 \times 10^{13} \frac{\text { ions }}{\mathrm{cm}^{2}}$ Ar ions after high temperature SHI.

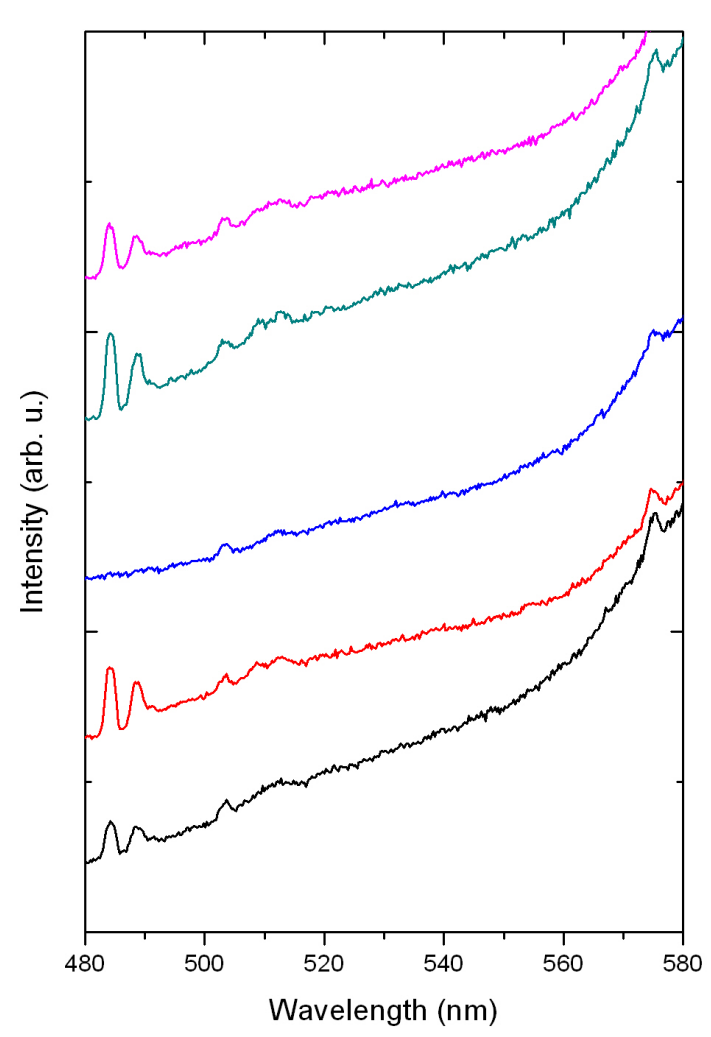

(b) Cathodouminescence spectra of Ia diamond implanted with $1 \times 10^{14} \frac{\mathrm{ions}}{\mathrm{cm}^{2}}$ Ar ions after temperature treatment.

Figure 5.33: Cathodoluminescence spectra of treated Ia diamond. Luminescence was recorded at different positions (shifted vertically), the spectrum recorded at the center position is shown with the light pink (left) or the blue (right) curve. Spectra recorded at the (111) sides were not included.

curve shows about $34 \%$ of the $484 \mathrm{~nm}$ line intensity and the dark green $61 \%$ after implantation with the high fluence.

The effect of swift heavy ion irradiation $(39 \mathrm{keV} / \mathrm{nm})$ on synthetic Ib diamond can be seen in fig. 5.35. The samples were measured with the same parameters, such as entrance slit opening and excitation current. The spectrum of the pristine sample, which was measured earlier, was included for comparison. The increase in intensity of the pristine diamond after swift heavy ion irradiation can rather be attributed to the adjustment of the achromatic lenses than to crystal quality improvement. As a figure of merit for the quality of the diamond samples, the intensity of the line at $484 \mathrm{~nm}$ will be compared. After swift heavy ion irradiation and low fluence implantation, $15 \%$ of the $484 \mathrm{~nm}$ line intensity are visible, which is $9 \%$ of the intensity of 


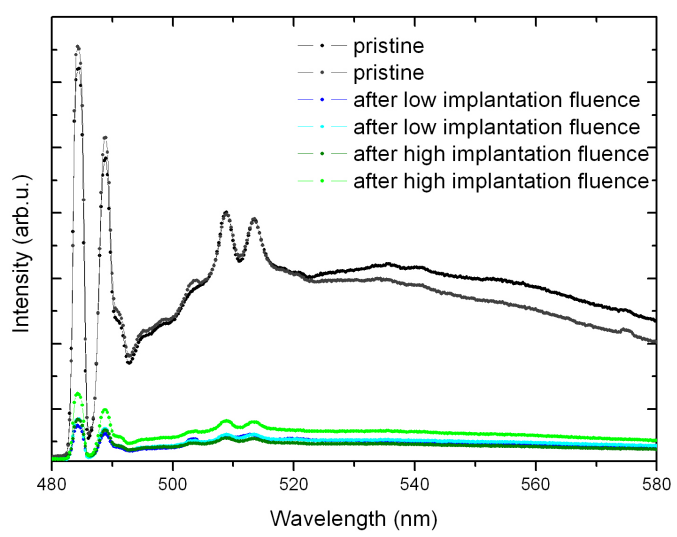

Figure 5.34: Cathodoluminescence of synthetic Ib diamond before (black, gray) and after (green, blue) implantation. The intensity of the nickel-related lines is quenched during implantation, but still noticeable.

the pristine sample shown. The sample implanted with the high fluence shows $24 \%$ of the initial intensity, which is $6.5 \%$ of the intensity of the pristine sample in fig. 5.35 .

The cathodoluminescence of diamond after high temperature irradiation is seen in fig. 5.36. Untreated diamond is not affected by swift heavy ion irradiation. The explanation for the increasing intensity after ion irradiation is the same as given above. The sample implanted with the low fluence shows $26 \%$ of the initial $484 \mathrm{~nm}$ line intensity (11\% of the intensity of the untreated sample shown). After high fluence implantation, $11 \%$ of the intensity can be found. This is $7 \%$ of the line intensity of the pristine sample shown. To summarize the results obtained from the Ib diamonds, unimplanted diamonds are not affected by swift heavy ion irradiation. The $484 \mathrm{~nm}$ line in low fluence implanted diamond is more intense after high temperature irradiation than room temperature irradiation. The $484 \mathrm{~nm}$ line in high fluence implanted diamond seems more intense after irradiation at high temperatures. However, the sample used for the room temperature irradiation with high implantation fluence shows strong luminescence after treatment. 


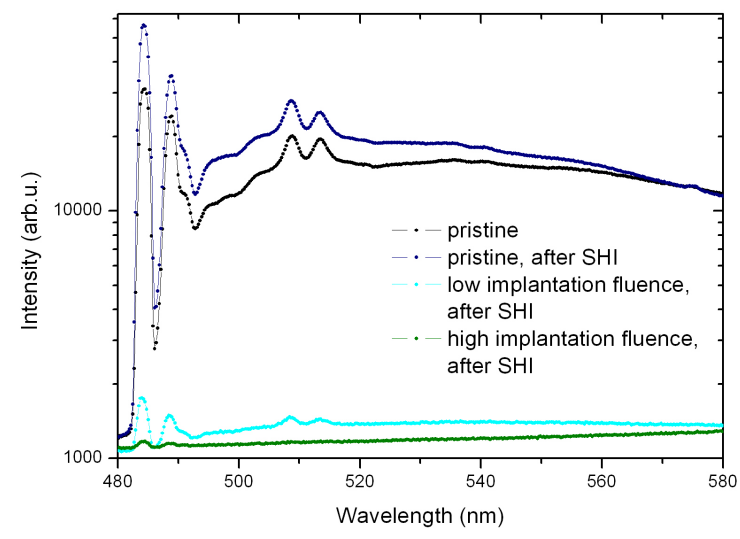

Figure 5.35: Cathodoluminescence of synthetic Ib diamond before and after SHI.

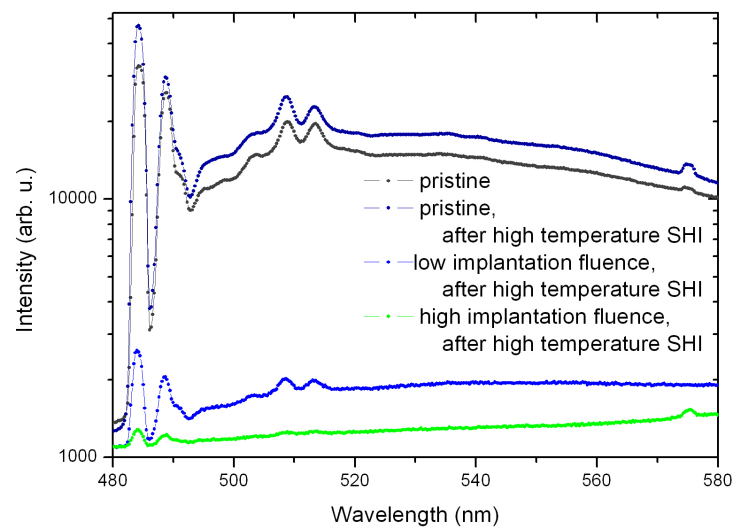

Figure 5.36: Cathodoluminescence of synthetic Ib diamond before and after high temperature $S H I$. 


\begin{tabular}{cccc} 
Sample & $484 \mathrm{~nm}$ line $\%$ : & (a) initial & (b) pristine sample shown \\
\hline \hline Low impl. fluence & SHI & 15 & 9 \\
\cline { 2 - 4 } & high temp. SHI & 26 & 11 \\
\hline \multirow{2}{*}{ High impl. fluence } & SHI & 24 & 6.5 \\
\cline { 2 - 4 } & high temp. SHI & 11 & 7 \\
\hline
\end{tabular}

Table 5.7: Percentage of the $484 \mathrm{~nm}$ line intensity after treatment of Ib diamond.

\subsection{Irradiation of silicon carbide}

Swift heavy ion beam induced annealing of $6 \mathrm{H}-\mathrm{SiC}$ during irradiation at room temperature was found before by BenYagoub and AUdREN [19]. In their work, the crystal structure was examined with the RBS/channeling technique. However, this technique is not as sensitive as luminescence measurements, which were performed in this work. Here, nitrogen doped $6 \mathrm{H}-\mathrm{SiC}$ is damaged by argon implantation and subsequently irradiated with swift gold, uranium or xenon ions at temperatures above room temperature to improve a possible annealing effect. The defect concentration was examined by photoluminescence measurements.

Commercially available nitrogen doped silicon carbide was used for this work. The photoluminescence of untreated $\mathrm{SiC}$, recorded at $12 \mathrm{~K}$ with an output power of $40 \mathrm{~mW}$, is shown in fig. 5.37 and fig. 5.39 . For this work, two sets of $\mathrm{SiC}$ monocrystalline wafer were used, both provided by SiCrystal AG. Their luminescence differs, as seen in those figures. In the band-edge region of $\mathrm{SiC}$, the band gap is $3 \mathrm{eV}$, the spectrum shows a plethora of fine lines, found in both sets of wafers and described in, e.g., [108, 85]. These lines can be attributed to the recombination of excitons bound to nitrogen and their phonon replica. The luminescence of one wafer is dominated by a broad band at $490 \mathrm{~nm}$, as seen in fig. 5.37. This band is also observed in the luminescence spectra of the second wafer, fig. 5.39. Samples from the second wafer showed an intense broad band located at $660 \mathrm{~nm}$. The broad band at $490 \mathrm{~nm}$ can be related to a donor-acceptor nitrogen-aluminum transition, described in e.g. [86. Silicon carbide may be contaminated with aluminum during sample growth. A band located at $660 \mathrm{~nm}$ was also found before in $6 \mathrm{H}-\mathrm{SiC}$ by TAMUlAitis et al. [109]. Several broad bands in SiC were found by TORCHYNSKA et al. [110]. The results obtained from the different set of wafers are presented separately because of the difference in photoluminescence. All spectra were collected at $12 \mathrm{~K}$ and with the HeCd-laser with an output power of $40 \mathrm{~mW}$.

Both sets of wafers were implanted with $100 \mathrm{keV}$ Ar-ions using the same fluences as used for diamond and GaN, thus, $3 \times 10^{13} \frac{\text { ions }}{\mathrm{cm}^{2}}$ (low fluence) and $10^{14} \frac{\text { ions }}{\mathrm{cm}^{2}}$ (high fluence). The implantation depth is $72 \mathrm{~nm}$. The implantation was performed with a noble gas to avoid any optical centers produced by a dopant. The vacancies which 


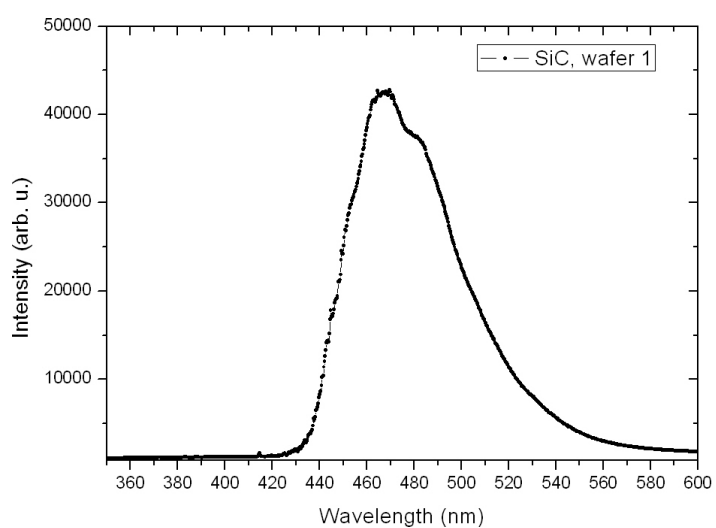

Figure 5.37: Photoluminescence of $6 \mathrm{H}$ $\mathrm{SiC}$ recorded at $12 \mathrm{~K}$, first wafer. A broad peak is seen at about $490 \mathrm{~nm}$.

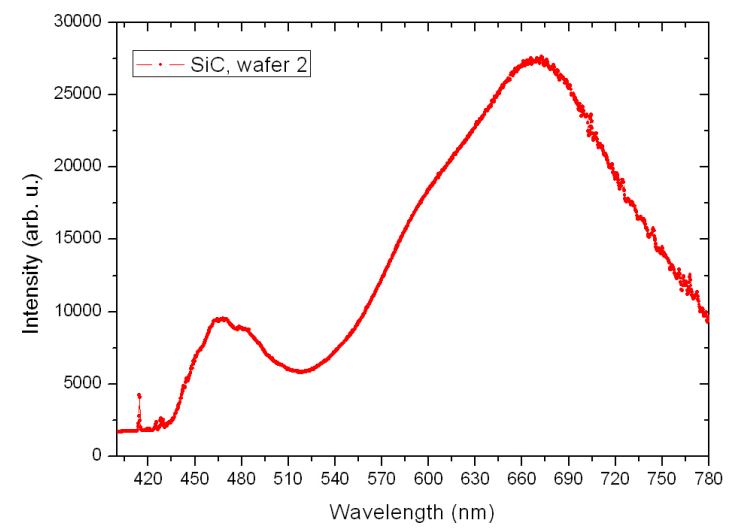

Figure 5.39: Photoluminescence of $6 \mathrm{H}$ $\mathrm{SiC}$ recorded at $12 \mathrm{~K}$, second wafer. Beside the peak at about $490 \mathrm{~nm}$, a broad peak is seen at $660 \mathrm{~nm}$.

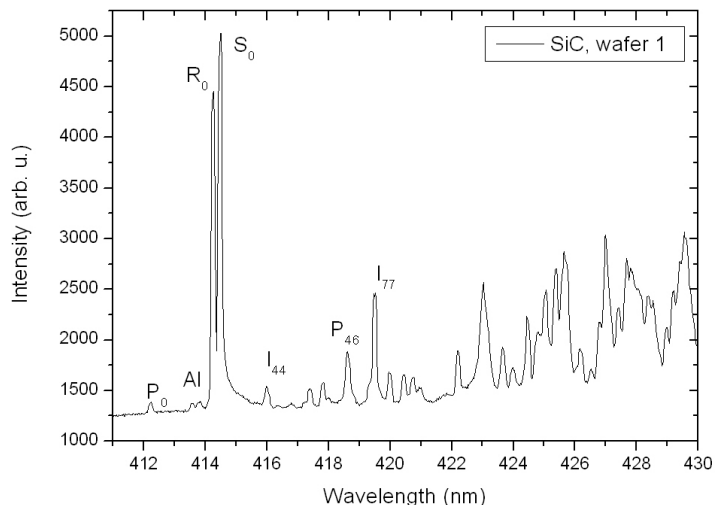

Figure 5.38: Near band-edge photoluminescence of $6 \mathrm{H}-\mathrm{SiC}$ recorded at $12 \mathrm{~K}$, first wafer. The lines related to excitons bound to nitrogen are visible, noted as $P_{0}, R_{0}$ and $S_{0}$. Also, some aluminum-related luminescence is visible.

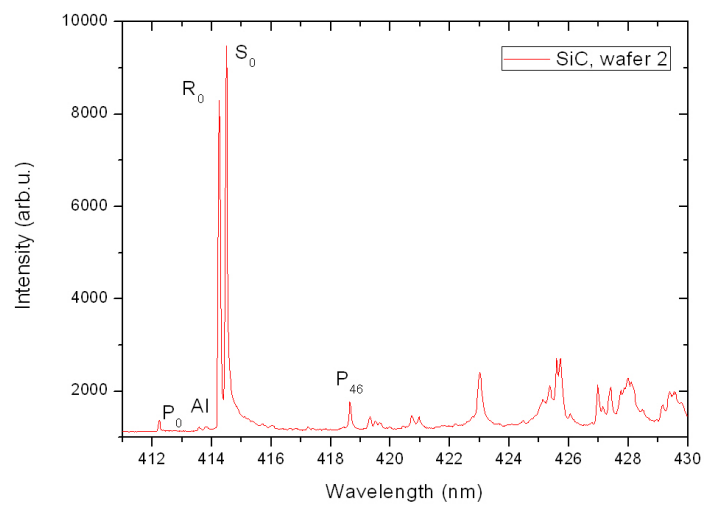

Figure 5.40: Near band-edge photoluminescence of $6 \mathrm{H}-\mathrm{SiC}$ recorded at $12 \mathrm{~K}$, second wafer. The zero-phonon lines related to nitrogen are visible. Some contribution of Al-impurities was also found in this spectrum. 


\begin{tabular}{llll}
$\begin{array}{l}\text { Ion species \& } \\
\text { energy } \\
\mathrm{MeV}\end{array}$ & $\begin{array}{l}\text { Electronic energy } \\
\text { loss } \\
\mathrm{keV} / \mathrm{nm}\end{array}$ & $\begin{array}{l}\text { Nuclear eneregy } \\
\text { loss } \\
\mathrm{keV} / \mathrm{nm}\end{array}$ & $\begin{array}{l}\text { Irradiation } \\
\text { temperature } \\
{ }^{\circ} \mathrm{C}\end{array}$ \\
\hline \hline $\mathrm{Xe}, 1400$ & 19 & $1.3 \times 10^{-2}$ & 500 \\
$\mathrm{U}, 1400$ & 39.5 & $3.8 \times 10^{-2}$ & $\begin{array}{l}\text { room } \\
\text { temperature }\end{array}$ \\
& & & 700 \\
$\mathrm{Au}, 945$ & 31.2 & $5.4 \times 10^{-2}$ & $\begin{array}{l}\text { room } \\
\text { temperature }\end{array}$ \\
& & & 500 \\
\hline
\end{tabular}

Table 5.8: Irradiation parameters used for SiC. The energy loss was calculated using SRIM2008

are formed during implantation might cause a change in luminescence.

The luminescence of $\mathrm{SiC}$ (wafer one) after implantation is seen in fig. 5.41. The samples were recorded under the same conditions, thus intensity is comparable. After implantation, the intensity is quenched, no additional lines occur. The nitrogen related luminescence is hardly visible after ion implantation. Luminescence intensity is decreasing with increasing implantation fluence, as expected.

The parameters of swift heavy ion irradiation used for ion beam annealing, such as ion species and energy, are given in table 5.8 . Irradiation fluence was $3 \times 10^{12} \frac{\text { ions }}{\mathrm{cm}}^{2}$ and $5 \times 10^{10 \frac{\mathrm{ions}}{\mathrm{cm}}^{2}}$. The samples cut from the first wafer were irradiated with xenon and uranium ions. The gold irradiation was performed on samples cut from the second wafer. Similar to the GaN samples, some $\mathrm{SiC}$ samples darken during swift heavy ion irradiation. However, the $\mathrm{SiC}$ material did not break under irradiation.

\section{Irradiation of $\mathrm{SiC}$, wafer one:}

In fig. 5.42, the luminescence of temperature treated $\mathrm{SiC}$ is shown. The samples were heated to $500{ }^{\circ} \mathrm{C}$ for 1.5 hours. Pristine $\mathrm{SiC}$ is not affected by this temperature treatment. It can be clearly seen that the luminescence of implanted samples recovers, but their intensity is lower compared to pristine SiC. Thus, the defects from implantation are not totally removed.

In fig. 5.43, the luminescence of $\mathrm{SiC}$ after irradiation with $19 \mathrm{keV} / \mathrm{nm}(1.4 \mathrm{GeV} \mathrm{Xe})$ is shown. The irradiated samples show a broad band located at $530 \mathrm{~nm}$, with fine lines toward lower wavelength. This band is found in unimplanted $\mathrm{SiC}$ and implanted SiC. The implanted samples show this band luminescence with decreased intensity. Several lines in this wavelength regime was found before after ion or electron irradiation [65, 111, 87]. Thus, one can conclude that the $\mathrm{SiC}$ samples are 


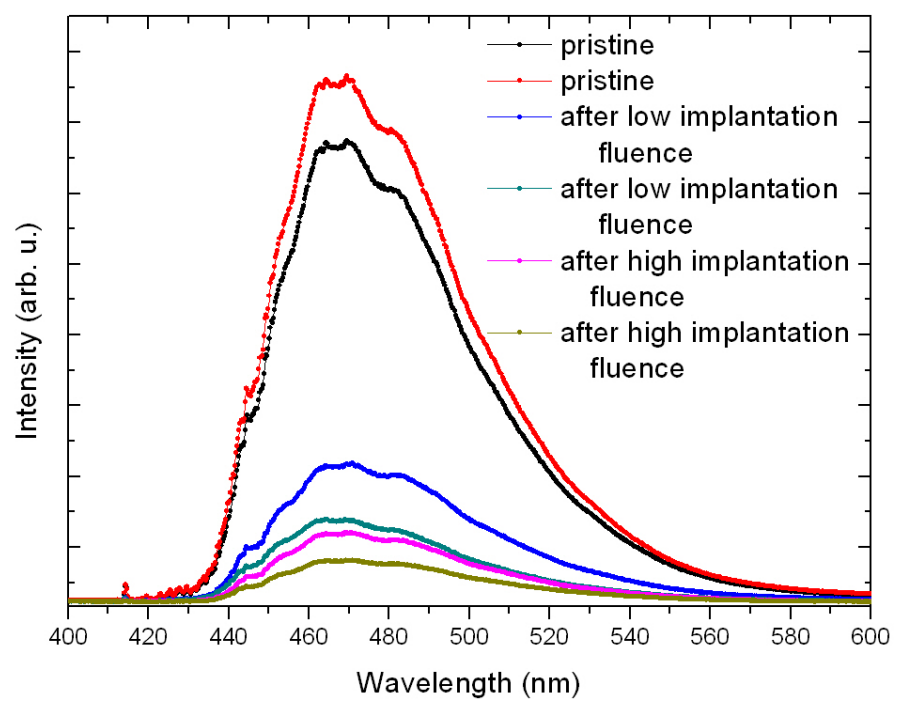

Figure 5.41: Photoluminescence of $6 \mathrm{H}-\mathrm{SiC}$ before (black, red) and after implantation (wafer1). The luminescence intensity is quenched, the higher the implantation fluence, the higher the damage production.

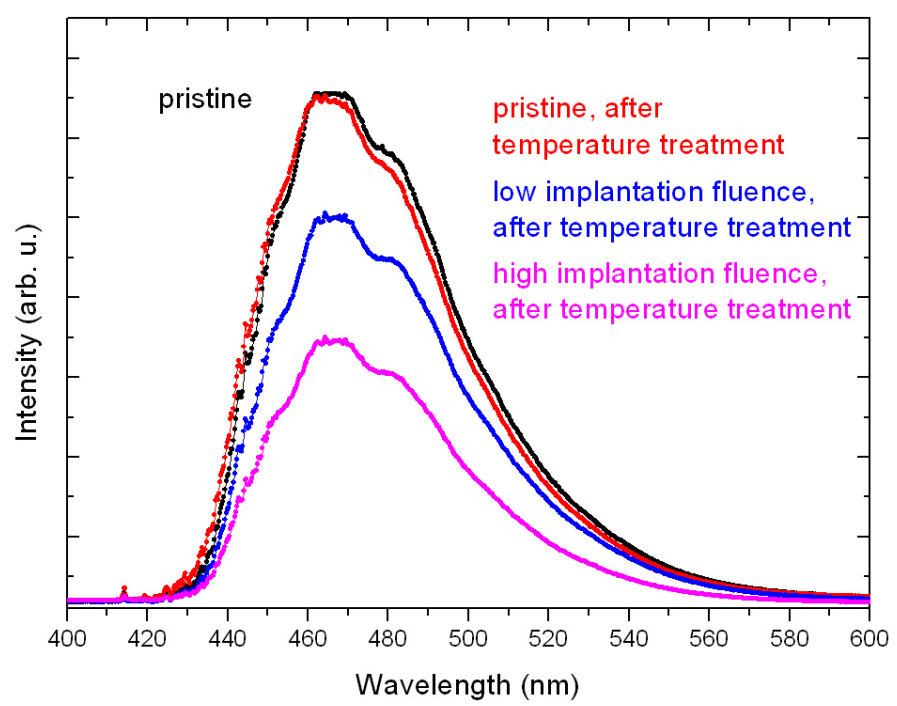

Figure 5.42: Photoluminescence $(14 \mathrm{~K})$ of pristine and implanted $6 \mathrm{H}$-SiC (first wafer) before (black) and after temperature treatment at $500{ }^{\circ} \mathrm{C}$ for $1.5 \mathrm{~h}$. 


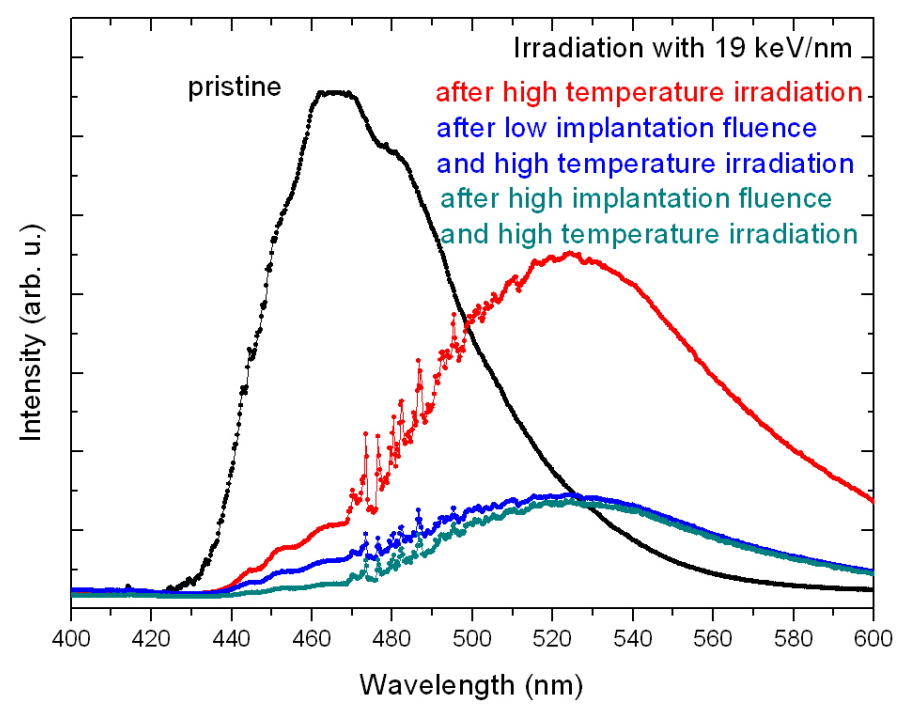

Figure 5.43: Photoluminescence of $6 \mathrm{H}-\mathrm{SiC}$ (first wafer) before (black) and after SHI $(19 \mathrm{keV} / \mathrm{nm})$ irradiation (red) and with previous implantation (blue, green). Irradiation fluence was $3 \times 10^{12} \frac{\text { ions }}{\mathrm{cm}}^{2}$.

damaged during irradiation. The fine lines observed after irradiation are shown in fig. 5.44. Unimplanted and implanted samples show similar lines.

Luminescence recorded after SHI irradiation with varying fluences and temperatures is given in fig. 5.45. After irradiation with $39.5 \mathrm{keV} / \mathrm{nm}(1.4 \mathrm{GeV} \mathrm{U})$ at $700{ }^{\circ} \mathrm{C}$ with $5 \times 10^{10} \frac{\text { ions }}{\mathrm{cm}^{2}}$, no luminescence change is found. After irradiation with higher fluence at lower temperatures, luminescence can be hardly recorded. However, this sample shows a weak band located at $490 \mathrm{~nm}$, shown in fig. 5.45(b). The sample is damaged during irradiation with $39.5 \mathrm{keV} / \mathrm{nm}$, but no luminescence line change was observed. Implanted $\mathrm{SiC}$ samples were irradiated wit $39.5 \mathrm{keV} / \mathrm{nm}$ at $700{ }^{\circ} \mathrm{C}$ with a fluence of $5 \times 10^{10} \frac{\mathrm{ions}^{2}}{\mathrm{~cm}}$. The luminescence recorded afterward is shown in fig. 5.46 . Similar to the pristine material, no luminescence line position change was found. However, the intensity decreases.

\section{Irradiation of $\mathrm{SiC}$, wafer two:}

In principal, the behavior of the luminescence after implantation of the second wafer is similar to the one of the first wafer, see fig. 5.47. Luminescence is quenched after implantation. Increasing of the implantation fluence results in decreasing of luminescence intensity. Nitrogen-related luminescence is still visible after implantation.

In the following, the results derived from the samples cut from the second wafer will be presented. The luminescence of unimplanted $\mathrm{SiC}$ after temperature treatment 

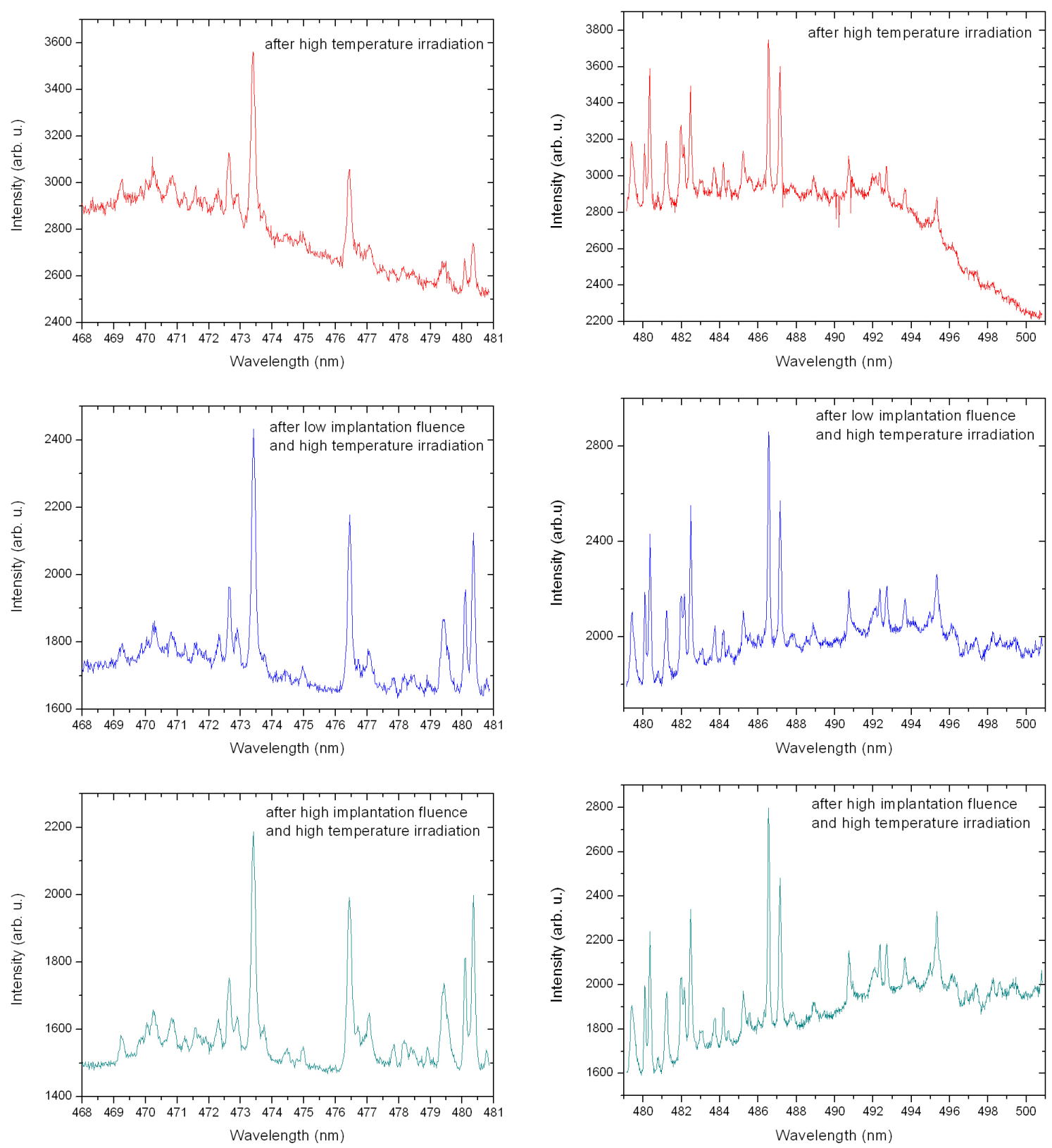

Figure 5.44: Photoluminescence of the sharp lines in 6H-SiC (first wafer) after high temperature SHI irradiation with $19 \mathrm{keV} / \mathrm{nm}$. 


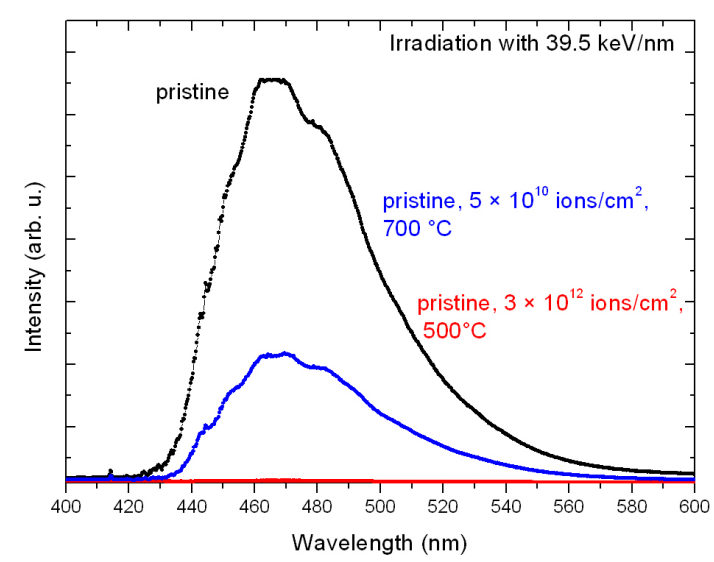

(a) Photoluminescence of $6 \mathrm{H}-\mathrm{SiC}$ (first wafer) before and after SHI irradiation with $39.5 \mathrm{keV} / \mathrm{nm}$.

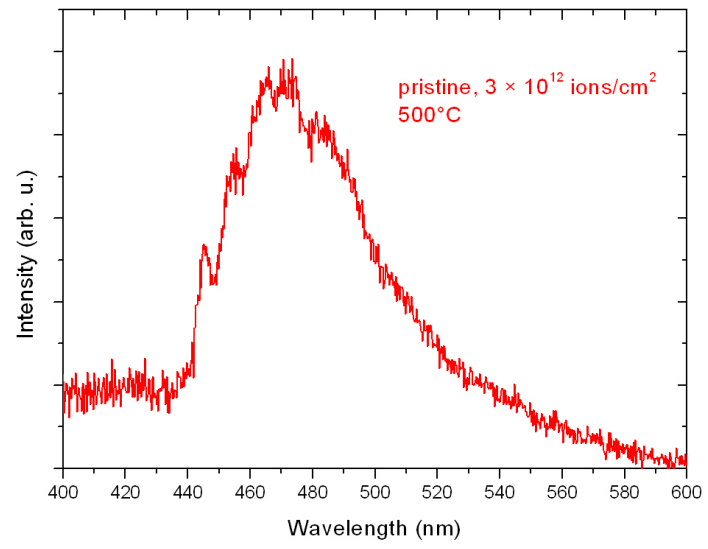

(b) Photoluminescence of $6 \mathrm{H}-\mathrm{SiC}$ (first wafer) after SHI irradiation with $39.5 \mathrm{keV} / \mathrm{nm}$, irradiation fluence was $3 \times 10^{12} \frac{\text { ions }}{\mathrm{cm}^{2}}$.

Figure 5.45: Photoluminescence of $6 \mathrm{H}$-SiC (first wafer) before and after SHI irradiation $(39.5 \mathrm{keV} / \mathrm{nm})$ with varying fluences. (b) shows the red curve in (a) with proper scaling.

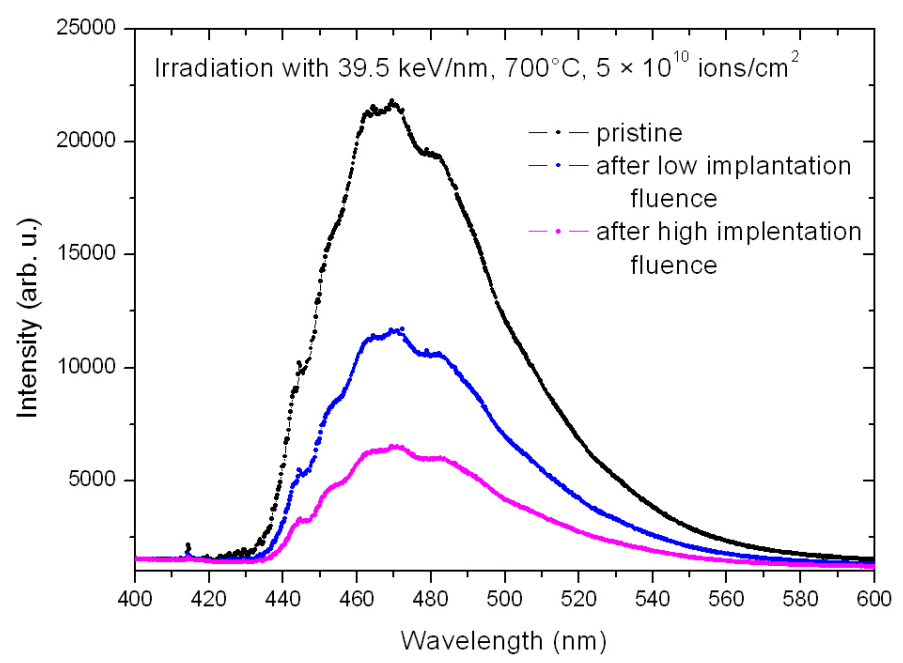

Figure 5.46: Photoluminescence of $6 \mathrm{H}-\mathrm{SiC}$ (first wafer) after SHI irradiation $(39.5 \mathrm{keV} / \mathrm{nm})$ before (black) and after implantation. Irradiation fluence was $5 \times 10^{10 \mathrm{ions}^{2}}{ }^{2}$, temperature was $700{ }^{\circ} \mathrm{C}$. 


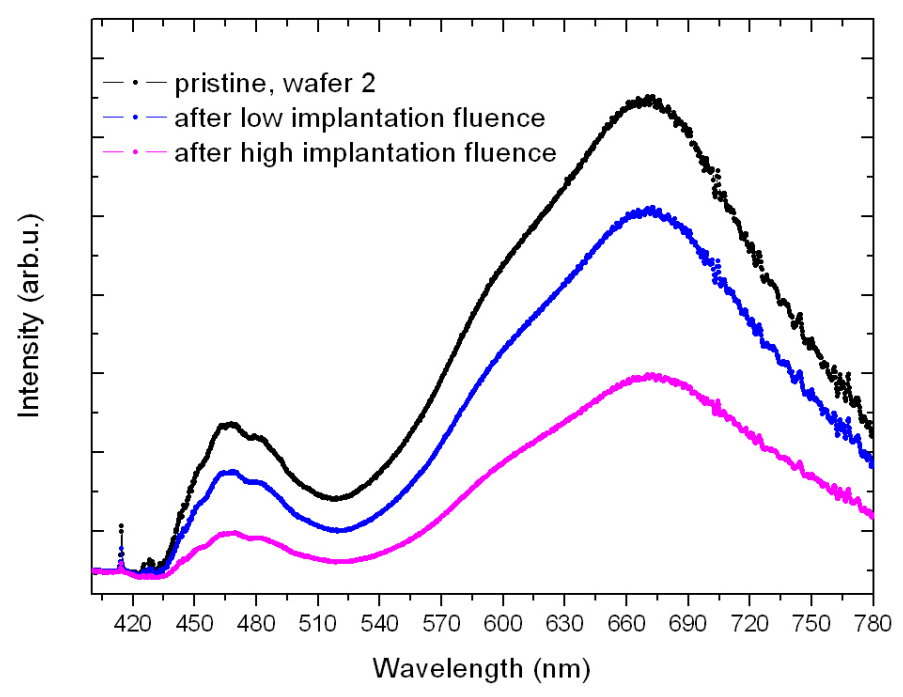

Figure 5.47: Photoluminescence of $6 \mathrm{H}-\mathrm{SiC}$ before (black) and after implantation (wafer 2). The luminescence intensity is quenched, but near-band edge luminescence is still visible.

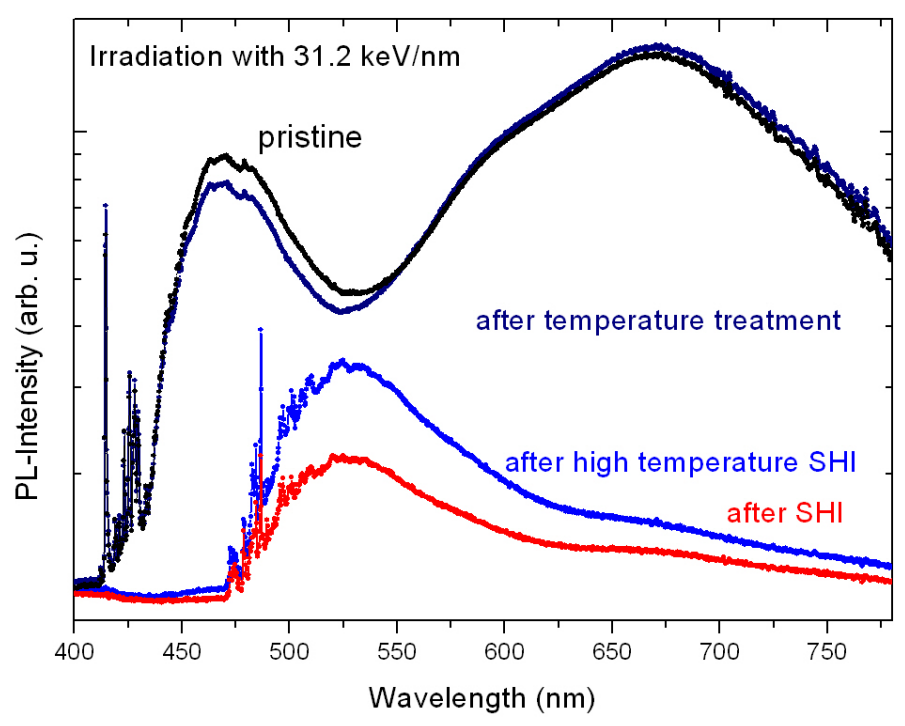

Figure 5.48: Photoluminescence of $6 \mathrm{H}-\mathrm{SiC}$ (second wafer) after SHI irradiation with $31.2 \mathrm{keV} / \mathrm{nm}$ and temperature treatment. Samples were kept at $500{ }^{\circ} \mathrm{C}$ for $3 \mathrm{~min}$. Irradiation fluence was $2 \times 10^{12} \frac{\text { ions }}{\mathrm{cm}}^{2}$. 


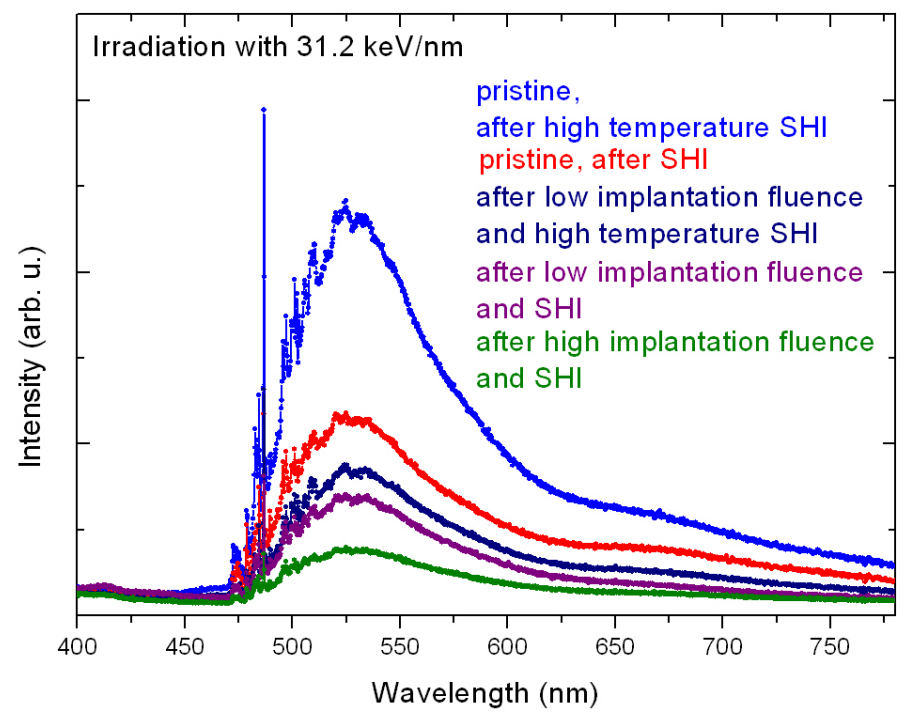

Figure 5.49: Photoluminescence of $6 \mathrm{H}-\mathrm{SiC}$ (second wafer) after SHI irradiation with $31.2 \mathrm{keV} / \mathrm{nm}$, before and after implantation. Irradiation fluence was $2 \times 10^{12} \frac{\mathrm{ions}}{\mathrm{cm}}^{2}$.

and SHI irradiation is shown in fig. 5.48. The samples were kept at $500{ }^{\circ} \mathrm{C}$ for 3 min. Temperature treatment of the pristine sample (royal blue) has no effect on the luminescence spectrum. After irradiation with $31.2 \mathrm{keV} / \mathrm{nm}(945 \mathrm{MeV} \mathrm{Au})$, a shift in luminescence is observed. A broad band at $530 \mathrm{~nm}$ is found with many sharp lines at lower wavelength. The line with the highest intensity is located at $486.59 \mathrm{~nm}(2.548 \mathrm{eV})$. A contribution of the band at $660 \mathrm{~nm}$ is visible. The sample irradiated at $500^{\circ} \mathrm{C}$ (blue) shows more intense luminescence than the sample irradiated at room temperature (red). Thus, temperature treatment during irradiation has a positive effect on luminescence. Luminescence of unimplanted and implanted samples after SHI at $500^{\circ} \mathrm{C}$ or room temperature are shown in fig. 5.49. All samples show the broad band located at $530 \mathrm{~nm}$. It can be seen that the luminescence of the samples irradiated at $500^{\circ} \mathrm{C}$ is higher compared to the samples irradiated at room temperature.

In fig. 5.50 and fig 5.51 a detailed view on the defect lines is given. The line with the maximum intensity is located at $486.6 \mathrm{~nm}(2.55 \mathrm{eV})$ and is found in all samples. The initial luminescence differs between samples cut from different wafers. The obtained results are similar. After irradiation with $21 \mathrm{kev} / \mathrm{nm}$ and $31.2 \mathrm{keV} / \mathrm{nm}$, a broad band located at $530 \mathrm{~nm}$ is observed. After irradiation with $39.5 \mathrm{keV} / \mathrm{nm}$, the band observed in the pristine samples is found. This is an evidence that irradiation with $39.5 \mathrm{keV} / \mathrm{nm}$ does not form defects, which produce the band at $530 \mathrm{~nm}$. However, the overall intensity is reduced. 


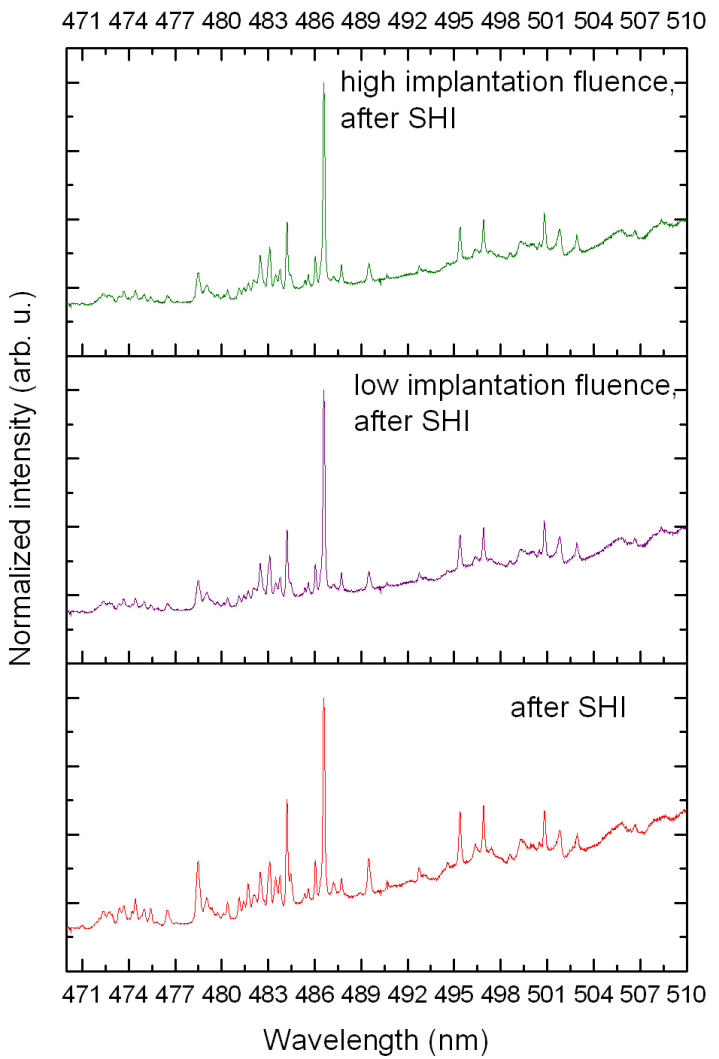

Figure 5.50: Photoluminescence of defect lines in $6 \mathrm{H}-\mathrm{SiC}$, second wafer, after SHI irradiation with $31.2 \mathrm{keV} / \mathrm{nm}$.A

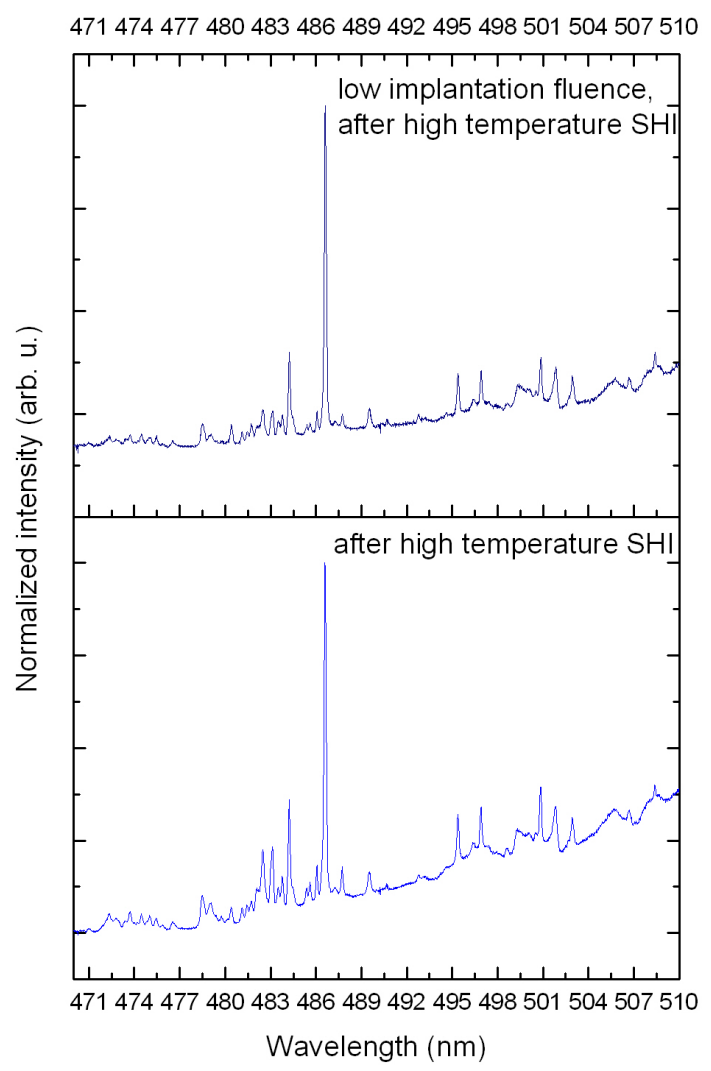

Figure 5.51: Photoluminescence of defect lines in $6 \mathrm{H}-\mathrm{SiC}$, second wafer, after high temperature SHI irradiation with $31.2 \mathrm{keV} / \mathrm{nm}$.

\begin{tabular}{cc}
$\mathrm{dE} / \mathrm{dx}_{\mathrm{el}}$. & Effect \\
\hline \hline 19 & Emergence of $530 \mathrm{~nm}$ band \\
31.2 & Emergence of $530 \mathrm{~nm}$ band \\
39.5 & No change in luminescence line position, but intensity decreases \\
\hline
\end{tabular}

Table 5.9: Summarized effects of SHI on $6 \mathrm{H}-\mathrm{SiC}$. 


\section{Chapter 6}

\section{Discussion and Conclusion}

This chapter gives a discussion of the previously presented results. First, the results obtained from measurements on ta- $\mathrm{C}$ will be discussed. This section is followed by the section concerning gallium nitride and diamond. The chapter ends with the section $\mathrm{SiC}$.

\subsection{Doping and irradiation of ta-C}

The results derived from the irradiated ta-C samples can be summarized as follows:

I. All samples show a plasmon loss of about $31 \mathrm{eV}$.

II. The AFM-measurements show that doped ta-C samples form ion tracks with a higher conductivity compared to undoped ta-C, see table 5.3 .

(a) Iron doped ta-C shows tracks with the highest conductivity.

(b) The variation of track conductivity is huge.

(c) After $\mathrm{C}_{60}$ irradiation, the track conductivity is even more increased.

(d) All tracks show similar conductivity after $\mathrm{C}_{60}$ irradiation.

III. The macroscopic transport measurements show that the conductivity contrast decreases due to doping.

(a) The conductivity contrast of ta-C is high.

(b) ta-C:N and ta-C:Cu show a noteworthy conductivity contrast.

The concentration of the dopant atoms was chosen in that way, that the high $\mathrm{sp}^{3}$ bond ratio of the ta-C-matrix should remain. The dopant concentration should not 


\begin{tabular}{|c|c|c|c|c|c|}
\hline Sample & ta-C & ta-C:N & ta-C:B & ta-C:Fe & ta-C:Cu \\
\hline Resistivity & $12 \pm 14$ & $5 \pm 5$ & $6 \pm 4$ & $0.22 \pm 0.08$ & $0.7 \pm 0.4$ \\
\hline $\begin{array}{l}\Omega \mathrm{cm} \text { ion irr. } \\
\text { Resistivity } \\
\Omega \mathrm{cm} \mathrm{C}_{60} \mathrm{irr} .\end{array}$ & $1.07 \pm 0.05$ & $0.9 \pm 0.3$ & $0.51 \pm 0.02$ & $0.097 \pm 0.004$ & 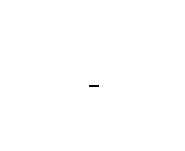 \\
\hline
\end{tabular}

Table 6.1: Resistivity of tracks in doped ta-C derived from AFM measurements. For calculation, a track length of $100 \mathrm{~nm}$ and a track diameter of $8 \mathrm{~nm}$ was assumed.

exceed 1 at\%, this was analyzed for copper [90] and nitrogen [112, 113]. The relatively large plasmon energy of about $31 \mathrm{eV}$ indicates a sp ${ }^{3}$ bond ratio of about $80 \%$. The plasmon energy for diamond (100\% sp $\mathrm{sp}^{3}$ bonding) is $33 \mathrm{eV}$ and for graphite (0\% $\mathrm{sp}^{3}$ bonding) $24 \mathrm{eV}$. The $\mathrm{sp}^{3}$ content of the samples can be calculated by linear interpolation of these plasmon energy values [34]. Each conductive filament in ta-C is produced by one impinging ion. During swift heavy ion irradiation, when ta- $\mathrm{C}$ is transformed along the ions path, many disordered $\mathrm{sp}^{2}$ bonds are produced [23]. There is no variation in ion beam energy, thus, the variation in ion track conductivity should result from local $\mathrm{sp}^{3}$ bond variation inside the film. This variation in ion track conductivity was also found in previous studies [97, 3], 4].

Doping of ta-C increases the conductivity of ion tracks, this is visible from the AFM-measurements. Doping of ta-C with boron or nitrogen is expected to increase the number of localized states near the Fermi level rather than shifting the Fermi level [5, 6] and thus increase the conductivity. A slight shift of the Fermi level was observed after nitrogen doping of ta-C, but not after boron doping [114. Using iron or copper as a dopant, the ion tracks should contain metal atoms and thus should show an ohmic current-voltage characteristic. The average resistivity of ion tracks in doped ta-C derived from the AFM measurements are summarized in table 6.1. The ion track length was assumed to equal the sample thickness, which is $100 \mathrm{~nm}$. For the diameter, a value of $8 \mathrm{~nm}$ was chosen. The error given in this table is either derived from the standard derivation from the arithmetical mean value or from the standard deviation from the Gaussian line fit. Regarding the ion irradiated samples, it can be seen that the resistivity of the ion tracks is reduced due to doping. Doping with metal ions is more effective than doping with boron or nitrogen. The most conductive tracks were found in ta-C:Fe. The resistivity in ta-C is heavily reduced from $12 \mathrm{M} \Omega$ to $1.07 \mathrm{M} \Omega$ after $\mathrm{C}_{60}$ irradiation. This resistivity decreases for doped samples. Again, the lowest value for the resistivity, $0.097 \mathrm{M} \Omega$, was found in ta-C:Fe. Unfortunately, the conductivity of ta- $\mathrm{C}$ also increases. The current through unirradiated ta- $\mathrm{C}$ is plotted over the temperature in fig. 6.1. The values for the resistivity at $300 \mathrm{~K}$ derived from these measurements are given in table 6.2. It can be seen that doping with boron (red curve) or iron (purple curve) results in very conductive films. The ta-C film doped with copper (blue curve) shows a similar conductivity 


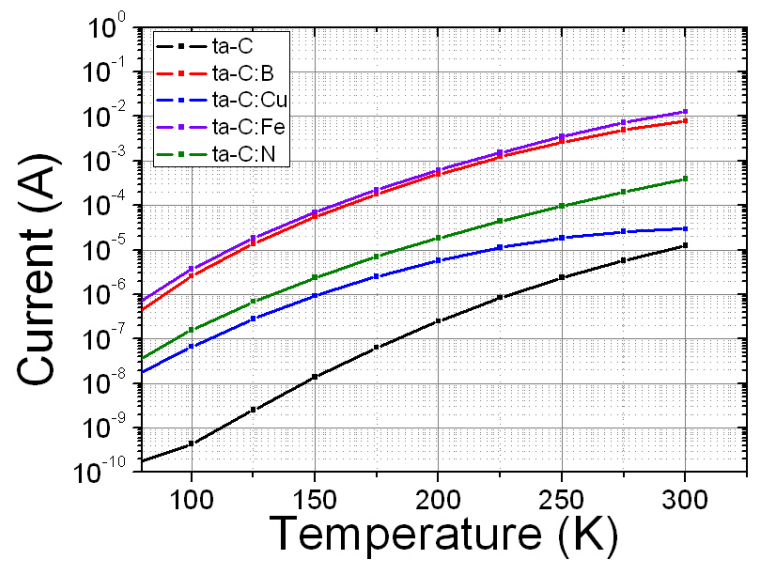

Figure 6.1: Current over temperature of doped and undoped unirradiated ta- $C$ with a voltage of $0.3 \mathrm{~V}$. Doping of ta-C with boron (red) or iron (purple) leads to conductive matrix.

as the pure ta-C film. However its conductivity decreases slower with decreasing temperature compared to the pure film. The conductivity of ta-C:N (green curve) is higher compared to ta-C, but it is not as conductive as ta-C:B or ta-C:Fe. It is known that iron and boron form carbide phases and copper does not. This may explain the drastic conductivity increase in ta-C:B and ta-C:Fe.

The results derived from the AFM-measurements are contrary to the results derived from the measurements with the macroscopic contact pad. The AFM-measurements were performed in contact mode, no increase in conductivity of unirradiated doped ta-C as seen in macroscopic measurements, see table 6.2, could be found. The ion tracks in ta-C:Fe are clearly visible and show the highest conductivity of all samples. However, the lowest conductivity contrast was found in macroscopic measurements of ta-C:Fe.

The modification of conductivity of doped ta-C is in good agreement with earlier findings. RonNing et al. found an increase of conductivity of ta-C after boron or nitrogen doping [5]. The conductivity increases with increasing dopant concentration. Boron doping was found to increase the conductivity more than nitrogen

\begin{tabular}{l||ccccc|} 
Sample & ta-C & ta-C:N & ta-C:B & ta-C:Fe & ta-C:Cu \\
\hline $\begin{array}{l}\text { Resistivity } \mathrm{M} \Omega \mathrm{cm} \\
\text { matrix macro. }\end{array}$ & 4 & 0.1 & 0.005 & 0.004 & 1.3
\end{tabular}

Table 6.2: Resistivity of doped and undoped ta- $C$ derived from macroscopic transport measurements. Sample thickness was $100 \mathrm{~nm}$, contact area was taken into account. 
doping.

One can conclude that doping of ta-C with boron or iron is not suitable for conductivity improvement for ion tracks, because the conductivity contrast almost vanishes. Nitrogen might be a good candidate for doping, the resistivity of ion tracks in ta$\mathrm{C}: \mathrm{N}$ is reduced. Unirradiated ta-C:N is more conductive than ta-C, but much less conductive than ta-C:Fe or ta-C:B. Copper seems to be a promising candidate for dopant, especially at higher temperatures. The ion track resistivity is heavily reduced compared to ta-C, but the conductivity of ta- $\mathrm{C}$ and ta-C: $\mathrm{Cu}$ are similar.

\subsection{Irradiation of gallium nitride}

Before discussing the results, a brief summary is given:

I. GaN was irradiated with various ions at different energies.

II. Near band-edge luminescence of GaN remains after swift ion irradiation with $137 \mathrm{MeV} \mathrm{C}, 587 \mathrm{MeV} \mathrm{Cr}$ and $668 \mathrm{MeV} \mathrm{Ni}$ using low fluences.

(a) The area ratio $r_{i}$ of near band-edge luminesence to intrinsic blue band luminescence is found as an empirical figure of merit for crystal quality.

III. Annealing effect was observed after low fluence $587 \mathrm{MeV}$ Cr irradiation for low fluence Mg-implanted GaN.

IV. After irradiation with an electronic energy loss of $9 \mathrm{keV} / \mathrm{nm}$, luminescence of GaN almost vanishes.

In this work, many GaN samples were irradiated with several ion species at different energies. It was found that irradiation damage is seen in photoluminescence spectra by decreasing the intensity of the near band-edge luminescence. Thus, the ratio of the intensity of the band-edge luminescence over the intensity of the broad band luminescence is calculated as a figure of merit for crystal quality. In fig. 6.2 this ratio calculated for the irradiated, undoped samples $\mathrm{r}_{i}$ over the ratio for the untreated samples $r_{0}$ is plotted against the electronic energy loss and irradiation fluence. A high $\frac{\mathrm{r}_{i}}{\mathrm{r}_{0}}$ ratio implies a high degree of annealing. A ratio of one would mean a complete annealing. With this ratio, a possible range in which ion beam induced annealing may occur can be defined. The electronic energy loss should be in the range of 2 to $15 \mathrm{keV} / \mathrm{nm}$ and the irradiation fluence may not exceed $10^{12} \frac{\mathrm{ions}}{\mathrm{cm}^{2}}$. Having the overview of the photoluminescence spectra of irradiated GaN in mind, see fig. 5.21, it seems to be superficial to regard only the electronic energy loss. For example, irradiation with silicon results in heavier damage than irradiation with 


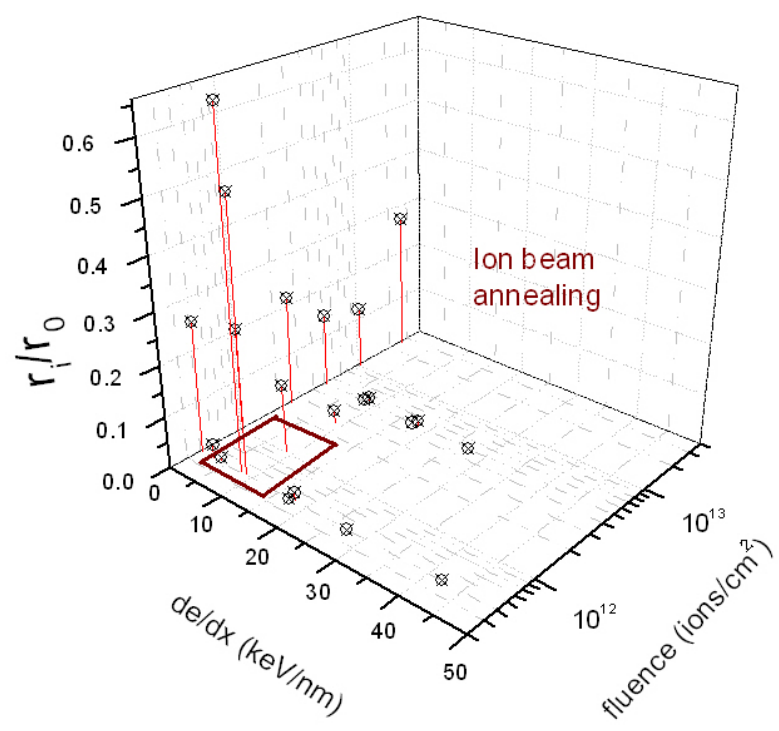

Figure 6.2: Area ratio (near band-edge to blue band) of irradiated, undoped $r_{i}$ and unirradiated $r_{0}$ samples over electronic energy loss and fluence.

chromium or nickel although the electronic energy loss is half as much. Thus, the ratio of electronic and nuclear energy loss was calculated and given in table 5.4. Using silicon at $6 \mathrm{MeV}$, the energy ratio is relatively low. Although the electronic excitation is low during silicon irradiation, the GaN sample is damaged due to the nuclear interactions. The irradiations with carbon and chromium at the chosen energies are the ones with the highest energy ratio. The pristine GaN samples show little damage after carbon irradiation at low fluences, an annealing effect occurs after chromium irradiation using $5 \times 10^{11} \frac{\text { ions }}{\mathrm{cm}^{2}}$ of GaN implanted with $3 \times 10^{13} \frac{\text { ions }}{\mathrm{cm}^{2}}$ $\mathrm{Mg}$ ions, but not after nickel irradiation using similar fluences, which shows a little lower energy ratio. This shows that not only the value of the electronic energy loss is of importance. The electronic energy loss has to exceed the nuclear energy loss by a factor of 2000. No annealing effect was observed for samples implanted with $10^{14} \frac{\mathrm{ions}}{\mathrm{cm}^{2}}$. Thus, the effectiveness of ion beam induced annealing is reduced by a high amount of defects.

Regarding the photoluminescence spectra of GaN irradiated with a variety of swift ions, fig. 5.21, the poor results concerning ion beam annealing obtained in [50] can be understood. The electronic energy loss of $200 \mathrm{MeV}$ Ag ions in GaN, which was used in their work, is $26 \mathrm{keV} / \mathrm{nm}$. Luminescence related to GaN was not observed after irradiation with $17 \mathrm{keV} / \mathrm{nm}$ in this work. Certainly, one has to include the implantation and irradiation fluence into consideration. The swift heavy ion irradiation 
fluences used in [50] are similar to the fluences used in this work. The implantation fluence was much higher than the fluences used in this work. The implantation with cobalt using high fluences of $10^{16} \frac{\text { ions }}{\mathrm{cm}^{2}}$ is performed at $350{ }^{\circ} \mathrm{C}$ to avoid sample amorphization. In this work, no annealing effect was found for samples implanted with the relatively low fluence of $10^{14} \frac{\mathrm{ions}}{\mathrm{cm}^{2}}$.

\subsection{Irradiation of diamond}

The results of swift heavy ion irradiation of diamond are summarized:

I. The luminescence of diamond is reduced due to ion implantation.

II. Undamaged diamond is not affected by swift heavy ion irradiation.

III. Pre-damaged diamond is further disturbed during swift heavy ion irradiation, no annealing effect was found.

Nickel is a typical contamination in synthetic diamond. Both type Ia and Ib diamond show a dominant nickel-related luminescence, as seen in fig. 5.30 and fig. 5.31. No nitrogen-related luminescence such as the N3 center, three nitrogen atoms next to a vacancy, see ref. [84], was observed. Also, no difference in luminescence of Ia or Ib diamond was found. The difference between these types of diamond is the embedding of the nitrogen contamination which may influence the luminescence. However, the nickel contamination gives rise to the luminescence in both diamond types.

After low implantation fluence of Ia diamond $\left(3 \times 10^{13} \frac{\mathrm{ions}}{\mathrm{cm}^{2}}\right)$, luminescence is still visible, see fig. 5.30. Argon as a noble gas is not expected not form optical centers, but vacancies caused by implantation may occur. However, no additional lines in implanted diamond were recorded, but the intensity of the $484 \mathrm{~nm}$ line decreases compared to the intensity of the $503 \mathrm{~nm}$ line. Decreasing of the overall intensity was found for the Ib diamond samples, see fig. 5.34. After high fluence implantation with $1 \times 10^{14} \frac{\mathrm{ions}}{\mathrm{cm}^{2}}$, hardly any luminescence could be found in Ia diamond, luminescence in $\mathrm{Ib}$ diamond is more quenched compared to the low fluence implanted samples. This is in good agreement with earlier findings. BRAUNSTEIN et al found a critical implantation dose of $1.5 \times 10^{14} \frac{\text { ions }}{\mathrm{cm}^{2}}$ for $350 \mathrm{keV}$ antimony ions, over which a graphite layer is formed and thus the crystal can not be recovered after thermal annealing [16]. This critical dose depends, beside the energy, on the mass of the implanted ions and is lower for carbon ions, see [115], section 8.1. UZAN-SAGUY et al. found a critical damage threshold of $10^{22}$ vacancies $/ \mathrm{cm}^{3}$ [116]. According to their findings, the critical implantation fluence for $100 \mathrm{keV}$ argon ions is $1.8 \times 10^{14} \frac{\mathrm{ions}}{\mathrm{cm}^{2}}$, which is almost twice as high as the maximum implantation fluence applied in this work. 
Untreated diamond withstands swift heavy ion irradiation, which is in good agreement with the findings of KRAUSER et al. [2]. If diamond is damaged due to implantation, it is damaged during swift heavy ion irradiation. This corresponds well to the findings that heavily damaged diamonds tends to rearrange in a $\mathrm{sp}^{2}$ bound phase during thermal annealing. Ion beam annealing of diamond was found before [17, 18], and the authors suggest that the nuclear energy loss is contributing to the annealing procedure. NAKATA proposes that both nuclear and electronic excitations cause an annealing effect. For the Xe irradiation performed in this work, the electronic energy loss exceeds the nuclear energy loss by a factor of about 2500 . This value amounts 650 for the Au-irradiation. This ratio is in the order of 2000 for the experiments performed by ADEL et al. with $2.3 \mathrm{MeV}$ He ions and $320 \mathrm{keV}$ $\mathrm{H}$ ions. For $3 \mathrm{MeV}$ Ne ions, the irradiation which was performed by NAKATA, this value equals 145 . However, the value of the electronic energy loss is much lower than the values resulting for the irradiations performed during this work, namely $0.33 \mathrm{keV} / \mathrm{nm}(2.3 \mathrm{MeV}$ He in channeling direction), $0.17 \mathrm{keV} / \mathrm{nm}(320 \mathrm{keV} \mathrm{H})$ and $3.52 \mathrm{keV} / \mathrm{nm}(3 \mathrm{MeV} \mathrm{Ne})$. One has to conclude that irradiation with the parameters used in this work is not suitable for ion beam annealing.

\subsection{Irradiation of silicon carbide}

The effect of implantation and irradiation on $6 \mathrm{H}-\mathrm{SiC}$ can be described as follows:

I. The photoluminescence intensity is reduced due to implantation but still detectable.

II. $6 \mathrm{H}-\mathrm{SiC}$ is damaged due to irradiation, the intensity further decreases

(a) A band located at $530 \mathrm{~nm}$ emerges.

(b) Irradiation with $1.4 \mathrm{GeV}$ U-ions does not result in emergence of the green band.

After implantation, the luminescence intensity is decreased, but still visible. According to [64] an implantation with a total number of displacements per atom of 0.2 dpa to $0.25 \mathrm{dpa}$ would lead to sample amorphization. The displacements per atoms caused by implantation with $100 \mathrm{KeV}$ Ar ions with a fluence of $10^{14} \frac{\mathrm{ions}}{\mathrm{cm}^{2}}$ are below this value, namely 0.12 (calculated with SRIM). No amorphous layer is expected due to implantation.

A typical defect found after irradiation in silicon carbide and annealing is the socalled D1 center with sharp lines located at $472.4 \mathrm{~nm} / 2.625 \mathrm{eV}$ (L1), $476.9 \mathrm{~nm} / 2.6 \mathrm{eV}$ (L2) and $482.5 \mathrm{~nm} / 2.57 \mathrm{eV}$ (L3) caused by vacancies [65, 111]. Sharp luminescence 
lines within this range was found after ion irradiated silicon carbide, but no dominant lines were found at these positions in samples cut from wafer one. The most intensive line found in samples from wafer two is located at $486.6 \mathrm{~nm}(2.55 \mathrm{eV})$. The irradiations performed by BENYAGOUB and AUDREN result in an electronic energy loss of about $33 \mathrm{keV} / \mathrm{nm}(827 \mathrm{MeV} \mathrm{Pb})$ and $22 \mathrm{keV} / \mathrm{nm}(910 \mathrm{MeV} \mathrm{Xe})$. These values are similar to the ones obtained within this work, see table 5.8. A clear annealing effect as in [19] was not observed within this work. This discrepancy can be explained by regarding the different analysis methods. In [19], the crystal was analyzed with RBS in channeling geometry which is not as sensitive to defects as, e.g., XRD analysis [117] or luminescence measurements, as applied in this work. However, one can agree with BENYAGOUB and AUDREN that the model of IBIEC is not suitable to describe the ion beam induced annealing observed in silicon carbide. A model similar to the particle activated prompt anneal PAPA model [25] is proposed to explain the annealing effect. In their work, the irradiation flux was kept below $2 \times 10^{8} \frac{\text { ions }}{s \cdot \mathrm{cm}^{2}}$ to avoid sample heating. During the irradiation experiments performed in this thesis, the flux was between $10^{9} \frac{\text { ions }}{\mathrm{s} \cdot \mathrm{cm}^{2}}$ and $10^{10} \frac{\text { ions }}{\mathrm{s} \cdot \mathrm{cm}^{2}}$. As irradiation was performed at higher temperatures, no efforts were made to avoid sample heating due to irradiation. In fact, high temperature irradiated samples show more intense luminescence than room temperature irradiated samples, see fig. 5.48.

After irradiation with $39.5 \mathrm{keV} / \mathrm{nm}$, no change in luminescence line positions was found, see fig. 5.45(a) and 5.46. This is an evidence that irradiation with $1.4 \mathrm{GeV}$ uranium ions does not form the defects with cause the emergence of the $530 \mathrm{~nm}$ luminescence band. Thus, one can conclude that a slight annealing effect from swift heavy ion irradiation induced defects occurred during irradiation. However, the intensity of the luminescence is decreased. Further efforts should be made to analyze the dependence of the ion flux and the irradiation temperature of ion beam induced annealing.

\subsection{Closing remarks}

Swift heavy ion irradiation is a versatile tool for local material and phase transformation. It was shown within this work that it can be applied for defect production and annealing as well. Within this work, ta-C films doped with nitrogen, boron, iron and copper were produced. All films show a large amount of $\mathrm{sp}^{3}$ bound carbon of $80 \%$. Conductive ion tracks showing a broad variation in conductivity were found after swift heavy ion irradiation. After doping of ta-C, the ion tracks show a higher conductivity during AFM analysis. The tracks with the highest conductivity were found after iron doping. However, the conductivity of the ta-C matrix also increases, almost no conductivity contrast of irradiated and unirradiated ta-C:Fe was found 
in macroscopic transport measurements. Copper is a promising dopant for ta- $\mathrm{C}$ as an increase in track conductivity was found but the matrix conductivity increase is low. It was shown, that with the massive electronic energy loss of $\mathrm{C}_{60}$ projectiles $(72 \mathrm{keV} / \mathrm{nm})$, the ion track conductivity in undoped and doped ta-C increases. This increase was expected by ZOLLONDZ et al. and shown within this work. After $\mathrm{C}_{60}$ irradiation, all ion tracks in ta-C show a similar conductivity which is an important requirement for device implementation.

For gallium nitride, a possible regime in which ion beam induced annealing may occur could be found. The useful electronic energy loss can vary between $2 \mathrm{keV} / \mathrm{nm}$ to $15 \mathrm{keV} / \mathrm{nm}$ and should exceed the nuclear energy loss by a factor of 2000 . A high amount of defects introduced by implantation hampers the annealing effect. Crystal recovery was only found for a sample implanted with the low implantation fluence of $3 \times 10^{13} \frac{\mathrm{ions}}{\mathrm{cm}^{2}} \mathrm{Mg}$-ions. No luminescence related to magnesium was observed. All irradiations on GaN were performed at room temperature, so varying the irradiation temperature is a parameter which has to be included in further research. However, one has to admit that ion beam induced annealing is not as effective as thermal annealing.

Swift heavy ion irradiation at temperatures above room temperature was performed on diamond. Diamond withstands swift heavy ion irradiation, as long it is not predamaged by implantation. However, ion beam induced annealing was not observed. A possible explanation could be that the electronic and nuclear energy loss during swift heavy ion irradiation is too high for annealing of pre-damaged diamond. Further experiments should focus on irradiations with lower masses and/or higher temperatures.

The experiments performed on nitrogen doped silicon carbide show, that silicon carbide is damaged during swift heavy ion irradiation. Luminescence analysis is more sensitive to defects as RBS/channeling analysis, which was performed by Benyagoub and Audren who found an annealing effect after swift heavy ion irradiation. A green luminescence band occurs after swift heavy ion irradiation with $1 \mathrm{GeV}$ Xe-ions and $945 \mathrm{MeV} \mathrm{Au}$ ions, samples showing this band do not show any luminescence related to excitons bound to nitrogen. The green band was not found after $1.4 \mathrm{GeV} \mathrm{U}$ ions, which results in a higher electronic energy loss. However, the overall intensity is reduced, increasing the irradiation fluence cause a decreasing of luminescence intensity. No luminescence could be recorded after $1.4 \mathrm{GeV} \mathrm{U}$ ions at room temperature using $5 \times 10^{12} \frac{\mathrm{ions}}{\mathrm{cm}^{2}}$. Only three irradiation experiments were performed, thus there is some room for parameter variation. Experiments regarding the influence of the ion flux on sample darkening and luminescence should be performed.

Much research was performed by other groups concerning ion beam annealing. An annealing effect was found after irradiation of diamond [17, 18] and $\mathrm{SiC}$ [19] using the RBS/channeling technique. In this work, $\mathrm{SiC}$ was irradiated with an energy 
loss comparable to [19]. Luminescence measurements, which are very sensitive to defects, show that $\mathrm{SiC}$ is damaged during irradiation. These results show that swift heavy ions may be unsuitable for ion beam annealing. 


\section{List of Figures}

2.1 Sketch of swift heavy ion irradiation . . . . . . . . . . . . 5

2.2 Sketch of low energy implantation. . . . . . . . . . . . . 8

2.3 Stopping power of uranium in tetrahedral amorphous carbon. . . . . 11

$2.4 \quad$ Measured $\mathrm{sp}^{3}$ content over deposition energy compared to $n_{T} / n_{S}$. . . 12

2.5 Photoluminescence of GaN:Mg taken from [41]. . . . . . . . . . . . 13

2.6 Stacking sequences of different SiC polytypes from [60]. . . . . . . . . 17

3.1 Sketch of a direct and indirect band-to-band transition. . . . . . . . 20

3.2 Photoluminescence of GaN, taken from [76]. . . . . . . . . . . . . . 21

3.3 Photoluminescence spectra of GaN:Mg [77]. . . . . . . . . . . . . . . . 21

3.4 Luminescence of the nickel-related 2.56 center. . . . . . . . . . . . . . 23

3.5 Luminescence of the $2.56 \mathrm{eV}$ nickel related line, from [82]. . . . . . . 23

3.6 Luminescence of a Ib diamond sample, showing the N3 and the H3

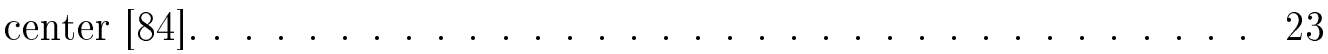

3.7 Nitrogen related luminescence in $6 \mathrm{H}-\mathrm{SiC}$ at the band-edge region [85]. 25

3.8 Photoluminescence of n-type $6 \mathrm{H}-\mathrm{SiC}[86] . \ldots \ldots \ldots . \ldots . \ldots . \ldots 25$

3.9 Luminescence lines of the D1 center [65]. . . . . . . . . . . 25

3.10 Defect lines in $\mathrm{SiC}$ found after electron irradiation [87]. . . . . . . 25

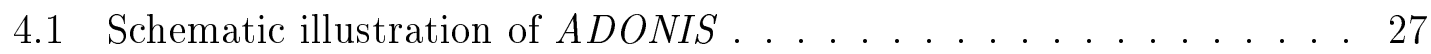

4.2 Sketch of deposition process $\ldots \ldots \ldots \ldots \ldots$

4.3 Photograph of M-branch at the GSI. . . . . . . . . . . . . . . . 31

4.4 Photograph of heater plate. . . . . . . . . . . . . . . . . . . . . . . . . . . . 31

$4.5 \quad$ View inside the heating chamber. . . . . . . . . . . . . . . . 31

$4.6 \quad$ Schematic illustration of electrical measurement setup. . . . . . . . 33

4.7 Sketch of contact pad on sample. . . . . . . . . . . . . . . . . 33

4.8 Sketch of luminescence analysis chamber. . . . . . . . . . . . . . 34

$5.1 \quad$ Photograph of ta-C. . . . . . . . . . . . . . . 37

$5.2 \quad$ AFM-current mapping and conductivity frequency of ion irradiated

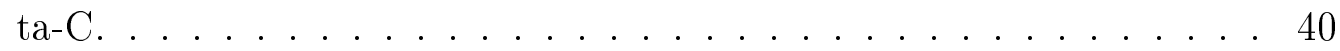


5.3 AFM-current mapping and current frequency of ion irradiated ta-C:N. 41

5.4 AFM-current mapping and conductivity frequency of ion irradiated

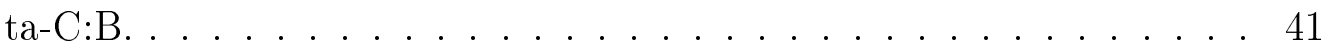

5.5 AFM-current mapping and conductivity frequency of irradiated ta-

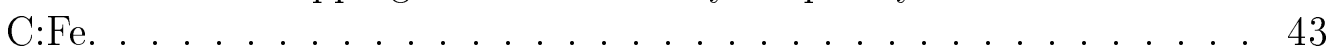

5.6 AFM-current mapping and conductivity frequency of irradiated ta-

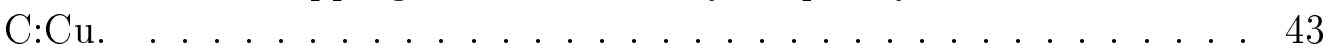

5.7 AFM-current mapping and conductivity frequency of $\mathrm{C}_{60}$ irradiated

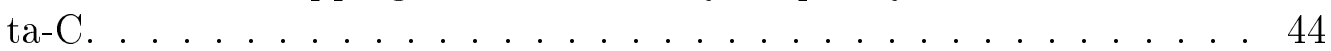

5.8 AFM-current mapping and conductivity frequency of $\mathrm{C}_{60}$ irradiated

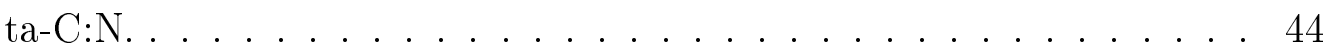

5.9 AFM-current mapping and conductivity frequency of $\mathrm{C}_{60}$ irradiated

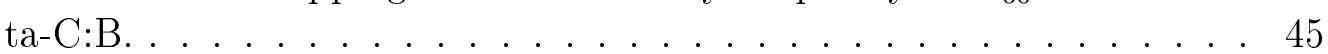

5.10 AFM-current mapping and conductivity frequency of $\mathrm{C}_{60}$ irradiated

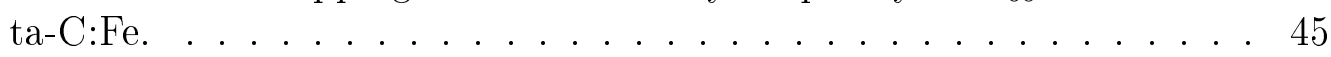

5.11 Estimation of $\mathrm{R}_{X}$, taken from [98]. . . . . . . . . . . . . . 46

5.12 Conductivity contrast of pure ta-C. . . . . . . . . . . . . . 50

5.13 Conductivity contrast of ta-C:N. . . . . . . . . . . . 50

5.14 Conductivity contrast of ta-C:B. . . . . . . . . . . . . . 51

5.15 Conductivity contrast of ta-C:Fe. . . . . . . . . . . . . . . . . 51

5.16 Conductivity contrast of ta-C:Cu. . . . . . . . . . . . . 52

5.17 Photoluminescence of untreated GaN, recorded at $12 \mathrm{~K}$.

5.18 Photoluminescence of GaN:Mg, as implanted, at $12 \mathrm{~K}$. . . . . . . . . 54

5.19 Luminescence recorded on an empty sample holder at $12 \mathrm{~K}$, laser power $40 \mathrm{~mW} . \ldots \ldots \ldots \ldots \ldots 5$

5.20 Photograph of implanted GaN after $593 \mathrm{MeV}$ Au irradiation . . . . . 55

5.21 Photoluminescence spectra of GaN after SHI irradiation. . . . . . . . 57

5.22 Photoluminescence spectra of GaN after $137 \mathrm{MeV} \mathrm{C}$ irradiation. . . . 58

5.23 Photoluminescence spectra of GaN after $668 \mathrm{MeV} \mathrm{Ni}$ irradiation. . . . 59

5.24 Photoluminescence spectra of GaN:Mg (low implantation fluence) after SHI irradiation. . . . . . . . . . . . . . . 6 60

5.25 Photoluminescence spectra of GaN:Mg (high implantation fluence) after SHI irradiation. . . . . . . . . . . . . . 61

5.26 Photoluminescence spectra of implanted GaN after $137 \mathrm{MeV}$ C irra-

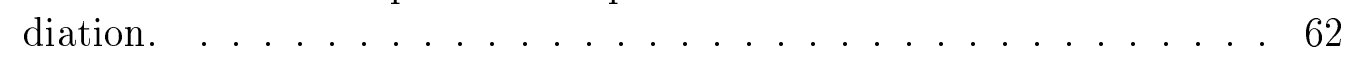

5.27 Photoluminescence spectra of GaN after $587 \mathrm{MeV}$ Cr irradiation. . . . 63

5.28 Photograph of synthetic diamond. . . . . . . . . . . . 64

5.29 Cathodoluminescence of synthetic Ia diamond. . . . . . . . . . . . . 65

5.30 Cathodoluminescence of treated synthetic Ia diamond. . . . . . . . . 66

5.31 Cathodoluminescence of synthetic Ib diamond. . . . . . . . . . . 67 
5.32 Cathodoluminescence of synthetic Ia diamond after high temperatue SHI irradiation measured at different positions. . . . . . . . . . 68

5.33 Cathodoluminescence spectra of treated Ia diamond. . . . . . . . . . 69

5.34 Cathodoluminescence of synthetic Ib diamond after implantation. . . 70

5.35 Cathodoluminescence of synthetic Ib diamond after SHI. . . . . . . . 71

5.36 Cathodoluminescence of synthetic Ib diamond after high temperature

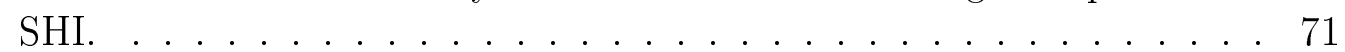

5.37 Photoluminescence of $6 \mathrm{H}-\mathrm{SiC}$ recorded at $12 \mathrm{~K}$, first wafer. . . . . . . 73

5.38 Near band-edge photoluminescence of $6 \mathrm{H}-\mathrm{SiC}$ recorded at $12 \mathrm{~K}$, first

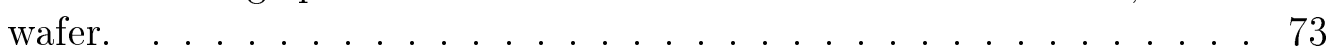

5.39 Photoluminescence of $6 \mathrm{H}-\mathrm{SiC}$ recorded at $12 \mathrm{~K}$, second wafer. . . . . 73

5.40 Near band-edge photoluminescence of $6 \mathrm{H}-\mathrm{SiC}$ recorded at $12 \mathrm{~K}$, sec-

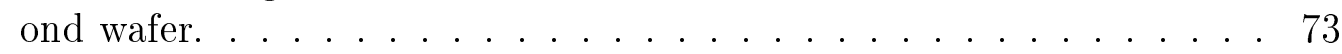

5.41 Photoluminescence of $6 \mathrm{H}-\mathrm{SiC}$ before and after implantation (wafer 1). 75

5.42 Photoluminescence of $6 \mathrm{H}-\mathrm{SiC}$ before and after temperature treatment (first wafer). . . . . . . . . . . . . . 75

5.43 Photoluminescence of $6 \mathrm{H}-\mathrm{SiC}$ (first wafer) after SHI irradiation with

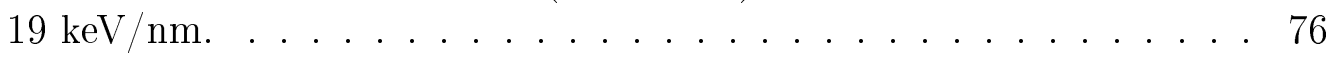

5.44 Photoluminescence of the sharp lines in $6 \mathrm{H}-\mathrm{SiC}$ (first wafer) after high temperature SHI irradiation with $19 \mathrm{keV} / \mathrm{nm} . \ldots . . . . . .777$

5.45 Photoluminescence of $6 \mathrm{H}-\mathrm{SiC}$ (first wafer) before and after SHI irradiation with $39.5 \mathrm{keV} / \mathrm{nm} . \ldots \ldots \ldots \ldots 78$

5.46 Photoluminescence of $6 \mathrm{H}-\mathrm{SiC}$ (first wafer) after SHI irradiation with $39.5 \mathrm{keV} / \mathrm{nm}$, before and after implantation. . . . . . . . . . 78

5.47 Photoluminescence of $6 \mathrm{H}-\mathrm{SiC}$ before and after implantation (wafer 2). 79

5.48 Photoluminescence of $6 \mathrm{H}-\mathrm{SiC}$ (second wafer) after SHI irradiation with $31.2 \mathrm{keV} / \mathrm{nm}$ and temperature treatment. . . . . . . . . . 79

5.49 Photoluminescence of $6 \mathrm{H}-\mathrm{SiC}$ (second wafer) after SHI irradiation with $31.2 \mathrm{keV} / \mathrm{nm}$, before and after implantation. . . . . . . . . 80

5.50 Photoluminescence of defect lines in $6 \mathrm{H}-\mathrm{SiC}$, second wafer, after SHI irradiation with $31.2 \mathrm{keV} / \mathrm{nm} . \ldots \ldots \ldots$. . . . . . . . 81

5.51 Photoluminescence of defect lines in $6 \mathrm{H}-\mathrm{SiC}$, second wafer, after high temperature SHI irradiation with $31.2 \mathrm{keV} / \mathrm{nm} . \ldots . . . . .881$

6.1 Current over temperature of doped and undoped unirradiated ta-C. . 85

6.2 Area ratio (near band-edge to blue band) of irradiated, undoped $\left(\mathrm{r}_{i}\right)$ $\begin{array}{ll}\text { and untreated GaN samples }\left(\mathrm{r}_{0}\right) \text { over electronic energy loss and fluence. } & 87\end{array}$ 


\section{List of Tables}

5.1 Deposition parameters of doped ta-C. . . . . . . . . . . . . . 38

5.2 Irradiation parameters used for ta-C. . . . . . . . . . . . . . 39

5.3 Summarized results of ta-C irradiation. . . . . . . . . . . . . . . 52

5.4 Overview of irradiation parameters used for GaN-samples. . . . . . . 56

5.5 Summarized results of SHI irradiated GaN. . . . . . . . . . . . . . . 63

5.6 Irradiation parameters used for diamond. . . . . . . . . . . . . . . 65

5.7 Percentage of the $484 \mathrm{~nm}$ line intensity after treatment of Ib diamond. 72

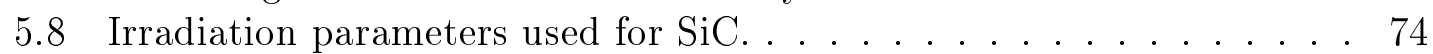

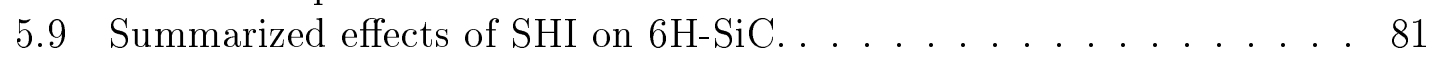

6.1 Resistivity of tracks in doped ta-C. . . . . . . . . . . . . . . . 84

6.2 Resistivity of doped and undoped ta-C. . . . . . . . . . . 85 


\section{Bibliography}

[1] Waiblinger, M. ; Sommerhalter, Ch. ; Pietzak, B. ; Krauser, J. ; Mertesacker, M. ; LuX-Steiner, M. C. ; Klaumünzer, S. ; WeiDinger, A. ; Ronning, C. ; Hofsëss, H.: Electrically conducting ion tracks in diamond-like carbon films for field emission. In: Applied Physics A 69 (1999), pp. 239-240

[2] Krauser, J. ; Zollondz, J.-H. ; Weidinger, A. ; Trautmann, C.: Conductivity of nanometer-sized ion tracks in diamond-like carbon films. In: Journal of Applied Physics 94 (2003), pp. 1959-1964

[3] Zollondz, J.-H. ; Schwen, D. ; Nix, A.-K. ; Trautmann, C. ; Berthold, J. ; Krauser, J. ; Hofsäss, H.: Conductive nanoscopic ion-tracks in diamond-like-carbon. In: Materials Science and Engineering C 26 (2006), pp. 1171-1174

[4] Nix, A.-K. ; Schwen, D. ; Ronning, C. ; Krauser, J. ; Trautmann, C. ; Hofsëss, H.: Electronic properties of graphite-like ion tracks in insulating tetrahedral amorphous carbon. In: Reviews on Advanced Materials Science 15 (2007), pp. 192-197

[5] Ronning, C. ; Griesmeier, U. ; Gross, M. ; Hofsëss, H. ; Downing, R.G. ; LAMAZE, G.P.: Conduction processes in boron-and nitrogen-doped diamond-like carbon films prepared by mass-separated ion beam deposition. In: Diamond and Related Materials 4 (1995), pp. 666-674

[6] Ronning, C. ; Dreher, E. ; Thiele, J.-U. ; Oelhafen, P. ; Hofsäss, H.: Electronic and atomic structure of undoped and doped ta-C films. In: Diamond and Related Materials 6 (1997), pp. 830 - 834

[7] Nastasi, M. ; Mayer, J. W. ; Hirvonen, J. K.: Ion-Solid Interactions. Cambridge University Press, 1996

[8] White, C. W. ; Narayan, J. ; Young, R. T.: Laser annealing of ionimplanted semiconductors. In: Science 204 (1979), pp. 461-468 
[9] Hodgson, R. T. ; Balgin, J. E. E. ; Pal, R. ; Neri, J. M. ; Hammer, D. A.: ion-beam annealing of semiconductors. In: Applied Physics Letters 37 (1980), pp. $187-189$

[10] Wesch, W. ; Kamarou, A. ; Wendler, E. ; Gärtner, K. ; Gaiduk, P. I. ; KLAUMÜnZER, S.: Ionisation stimulated defect annealing in GaAs and InP. In: Nuclear Instruments and Methods in Physics Research B 206 (2003), pp. 1018-1023

[11] Kamarou, A. ; Wesch, W. ; Wendler, E. ; Klaumünzer, S.: amage formation and annealing in InP due to swift heavy ions. In: Nuclear Instruments and Methods in Physics Research B 225 (2004), pp. 129-135

[12] Schatz, G. ; Weidinger, A.: Nukleare Festkörperphysik. B. G. Teubner, 1997

[13] Hofsëss, H. ; Lindner, G.: Emission channeling and blocking. In: Physics Reports 201 (1991), pp. 121-183

[14] Vij D. R.(EDitor): Luminescence of Solids. Plenum Press, 1998

[15] Chan, J. S. ; Cheung, N. W. ; Schloss, L. ; Jones, E. ; Wong, W. S. ; Newman, N. ; Liu, X. ; Weber, E. R. ; Gassman, A. ; Rubin, M. D.: Thermal annealing characteristics of Si and Mg-implanted GaN thin films. In: Applied Physics Letters 68 (1996), pp. 2702 - 2704

[16] Braunstein, G. ; Talmi, A. ; Kalish, R. ; Bernstein, T. ; Beserman, R.: Radiation-damage and annealing in Sb implanted diamond. In: Radiation Effects and Defects in Solids 48 (1980), pp. 139-144

[17] Adel, M. ; Kalish, R. ; Richter, V.: Light-ion-beam-induced annealing of implantation damage in diamond. In: Journal of Material Research 1 (1986), pp. $503-509$

[18] NAKATA, J.: Annealing of ion-implanted defects in diamond by MeV ion-beam irradiation. In: Physical Review B 60 (1999), pp. 2747 - 2761

[19] Benyagoub, A. ; Audren, A.: Mechanism of the swift heavy ion induced epitaxial recrystallization in predamaged silicon carbide. In: Journal of Applied Physics 106 (2009), pp. 083516

[20] Schimietz, G. ; Staufenbiel, F. ; Roth, M. ; Czerski, K. ; Grande, P. L.: Electrons as a tool for short-time track characterization. In: Book of Abstracts of the Sixth International Symposium on Swift Heavy Ions in Matter, Aschaffenburg, Germany, 2005 
[21] Toulemonde, M ; Dufor, C. ; Paumier, E.: Transient thermal process after high-energy heavy-ion irradiation of amorphous metals and semiconductors. In: Physical Review B 46 (1992), pp. 14362 - 14368

[22] ScHwen, D.: Structural ad electronic properties of swift heavy ion tracks in amorphous carbon, University of Göttingen, Phdthesis, 2007

[23] Sorkin, A. ; Adler, J. ; KAlish, R.: Computer simulations of damage due to passage of a heavy fast ion through diamond. In: Physical Review B 70 (2004), pp. 064110

[24] Schiwietz, G. ; Xiao, G. ; Luderer, E. ; GRande, P. L.: Auuger electrons from ion tracks. In: Nuclear Instruments and Methods in Physics Research $B$ $164-165$ (2000), pp. $353-364$

[25] Chadderton, L. T. ; Fink, D.: Fullerene genesis by ion beams III. On the absence of latent tracks in $\mathrm{GeV}$ ion irradiated graphite. In: Raiation effects and Defects in Solids 152 (2000), pp. 87-107

[26] Seitz, F. ; Koehler, J.S.: Displacements of Atoms during Irradiation in Solid State Physics Vol 2. Academic Press, 1956, pp. 307 - 449

[27] Priolo, F. ; Spinella, C. ; Rimini, E.: Phenomenological description of ion-beam-induced epitaxial crystallization of amorphous silicon. In: Physical Review B 41 (1990), pp. 5235-5242

[28] Battaglia, A. ; Priolo, F. ; Rimini, E. ; Ferla, G.: Ion-induced annealing and amorphization of isolated damage clusters in Si. In: Applied Physics Letters 56 (1990), pp. 2622-2624

[29] Ziegler, J. F. ; Biersack, J. P. ; Ziegler, M. D.: SRIM - The Stopping and Range of Ions in Matter. SRIM Co., 2008

[30] Ryssel, H. ; Ruge, I.: Ionenimplantation. B. G. Teubner, 1978

[31] BoHR, N.: Scattering and Stopping of fission fragments. In: Physical Review 58 (1940), pp. $654-655$

[32] Bohr, N.: Velocity-Range Relation for Fission Fragments. In: Physical Review 59 (1941), pp. 270-275

[33] Northcliffe, L. C.: Energy Loss and Effective Charge of Heavy Ions in Aluminium. In: Physical Review 120 (1960), pp. 1744 - 1758 
[34] Hofsäss, H. ; Feldermann, H. ; Merk, R. ; Sebastian, M. ; Ronning, C.: Cylindrical spike model for the formation of diamondlike thin films by ion deposition. In: Applied Physics A,Materials Science $8 \mathcal{G}$ Processing 66 (1998), pp. $153-181$

[35] Robertson, J.: Diamond-like amorphous carbon. In: Materials Science and Engineering $R 37$ (2002), pp. 129 - 281

[36] Mott, N. F.; DAVIs, E. A.: Electronic processes in non-crystalline materials. Clarendon Press Oxford, 1979

[37] Pollak, M. ; Riess, I.: A perlocation treatment of high-field hopping transport. In: Journal of Physics C: Solid State Physics 9 (1976), pp. 2339

[38] Schwen, D. ; Ronning, C. ; Hofsëss, H.: Field emission studies on swift heavy ion irradiated tetrahedral amorphous carbon. In: Diamond and Related Materials 13 (2004), pp. 1032

[39] Krauser, J. ; nix, A.-K. ; Gehrke, H.-G. ; Hofsäss, H. ; Trautmann, C. ; Weidinger, A. ; WÜnsch, F. ; BRUns, J.: Ion track lithography and graphitic nanowires in diamondlike carbon. In: Journal of Vacuum Science and Technology B 26(6) (2008), pp. 2468-2472

[40] Ronning, C.: Ion-beam synthesis and growth mechanism of diamond-like materials. In: Applied Physics A, Materials Science \& Processing 77 (2003), pp. $39-50$

[41] Reshchikov, M. A. ; Yi, G.-C. ; Wessels, B. W.: Behavior of 2.8- and 3.2-eV photoluminescence bands in Mg-doped GaN at different temperatures and excitation densities. In: Physical Review B 59 (1999), pp. 13176 - 13182

[42] Nakamura, S. ; Fasol, G.: The blue laser diode - GaN based light emitters and lasers. Springer-Verlag Deutschland, 1997

[43] Strite, S. ; Morkoç, H.: GaN, AlN and InN: A review. In: Journal of Vacuum Science \& Technology B 10 (1992), pp. 1237 - 1266

[44] Davies, R. F. ; Roskowski, A. M. ; Preble, E. A. ; Speck, J. S. ; Heying, B. ; Freitas, J. A. ; Glaser, E. R. ; Carlos, W. E.: Gallium nitride materials - Progress, status and potential roadblocks. In: Proceedings of the IEEE 90 (2002), pp. 993 - 1004

[45] ReshChIKOV, MA ; MoRKoÇ, H: Luminescence properties of defects in GaN. In: Journal of Applied Physics 97 (2005), pp. 061301 
[46] Götz, W. ; Johnson, N. M. ; Walker, J. ; Bour, D. P. ; Street, R. A.: Activation of acceptors in Mg-doped GaN grown by metalorganic chemical vapor deposition. In: Applied Physics Letters 68 (1996), pp. 667 - 669

[47] Sheu, J. K. ; Su, Y. K. ; Chi, G. C. ; Pong, B. J. ; Chen, C. Y. ; Huang, C. N. ; Chen, W. C.: Photoluminescence spectroscopy of Mg-doped GaN. In: Journal of Applied Physics 84 (1998), pp. 4590 - 4594

[48] Kumar, V. S. ; Kumar, M. S. ; Puviarasu, P. ; Kumar, J. ; Mohanty, T ; Kanjilal, D. ; Asokan, K. ; Tripathi, A. ; Fontana, M. ; Camarani, A.: Investigations on the $100 \mathrm{MeV} \mathrm{Au}{ }^{7+}$ ion irradiation of GaN. In: Semiconductor Science and Technology 22 (2007), pp. 511-516

[49] Kucheyev, S. O. ; Timmers, H. ; Zou, J. ; Williams, J. S. ; Jagadish, C. ; LI, G.: Lattice damage produced in GaN by swift heavy ions. In: Journal of Applied Physics 95 (2004), pp. 5360 - 5365

[50] Baranwal, V. ; Pandey, A. C. ; Gerlach, J. W. ; Rauschenbach, B. ; Karl, H. ; Kanjilal, D. ; Avasthi, D. K.: Rapid thermal and swift heavy ion induced annealin of Co ion implanted GaN films. In: Journal of Applied Physics 103 (2008), pp. 124904

[51] MaY, P. W.: Diamond thin films: a 21st-century material. In: Philosophical Transactions of the Royal Society of London Series A-mathematical physical and engineering sciences 358 (2000), pp. $473-495$

[52] NeBel, C. E.: Semiconductor materials - From gemstone to semiconductor. In: Nature Materials Science and Engineering B 2 (2003), pp. 431-432

[53] WalkeR, J.: Optical absorption and luminescence in diamond. In: Reports on Progress in Physics 42 (1979), pp. 1605-1659

[54] Glasmacher, M. U. A .and L. U. A .and Lang ; Keppler, H. ; Langenhorst, F. ; Neumann, R. ; Schardt, D. ; Trautmann, C. ; Wagner, G. A.: Phase transitions in solids stimulated by simultaneous exposure to high pressure and relativistic heavy ions. In: Physical Review Letters 96 (2006), pp. 195701

[55] Zhang, X. K. ; Guo, J. G. ; YaO, Y. F.: Boron doping of Diamonf Films by $\mathrm{B}_{2} \mathrm{O}_{3}$ Vaporization. In: Physica status solidi (a) 133 (1992), pp. 377-383

[56] Tang, Y.; Aslam, D. M.: Technology of polycrystalline diamond thin films for microsystems applications. In: Journal of Vacuum Science \& Technology B 23 (2005), pp. 1080-1095 
[57] Uzan-Saguy, C. ; Cytermann, C. ; Fizgeer, B. ; Richter, V. ; Brener, R.: Diffusion of lithium in diamond. In: physica status solidi (a) 193 (2002), pp. $508-516$

[58] Braunstein, G. ; Kalish, R.: Damage and lattice location studies in hightemperature ion-implanted diamond. In: Applied Physics Letters 38 (1981), pp. $416-418$

[59] Ueda, K. ; Kasu, M. ; Makimoto, T.: High-pressure and high-temperature annealing as an activation ethod for ion-implanted dopands in diamond. In: Applied Physics Letters 90 (2007), pp. 122102

[60] Powell, A. R. ; Rowland, R. B.: SiC materials - Progress, status and potential roadblocks. In: Proceedings of the IEEE 90 (2002), pp. $942-955$

[61] Sha, Z. D. ; Wu, X. M. ; Zhuge, L. J. ; Meng, Y. D.: Initial study on the structure and photoluminescence properties of $\mathrm{SiC}$ films doped with Co. In: Physica E 35 (2006), pp. 38 - 41

[62] Morkoç, H. ; Strite, S. ; Gao, G. B. ; Lin, M. E. ; Sverdlov, B. ; Burns, M.: Large-band-gap SiC, III-V nitride and II-VI ZnSe-based semiconductor device technologies. In: Journal of Applied Physics 76 (1994), pp. 1363 - 1398

[63] Bohn, H. G. ; Williams, J. M. ; Mchargue, C. J. ; Begun, G. M.: Recrystallization of ion implanted $\alpha$-SiC. In: Journal of Materials Research 2 (1987), pp. $107-116$

[64] Mchargue, C. J. ; Williams, J. M.: Ion implantation effects in silicon carbide. In: Nuclear Instruments and Methods in Physics Reserach B 80/81 (1993), pp. $889-894$

[65] Patrick, L. ; Choyke, W. J.: Photoluminescence of radiation defects in ion-implanted 6H-SiC. In: Physical Review B 5 (1972), pp. 3253-3259

[66] Gao, Y. ; Soloviev, S. I. ; Sudarshan, T. S. ; Tin, Chin-Che: Selective doping of $4 \mathrm{H}-\mathrm{SiC}$ by codiffusion of aluminum and boron. In: Journal of Applied Physics 90 (2001), pp. 5647 - 5651

[67] Heft, A. ; Wendler, E. ; Bachmann, T. ; Glaser, E. ; Wesch, W.: Defect production and annealing in ion implanted silicon carbide. In: Materials Science and Engineering B 29 (1995), pp. 142 - 146

[68] Benyagoub, A. ; Audren, A. ; Thomé, L. ; Garrido, F.: Athermal crystallization induced by electronic excitations in ion-irradiated silicon carbide. In: Applied Physics Letters 89 (2006), pp. 241914 
[69] Audren, A. ; Monnet, I. ; Gosset, D. ; Leconte, Y. ; Portier, X. ; Thomé, L. ; Garrido, F. ; Benyagoub, A. ; Levalois, M. ; HerlinBoime, N. ; ReYNAUd, C.: Effects of electronic and nuclear interactions in SiC. In: Nuclear Instruments and Methods in Physics Research B 267 (2009), pp. $976-979$

[70] Heera, V. ; Kögler, R. ; Skorupa, W. ; Stoemenos, J.: Complete recrystallization of amorphous silicon carbide layers by ion irradiation. In: Applied Physics Letters 67 (1995), pp. 1999 - 2001

[71] WannieR, G. H.: The Structure of Electronic Excitation Levels in Insulating Crystals. In: Physical Review 52 (1937), pp. 191 - 197

[72] KlingshiRn, C.: Semiconductor Optics. Spinger, 2005

[73] Hovington, P. ; Drouin, D. ; Gauvin, R.: CASinO: A New Monte Carlo Code in C Language for Electron Beam Interaction - Part I: Description of the Program. In: Scanning 19 (1997), pp. 1 - 14

[74] Drouin, D. ; Hovington, P. ; Gauvin, R.: CASinO: A New Monte Carlo Code in C Language for Electron Beam Interaction - Part II: Tabulated Values of the Mott Cross Section. In: Scanning 19 (1997), pp. $20-28$

[75] Hovington, P. ; Drouin, D. ; Gauvin, R. ; Joy, D. C. ; Evans, N.: CASINO: A New Monte Carlo Code in C Language for Electron Beam Interaction - Part III: Stopping Power at Low Energies. In: Scanning 19 (1997), pp. $29-35$

[76] Ronning, C. ; Carlson, E.P. ; Davis, R.F.: Ion implantation into gallium nitride. In: Physics Reports 351 (2001), pp. 349-385

[77] Hess, S. ; Taylor, R. A. ; Ryan, J. F. ; Cain, N. J. ; Roberts, V. ; Roberts, J.: Photoluminescence Studies of Mg-Doped and Si-Doped Gallium Nitride Epilayers. In: physica status solidi (b) 210 (1998), pp. $465-470$

[78] Dingle, R. ; Sell, D. D. ; Stokowski, S. E. ; Ilegems, M.: Absorption, Reflectance and Luminescence of GaN Epitaxial Layers. In: Physical Review B 4 (1971), pp. $1211-1218$

[79] Ronning, C.: Untersuchung zum Wachstum und zur Dotierung diamantähnlicher Schichten,hergestelltüber die Deposition massenseparierter Ionen, Universität Konstanz, Dokorarbeit, 1996

[80] Zaitsev, A. M.: Vibronic spectra of impurity-related optical centers in diamond. In: Physical Review B 61 (2000), pp. 12909-12922 
[81] Davis, G.: The A nitrogen aggregate in diamond - its symmetry and possible structure. In: Journal of Physics C: Solid State Physics 9 (1976), pp. L537L542

[82] Collins, A. T. ; Spear, P. M.: The $1.40 \mathrm{eV}$ and $2.56 \mathrm{eV}$ centres in synthetic diamond. In: Journal of Physics C: Solid State Physics 16 (1983), pp. 963-973

[83] Pereira, E. ; Pereira, L. ; Hofmann, D. M. ; Stadler, W. ; Meyer, B. K.: Excited levels of the $2.56 \mathrm{eV}$ emission in synthetic diamond. In: Radiation Effects and Defects in Solids 135 (1995), pp. 143-148

[84] Collins, A. T. ; Connor, A. ; Ly, C. H. ; Shareef, A. ; Spear, P. M.: High-temperature annealing of optical centers in type-I diamond. In: Journal of Applied Physics 97 (2005), pp. 083517

[85] Ivanov, IG ; Hallin, C ; Henry, A ; Kordina, O ; Janzén, E: Nitrogen doping concentration as determined by photoluminescence in $4 \mathrm{H}-$ and $6 \mathrm{H}-\mathrm{SiC}$. In: Journal of Applied Physics 80 (1996), pp. 3504-3508

[86] Botsoa, J. ; Bluet, J. M. ; Lysenko, V. ; Marty, O. ; Barbier, D. ; Guillot, G.: Photoluminescence of $6 \mathrm{H}-\mathrm{SiC}$ nanostructures fabricated by electrochemical etching. In: Journal of Applied Physics 102 (2007), pp. 083526

[87] Ling, C. C. ; Chen, X. D. ; Gong, M. ; Yang, C. L. ; Ge, W. K. ; Wang, J. N.: Electron energy dependence on inducing the photoluminescence lines of $6 \mathrm{H}-\mathrm{SiC}$ by electron irradiation. In: Physica B 376 - 377 (2006), pp. $374-$ 377

[88] Sidenius, G.: The high temperature hollow cathode ion source. In: Nuclear Instruments and Methods 38 (1965), pp. $19-22$

[89] Hofsëss, H. ; Binder, H. ; Klumpe, T. ; Recknagel, E.: Doping and growth of diamond-like carbon films by ion beam deposition. In: Diamond and Related Materials 3 (1993), pp. 137-142

[90] Gerhards, I. ; Ronning, C. ; Hofsäss, H. ; Seibt, M ; Gibhardt, H.: Ion beam synthesis of diamond-like carbon films containing copper nanocrystals. In: Journal of Applied Physics 93 (2003), pp. 1203 - 1207

[91] Díaz, J. ; Paolicelli, G. ; Ferrer, S. ; Comin, F.: Separation of the sp ${ }^{3}$ and $\mathrm{sp}^{2}$ components in the $\mathrm{C} 1 \mathrm{~s}$ photoemission spectra of amorphous carbon films. In: Physical Review B 54 (1996), pp. 8064 - 8069 
[92] Reinke, P. ; Garnier, M. G. ; Oelhafen, P.: In situ photoelectron spectroscopy analysis of tetrahedral amorphous carbon films. In: Journal of Electron Spectroscopy and Related Phenomena 136 (2004), pp. 239 - 245

[93] Puchert, M. K. ; Davis, C. A. ; McKenzie, D. R. ; James, B. W.: Gasplasma interactions in an filtered cathodic arc. In: Journal of Vacuum Science E Technology A 10 (1992), pp. 3493

[94] Yamaguchi, A. ; Ihara, M. ; Komiyama, H.: Temperature dependence of growth rate for diamonds grown using a hot filament assistet chemical vapor deposition method at low substrate temperatures. In: Journal of Applied Physics 64 (1994), pp. 1306

[95] Uhrmacher, M. ; HofsÄss, H.: Ion accelerator facilities at the University of Göttingen. In: Nuclear Instruments and Methods in Physics Research B 240 (2005), pp. $48-54$

[96] Binning, G. ; Quate, C. F. ; Gerber, Ch.: Atomic Force Microscope. In: Physical Review Letters 56 (1986), pp. 930-933

[97] NIX, A.-K.: Elektrisch Eigenschaften von graphitischen Ionenspuren in diamantartigen Kohlenstoffschichten, Georg-August-Universität Göttingen, Diplomarbeit, 2005

[98] GeHrke, H.-G.: Characteriszation of Swift heavy Ion Tracks in Tetrahedral Amourphous Carbon and Fabrication of Self-Aligned Nano Structures, GeorgAugust-Universität Göttingen, diploma thesis, 2008

[99] Gruber, J. B. ; Vetter, U. ; Hofsëss, H. ; Zandi, B. ; Reid, M. F.: Spectra and energy levels of $\mathrm{Gd}^{3+}\left(4 \mathrm{f}^{7}\right)$ in AlN. In: Physical Review B 69 (2004), pp. 195202

[100] BRÜSEWITZ, C.: Electroluminescence and electrical characterisation of AlN/SiC-heterojunctions, Georg-August-Universität Göttingen, bachelor thesis, 2009

[101] EL-SAID, A. S.: Tracks of 30-MeV C 60 clusters in yttrium iron garnet studied by scanning force microscopy. In: Nuclear Instruments and Methods in Physics Research B 267 (2009), pp. $953-956$

[102] Tomaschko, Ch. ; Brandl, D. ; Kügler, R. ; Schurr, M. ; Voit, H.: Energy loss of $\mathrm{MeV}$ carbon cluster ions in matter. In: Nuclear Instruments and Methods in Physics Research B 103 (1995), pp. $404-411$ 
[103] Ben-Hamu, B. ; Baer, A. ; Feldman, H. ; Levin, J. ; Heber, O. ; Amitay, Z. ; VAGER, Z. ; ZAJFMAN, D.: Energy loss of fast clusters through matter. In: Pysical Review A 56 (1997), pp. 4786 - 4794

[104] OH, E. ; PARK, H. ; PARK, Y.: Excitation density dependence of photoluminescence in GaN:Mg. In: Applied Physics Letters 72 (1998), pp. 70 72

[105] PRINS, J. F.: Ion implantation of diamonds for electronic applications. In: Semiconductor Science and Technology 18 (2003), pp. S27-S33

[106] Aharonovich, I. ; Santori, C. ; Fairchild, B. A. ; Orwa, J. ; Ganesan, K. ; Fu, K.-M. C. ; Beausoleil, R. G. ; Greentree, A. D. ; Prawner, S.: Producing optimized ensembles of nitrogen-vacancy color centres for quantum information applications. In: Journal of Applied Physics 106 (2009), pp. 124904

[107] Watanabe, H. ; Kitamura, T. ; Nakashima, S. ; Shikata, S.: Cathodoluminescence characterization of a nitrogen-doped homoepitaxial diamond thin film. In: Journal of Applied Physics 105 (2009), pp. 093529

[108] Choyke, W. J. ; PATRICK, L.: Exciton recombination radiation and phonon spectrum of 6H-SiC. In: Physical Review 127 (1962), pp. 1868-1877. - ISSN 0031-899X

[109] Tamulaitis, G. ; Yilmaz, I. ; Shur, M. S. ; Anderson, T. ; Gaska, R: Carrier lifetime in conductive and vanadium-doped $6 \mathrm{H}-\mathrm{SiC}$ substrates. In: Applied Physics Letters 84 (2004), pp. 335 - 337

[110] Torchynska, T. V. ; Díaz Cano, A. ; Dybic, M. ; Ostapenko, S. ; Mynbaeva, M.: Stimulation of excitonic and defect-related luminescence in porous SiC. In: Physica B 376-377 (2006), pp. 369-369

[111] Zhong, Z. Q. ; Wu, D. X. ; Gong, M. ; Wang, O. ; ShI, S. L. ; Xu, S. J. ; Chen, D. ; Ling, C. C. ; Fung, S. ; Beling, C. D. ; Brauer, G. ; Anwand, W. ; Skorupa, W.: Primary photoluminescence in as-neutron (electron) -irradiated n-type 6H-SiC. In: Journal of Applied Physics 99 (2006), pp. 093511

[112] Davies, C. A. ; McKenzie, D. R. ; Yin, Y. ; Kravtchinskaia, E. ; AmaRatunga, G. A. J. ; VeErasamy, V. S.: Substitutional nitrogen doping of tetrahedral amorphous carbon. In: Philosophical Magazine B 69 (1994), pp. $1133-1140$ 
[113] Kleinsorge, B. ; Ferrari, A. C. ; Robertson, J. ; Milne, W. I.: Influence of nitrogen and temperature on the deposition of tetrahedrally bonded armorphous carbon. In: Journal of Applied Physics 88 (2000), pp. 1149 - 1157

[114] Arena, C. ; Kleinsorge, B. ; Robertson, J. ; Milne, W. I. ; Welland, M. E.: Electronic and topographic structure of ta-C, ta-C:N and ta-C:B investigated by scanning tunneling microscopy. In: Diamond and Related Materials 8 (1999), pp. 435 - 439

[115] Dresselhaus, M. S. ; KAlish, R.: Ion implantation in diamond, graphite and related materials. Springer series in Materials Science, Vol. 22, 1992

[116] Uzan-Saguy, C. ; Cytermann, C. ; Brener, R. ; Richter, V. ; ShaAnan, M. ; Kalish, R.: Damage threshold for ion-beam induced graphitization of diamond. In: Applied Physics Letters 67 (1995), pp. 1194- 1196

[117] Savin, W. ; Feldman, L. C.: Depth-dependent analysis in RBS/channeling. In: Nuclear Instruments and Methods in Physics REsearch B 45 (1990), pp. $417-419$ 


\section{Publications}

2006:

J.-H. Zollondz, D. Schwen, A.-K. Nix, C. Trautmann, J. Berthold, J. Krauser, H. Hofsäss, Conductive nanoscopic ion-tracks in diamond-like-carbon in Materials Science and Engineering C, 26 (2006) 1171

200\%:

A.-K. Nix, D. Schwen, C. Ronning, J. Krauser, C. Trautmann, H. Hofsäss, Electronic properties of graphite-like ion-tracks in insulating tetrahedral amorphous carbon in Reviews on Advanced Materials Science, 15 (2007) 192

2008:

J. Krauser, A.-K. Nix, H.-G. Gehrke, H. Hofsäss, C. Trautmann, A. Weidinger, F. Wünsch, J. Bruns, Ion track lithography and graphitic nanowires in diamondlike carbon in Journal of Vacuum Science and Technology B, 26/6 (2008) 2468

2009:

A.-K. Nix, H.-G. Gehrke, J. Krauser, C. Trautmann, A. Weidinger, H. Hofsäss, Track-etched nanopores in spin-coated polycarbonate films applied as sputtering mask in Nuclear Instruments and Methods in Physics Research B, 267 (2009) 1032

2010:

H.-G. Gehrke, A.-K. Nix, H. Hofsäss, J. Krauser, C. Trautmann, A. Weidinger, Self-Aligned Nanostructures Created by Swift Heavy Ion Irradiation in Journal of Applied Physics, 107 (2010) 094305 



\section{Lebenslauf}

\section{Persöhnliche Daten:}

Name:

Nix, Anne-Katrin

Geburtsdatum:

6. April 1981

Geburtsort:

Dortmund

Nationalität:

Familienstand:

Deutsch

ledig

\section{Bildungsweg:}

08.19.87 bis 07.1991:

08.1991 bis 06.2000 :

24.06.2000:

01.10.2000:

19.09.2002:

01.10.2002:

01.04 .2004

10.11.2005:

Seit 01.02.2006:
Gilden-Grundschule in Dortmund-Huckarde Leibniz Gymnasium der Stadt Dortmund Erwerb der Allgemeinen Hochschulreife am Leibniz Gymnasium Dortmund Beginn des Studiums der Physik an der Universität Dortmund Erwerb des Vordiploms in Physik an der Universität Dortmund, Note "gut" Studienplatzwechsel zur Georg-August Universität in Göttingen

Anfertigung der Diplomarbeit im II. Physikalischen Institut der Universität Göttingen, Titel der Arbeit:

Elektrische Eigenschaften von graphitischen Ionenspuren in diamantartigen Kohlenstoffschichten unter der Betreuung von Prof. Dr. Hans Hofsäss Erwerb des Diploms in Physik an der Georg-August Universität Göttingen, Note "gut" Promotion am II. physikalisches Institut der Universität Göttingen unter der Betreuung von Prof. Dr. Hans Hofsäss 



\section{Danksagung}

Hier möchte ich allen danken, die zu meiner erfolgreichen Dissertation beigetragen haben. Da sei zuerst Herrn Prof. Dr. Hofsäss gedankt, der mich nicht nur während meiner Diplomzeit, sondern auch während der Doktorandenzeit betreut hat. Vielen Dank für die wertvolle Zeit.

Des Weiteren möchte ich Herrn Prof. Dr. Seibt für das korreferieren meiner Arbeit bedanken.

Einen lieben Dank and Christa Wohlfarth, Bernadette Tyson, Lucie Hamdi und Heike Ahrens für ihre Unterstützung in organisatorischen Angelegenheiten.

Nicht zu vergessen ist das Team der Feinmechanik-Werkstatt des II. Physikalischen Instituts. Insbesondere sei hier Peter Arnsberger genannt, der Werkstücke von mir, in letzter Minute in Auftrag gegeben, bearbeitet hat. Andreas König sei hier für seine Begrüßungen, aber natürlich nicht nur, gedankt (Mein schönes Fräulein, darf ich wagen - Mein Arm und Geleit Ihr anzutragen?). Vielen Dank auch an das Team der Zentralwerkstatt, die die Bestrahlungskammern am M3-Zweig angefertigt haben. Ein Dank geht an Holger Schebela und Detlef Purschke für die Hilfe an Miss MaRPel und Ionas.

Ich möchte der ganzen Arbeitsgruppe Hofsäss für die gemeinsame Zeit und Unterstüzung am II. Physikalischen Institut danken. Bedonders sei hier Dr. Ulrich Vetter, Dr. Hayo Zutz, Dr. Sven Müller, Hans-Gregor Gehrke und Marc Brötzmann gedankt. Danke auch an Niels Borth für die gute, wenn auch kurze, Büroathmosphäre. Ich möchte auch den ehemaligen Mitgliedern Dr. Daniel Schwen, Dr. Daniel Stichtenoth und Dr. Inga Hannstein danken.

Prof. Dr. Johann Krauser sei hier für seine Zusammenarbeit und seine AFMMessungen gedankt.

Ich möchte auch Prof. (em.) Dr. Alois Weidinger für die viele Anregungen und Diskussionen und aufmunternden Worte danken.

Auch vielen Dank an Dr. Christina Trautmann für die vielen Bestrahlungen, Dr. Daniel Severin und Markus Krause für ihre Unterstützung und Geduld am M-Zweig und der der Ofenkammer (Helmholtzzentrum für Schwerionenforschung in Darmstadt).

Vielen Dank nach Frankreich zu Dr. Serge Della Negra am Institut de Physique 
Nucleaire D'Orsay für die $\mathrm{C}_{60}$ Bestrahlung. Ich möchte mich auch bei Dr. Elke Wendler, Prof. Dr. Werner Wesch (Universität Jena) und Dr. Andrey Kamarou (ehem. Universität Jena) für die Gold/Krypton-Bestrahlung bedanken.

Den technischen Mitarbeitern des I. Physikalischen Institutes Uta Filippich, Ning An und Antje Krüger möchte ich für das Zersägen der Wafer danken.

Ich möchte mich auch bei Dr. Wen-Jun Zhang und Dr. Antonio Zapien für ihre Gastfreundschaft und Zusammenarbeit in Hong-Kong danken.

Ich möchte auch allen Freunden danken, die ich während meiner Zeit in Göttingen kennen gelernt habe.

Meiner Mutter möchte ich für ihr Vertrauen in meine Fähigkeiten danken.

Zu guter letzt möchte ich meiner Liebe Dennis danken, ohne die ich so manches Mal verzweifelt wäre. 